\title{
INTERAÇÃO DE LASER COM NEURÔNIOS: ÓPTICA DE TECIDOS E FOTONEUROMODULAÇÃO DA DOR
}

\section{MARCELO VICTOR PIRES DE SOUSA}

Orientadora: Profa. Dra. Elisabeth Mateus Yoshimura

Co-Orientador: Prof. Dr. Carlos Amilcar Parada

Tese de doutorado apresentada ao Instituto de Física da Universidade de São Paulo para a obtenção do título de Doutor em Ciências

Banca Examinadora:

Prof. Dra. Elisabeth Mateus Yoshimura (Instituto de Física da Universidade de São Paulo)

Prof. Dra. Maria Teresa Moura Lamy (Instituto de Física da Universidade de São Paulo)

Prof. Dr. Adriano Mesquita Alencar (Instituto de Física da Universidade de São Paulo)

Prof. Dra. Rosana de Lima Pagano (Instituto Sírio-Labanês de Ensino e Pesquisa)

Prof. Dra. Maria Cristina Chavantes (InCor-HC/FMUSP)

São Paulo 


\section{FICHA CATALOGRÁFICA \\ Preparada pelo Serviço de Biblioteca e Informação do Instituto de Física da Universidade de São Paulo}

\section{Sousa, Marcelo Victor Pires de}

Interação de laser com neurônios: óptica de tecidos e fotoneuromodulação da dor. São Paulo, 2014.

Tese (Doutorado) - Universidade de São Paulo. Instituto de Física. Departamento de Física Nuclear

Orientador: Profa. Dra. Elisabeth Mateus Yoshimura

Área de Concentração: Fotobiologia

Unitermos: 1.Física médica; 2. Biofísica; 3. Neurociências; 4. Engenharia tecidual; 5. Fotobiologia.

USP/IF/SBI-083/2014 
Dedico esse trabalho aos meus pais,

Antônio Pires de Sousa e Rosângela Maria de Sousa,

e a minha amada Vivianne de Sousa Rocha,

pois, são eles que me fazem querer ir sempre mais longe. 
"Eu sou de uma terra que o povo padece

Mas não esmorece e procura vencer.

Da terra querida, que a linda cabocla

De riso na boca zomba no sofrer

Não nego meu sangue, não nego meu nome

olho para a fome, pergunto o que ha?

Eu sou brasileiro, filho do Nordeste,

Sou cabra da Peste, sou do ceara."

(Patativa do Assaré)

Esse poema representa minha esperança de um Brasil sem preconceitos em relação ao Nordeste e um mundo sem preconceitos em relação ao Brasil. 


\section{Agradecimentos:}

Aos meus pais e ao meu irmão (Victor Hugo Pires de Sousa), pelo amor, carinho, dedicação, apoio e por fazerem minha vida mais tranquila e feliz.

À Vivi, por ser minha amada companheira de todas as horas.

À professora doutora Elisabeth Mateus Yoshimura, pela dedicação, compreensão, amizade, além de me orientar e ser o modelo de cientista que eu quero seguir.

À toda família Sousa.

Aos meus amigos da SLC, do ATS e da UFC, pela amizade de toda uma vida.

Aos amigos que conheci em São Paulo e Boston pelo incentivo.

Aos amigos da pensão, por serem minha família em São Paulo.

À professora Emico Okuno, por ter escrito o livro que me fez vir a São Paulo e pelas várias conversas que me ensinaram muito sobre muitas coisas.

Aos colegas e amigos da Dosimetria, por tornarem o ambiente de trabalho um local de paz e tranquilidade.

Ao professor Michael $\mathrm{R}$ Hamblin e demais amigos e colegas do Wellman Center for Photomedicine, Massachussetts General Hospital e havard Medical School.

À professora Martha Simões e demais colegas do Centro de Lasers e aplicações.

À doutora Maria Cristina Chavantes, por dividir comigo seus conhecimentos sobre medicina, laser, a vida e tudo mais. 


\section{Sumário}

Ficha catalográfica ii

Lista de abreviações e símbolos xi

Resumo xiii

Abstract $x v$

Prefácio $\quad$ xvii

Apresentação xviii

Motivação xviii

Objetivos xix

1. INTRODUÇÃO 1

1.1. Anatomia do encéfalo de roedores 1

1.2. Fisiologia do neurônio 2

1.3. Neurofisiologia da dor 5

1.4. Interação da luz com tecidos neurais 9

1.5. Teoria do transporte de fótons 11

1.6. Analgesia com laser de baixa intensidade 13

1.7. Estimulação mecânica com filamentos von Frey e testes de nocicepção (placa fria, fonte radiante de calor e injeção de formalina)

1.8. Imunofluorescência e microscopia confocal 16

1.9. Marcação de tecido com HE $\quad 19$

2. ÓPTICA DE TECIDOS BIOLÓGICOS 20

2.1. Introdução 20

2.2. Material e métodos $\quad 20$

2.2.1. lluminação transcraniana do encéfalo de rato 22

2.2.2. Mapeamento óptico do encéfalo de rato 24

2.3. Resultados e discussão $\quad 25$

2.3.1. Iluminação transcraniana do encéfalo de rato 25

2.3.2. Mapeamento óptico do encéfalo de rato 32

2.4. Conclusão 36

3. FOTONEUROMODULAÇÃO DA DOR 37

3.1. Material e métodos $\quad 37$

3.2. Resultados e discussão 43

3.2.1. Limiar de dor $\quad 44$

3.2.2. Testes de nocicepção 45

3.2.3. Alterações bioquímicas no encéfalo 49

3.3. Conclusão

4. CONSIDERAÇÕES FINAIS E PERSPECTIVAS FUTURAS 57

REFERÊNCIAS 58

Apêndice A 61 
Apêndice $B$ 69

Apêndice $\mathrm{C}$

76

Anexo A

81

Anexo B

87 


\section{LISTA DE ABREVIAÇÕES}

\begin{tabular}{ll}
\hline ABREVIAÇÃO & SIGNIFICADO \\
\hline AMP & Monofosfato de adenosina \\
ATP & Trifosfato de Adenosina \\
COX & Citocromo-C-Oxidase \\
CW & Modo de iluminação contínua (continuous wave) \\
ddp & diferença de potencial \\
DP & Desvio padrão da amostra \\
FC & Fragmento que cristaliza \\
FLA & Fragmento que contém o sítio ligante ao antígeno \\
GC & Grupo controle \\
GI1 & Canal de glutamato tipo 1 \\
GL120 & Grupo iluminado transcranianamente durante 120 s \\
GL24 & Grupo iluminado transcranianamente durante 24 s \\
HE & Hematoxilina-Eosina \\
IF & Imunofluorescência \\
IV & Infravermelho \\
LBI & Laser de Baixa Intensidade \\
OAT & Tomografia optoacústica \\
OCT & Tomografia por coerência óptica \\
PA & Potencial de Ação \\
PAP & Fosfatase ácida prostática (prostatic acid phosphatase) \\
PR & Potencial de Repouso \\
S1 & Córtex Somestésico Primário \\
SN & Sistema Nervoso \\
SNC & Sistema Nervoso Central \\
SNP & Sistema Nervoso Periférico \\
TCE & Traumatismo crânio-encefálico \\
TLBI & Terapia com Laser de Baixa intensidade \\
TTF & Teoria do Transporte de Fótons \\
\hline & \\
\hline
\end{tabular}


Resumo: A Terapia com Laser de Baixa Intensidade (TLBI) pode ser utilizada para tratar dores agudas e crônicas. Entender as vias da dor e as interações de fótons com tecidos neurais possibilitará compreender melhor essas terapias. A nocicepção pode ser autocontrolada por analgésicos endógenos, opióides naturais que bloqueiam a liberação de neurotransmissores excitatórios e, portanto, fazem uma inibição sensorial total e inespecífica. Sabe-se que a TLBI pode estimular a liberação desses analgésicos endógenos e inibir temporariamente o transporte axonal em fibras de pequeno diâmetro. Conhecer a fluência luminosa no interior do tecido neural é essencial para avaliar as hipóteses descritas, no entanto, devido à complexidade dos tecidos biológicos, calcular (ou simular) as interações da luz com os tecidos é impraticável. Para superar esse problema, desenvolvemos experimentos para estimar a fluência de luz em aplicação transcraniana de laser e mapeamos as propriedades ópticas do encéfalo de rato. Foi possível diferenciar tecidos encefálicos por suas características de atenuação da intensidade luminosa e estimar a profundidade da penetração da luz que pode ser de mais de $20 \mathrm{~mm}$. Encontramos redução da dor evocada por pressão, calor, frio ou inflamação após TLBI transcraniana em camundongos. Para esse estudo comportamental, desenvolvemos um equipamento para avaliar o limiar de dor por aplicação de pressão nos animais, que opera com melhor precisão que os instrumentos comerciais. Os mecanismos de fotoneuromodulação foram investigados por quantificação de Trifosfato de Adenosina (ATP), imunofluorescência e marcação com hematoxilina-eosina de tecidos encefálicos que foram visualizados por microscópio confocal. A iluminação transcraniana aumentou a produção de ATP e de Fosfatase ácida prostática (um analgésico endógeno) e reduziu a quantidade do neurotransmissor glutamato, responsável pela condução da informação nociceptiva. Por outro lado, não observamos alteração na concentração de tubulina, um dos constituintes do citoesqueleto, e a marcação com hematoxilina-eosina revelou que não houve dano ao tecido decorrente da iluminação. Os achados apresentados nesse estudo atestam a relevância e eficácia da fotoneuromodulação proveniente de iluminação transcraniana com laser de $808 \mathrm{~nm}$ para suprimir a nocicepção em camundongos. Esse estudo é pioneiro na elucidação dos mecanismos de ação da fotoneuromodulação da dor in vivo. 
Abstract: Low-level Light therapy (LLLT) can treat acute and chronic pain. Getting knowledge about the pain pathways and the photon-neuron interactions may contribute to a better understanding of this therapy. The nociception may be self-controlled by endogenous analgesics, natural opioids that block the release of excitatory neurotransmitters, and thus make a total and nonspecific sensory inhibition. It is known that LLLT can stimulate the release of these endogenous analgesics, so it temporarily inhibits axonal transport in small diameter fibers. The knowledge of light fluence through neural tissue is essential to test the discussed assumptions. However, due to the complexity of biological tissues, the calculation (or simulation) of light-tissue interactions is impractical. In order to overcome this problem, we developed an experimental setup to estimate the light fluence in a transcranial LLLT and to map the optical properties of rat brains. It was possible to differentiate cerebral tissues and to estimate the depth of light penetration, which is more than $20 \mathrm{~mm}$. We found a decrease in pain evoked either by pressure, heat, cold or inflammation after transcranial LLLT in mice. For this animal behavioral study, we developed an equipment to assess the pain threshold with pressure stimulus, which operates with better precision than commercial instruments. The LLLT mechanisms were investigated by Adenosine triphosphate ATP quantification, immunofluorescence and haematoxylin and eosin staining of brain tissues which were imaged by confocal microscopy. The transcranial irradiation increased ATP and prostatic acid phosphatase (an endogenous analgesic) production and reduced the amount of glutamate, the neurotransmitter responsible for conducting nociceptive information. There was no change in the concentration of tubulin, a constituent of the cytoskeleton, and the haematoxylin and eosin staining revealed no tissue damage due to the irradiation. This study is pioneer in elucidating the mechanisms of in vivo photoneuromodulation of pain. 


\section{Prefácio}

Este texto dissertará sobre a interação de laser com tecidos biológicos, bem como sobre o efeito analgésico decorrente dessa interação. Além disso, ele pretende ser um guia transdisciplinar para estudos e experimentos vindouros. Nele estão descritos trabalhos experimentais realizados em São Paulo (Instituto de Física da USP e Centro de Laser e Aplicações do IPEN); Campinas (Instituto de Biologia da Unicamp) e em Boston - Massachusettes Estados Unidos da América (Wellman Center for Photomedicine do Massachusettes General Hospital e Harvard Medical School)

A apresentação esclarece a motivação para esse estudo e descreve sucintamente os objetivos gerais e específicos desta pesquisa.

O capítulo 1 é uma introdução aos conhecimentos fundamentais para entender este trabalho.

O capítulo 2 discorre sobre experimentos a respeito da óptica de tecidos biológicos.

O capítulo 3 apresenta resultados sobre os mecanismos de ação da fotoneuromodulação da dor.

O capítulo 4 mosta as conexões entre os capítulos dessa tese e fala sobre expectativas futuras para os temas aqui discutidos.

Nos apêndices A, B e C são apresentados os textos completos de trabalhos relacionados a esta tese já publicados, a saber: Laser scattering by transcranial rat brain illumination (anais do congresso SPIE Photonics Europe 2012); Inhomogeneity in optical properties of rat brain: a study for LLLT dosimetry (anais do congresso SPIE Photonics West 2013); Building, testing and validating a set of home-made von Frey filaments: a precise, accurate and cost effective alternative for nociception assessment (Journal of Neuroscience Methods 2014)

Os anexos A e B são os protocolos para imuno-histoquímica e quantificação de ATP tissular que são praticados no Wellman Center for Photomedicine, Massachussetts General Hospital. 


\section{Apresentação}

A Ciência tem como uma de suas principais razões de ser a busca por conhecimentos que possam levar à melhoria da qualidade de vida das pessoas e consequentemente ao desenvolvimento das sociedades. Esse objetivo vem se tornando cada vez mais difícil de ser atingido pelo conhecimento particionado em disciplinas. Por isso, a interdisciplinaridade, e, mais recentemente, a transdisciplinaridade têm se tornado buscas comuns na ciência moderna.

Um ramo frutífero para a interdisciplinaridade é a interação entre Física e Medicina. No presente trabalho apresentaremos de forma translacional, como a luz, uma entidade estudada pela Física por séculos, pode ajudar a amenizar ou a resolver a dor, um problema milenar da Medicina.

\section{Motivação}

A dor é uma experiência sensorial e emocional desagradável associada a uma lesão real ou potencial, ou descrita em termos de tal (definição da Associação Internacional para o Estudo da Dor - IASP). Os nociceptores são os receptores para dor do Sistema Nervoso Periférico (SNP) e o início da via ascendente da dor. Poderíamos de forma simplista, sem considerar aspectos emocionais, culturais e sociais, dizer que a dor é a sensação obtida pelo estímulo dos nociceptores.

Nas últimas décadas, pesquisadores das mais variadas áreas têm se interessado por entender e tratar a dor. A razão disso é, principalmente, o aumento dos casos de pacientes com dor, fenômeno conectado ao envelhecimento da população mundial. Durante o século XX, a expectativa de vida dos brasileiros aumentou de 33,4 para 68,6 anos. Na última década 0 número de pessoas com mais de 60 anos duplicou no Brasil. $\mathrm{O}$ aumento da idade média da população leva ao aumento dos casos de dores crônicas, pois há maior número de pessoas com dores pós-traumáticas e/ou dores reumáticas, dores devido a órgãos e tecidos debilitados, entre outras [1].

A utilização de Terapia com Laser de Baixa Intensidade (TLBI) tornou-se importante alternativa às drogas analgésicas. Os principais motivos para 0 
aumento da utilização dessas terapias são: o amplo espectro de tratamentos analgésicos possíveis; até o momento as TLBI são consideradas não viciantes e não há efeitos adversos conhecidos decorrentes dessas terapias [2].

Embora exista ampla gama de estudos descrevendo efeitos e possíveis aplicações da TLBI, ainda há muito para pesquisar, desenvolver e criar nessa área do conhecimento. Em particular, os mecanismos de ação carecem de uma explicação definitiva e amplamente aplicável; e a dosimetria de radiação não ionizante interagindo com a matéria precisa ser alicerçada sobre grandezas precisas, uniformes e de fácil medição.

\section{Objetivos}

Os principais objetivos desse projeto são:

I. Avaliar a interação da luz com tecidos biológicos em uma iluminação transcraniana de encéfalo de rato.

a. Descobrir como varia o perfil de intensidade da luz em uma iluminação transcraniana.

b. Estimar a penetração da luz através dos tecidos biológicos em uma iluminação transcraniana.

c. Comparar as interações de luz vermelha e infravermelha com tecidos biológicos.

II. Mapear as propriedades ópticas do encéfalo de rato.

a. Avaliar a transmissão de luz (vermelha e infravermelha) através de amostras de encéfalo de rato.

b. Distinguir regiões do encéfalo de ratos quanto à atenuação da luz.

c. Discutir formas de iluminação baseadas nas propriedades ópticas do encéfalo.

III. Avaliar a alteração no limiar de dor obtida com TLBI transcraniana em camundongos.

a. Verificar se há aumento do limiar de dor evocada por filamentos von Frey.

b. Descobrir por quanto tempo o limiar de dor permanece alterado. 
c. Avaliar a influência do tempo de iluminação nas alterações do limiar de dor dos animais.

IV. Avaliar a generalidade da ação da TLBI transcraniana na redução da dor

a. TLBI para redução da dor em animais hígidos ou sujeitos à inflamação evocada por formalina.

V. Procurar alterações histológicas, morfológicas e bioquímicas nos encéfalos de camundongos após TLBI.

a. Imunofluorescência histológica de canais de glutamato, tubulina e Fosfatase ácida prostática (PAP, do inglês Prostatic acid phosphatase), uma substância correlacionada à antinocicepção de longo prazo.

b. Marcação com HE para verificar possíveis alterações morfológicas. 


\section{INTRODUÇÃO}

Nesse capitulo será apresentada a fundamentação teórica necessária para o entendimento dessa tese como: anatomia e fisiologia do sistema nervoso; interação da luz com tecidos biológicos e seus efeitos analgésicos; testes de nocicepção, ensaios bioquímicos e aquisição de imagens de tecidos biológicos.

\subsection{Anatomia do encéfalo de roedores}

Os experimentos para caracterização óptica dos tecidos neurais foram executados em encéfalo de rato e a fotoneuromodulação transcraniana em camundongos. Por isso, apresentaremos alguns aspectos básicos da anatomia do encéfalo desses animais (ordem Rodentia, família Muridae). Nossa pretensão é unicamente apresentar algumas estruturas e nomenclaturas simples para que possamos, no decorrer desse texto, nos referir a elas livremente. Quando possível, faremos um paralelo com o encéfalo humano, com isso, esperamos esclarecer as extrapolações para as terapias em humanos.

O encéfalo é formado pelo cérebro, cerebelo e tronco encefálico (figura 1.1). O cérebro controla funções elaboradas como movimentos, sentidos, linguagem, aprendizado e memória. O cerebelo está principalmente relacionado com o controle motor. O tronco encefálico, constituído por ponte, mesencéfalo e medula oblonga, faz a conexão do cérebro com a medula espinhal, e está envolvido com funções autônomas, como respiração, regulação cardiovascular e controle da dor.

O cérebro é o mais complexo dos órgãos, possui uma infinidade de subestruturas, formadas por diferentes tipos de neurônios. Muitas das funções cerebrais são compartimentadas, ou seja, apenas algumas das estruturas do cérebro são responsáveis por uma determinada atividade. As diferenças bioquímicas da composição dos neurônios bem como a densidade de neurônios em uma região afetam as propriedades ópticas desses tecidos.

O córtex cerebral é a parte mais externa do cérebro de mamíferos e, evolutivamente, foi a última região a surgir. Os neurônios corticais, em geral, não são mielinizados, por isso, o córtex tem coloração cinza. Essa região do 
cérebro coordena as funções mais complexas como: linguagem, memória, capacidade cognitiva e consciência. O hipocampo é uma estrutura localizada no interior do cérebro e seu mau funcionamento está relacionado a uma série de patologias, como: doença de Alzheimer, esquizofrenia e epilepsia.

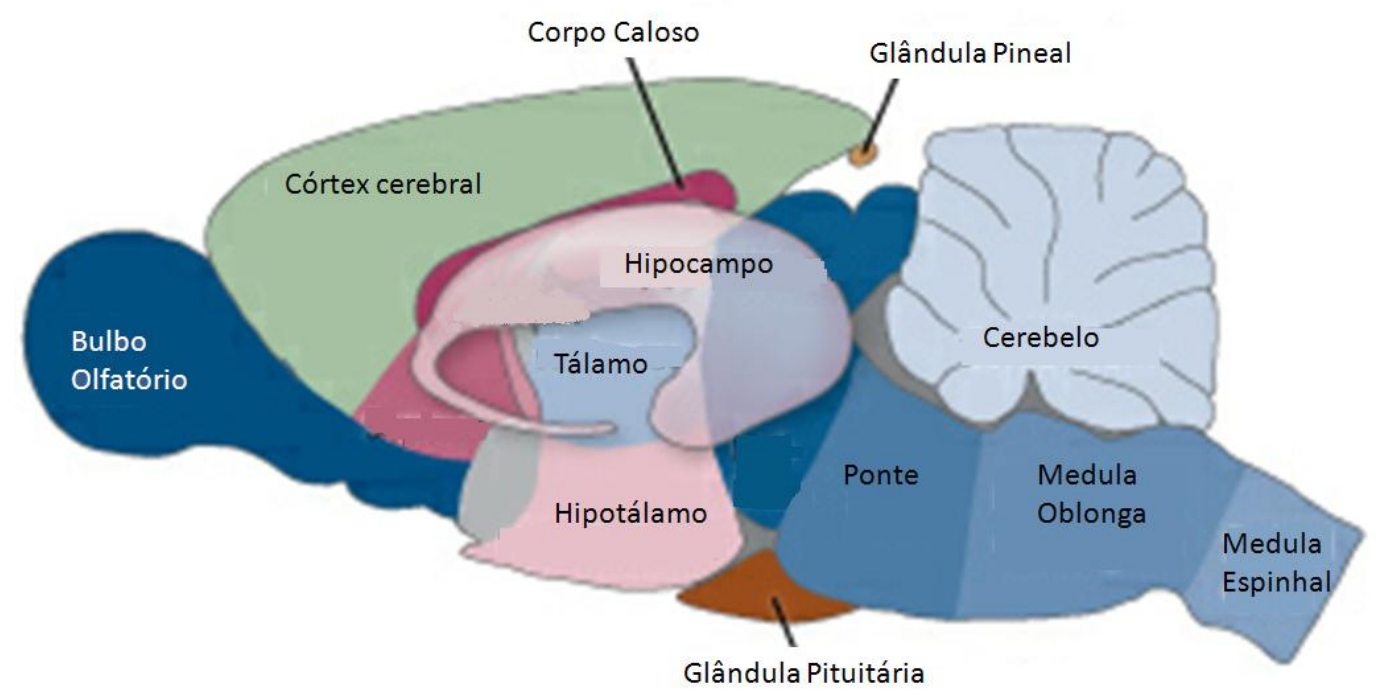

Figura 1.1: Encéfalo de rato. Adaptado de Lent et al [4].

\subsection{Fisiologia do neurônio}

O sistema nervoso é constituído por neurônios e gliócitos, células que proporcionam suporte e nutrição para os neurônios. Os neurônios são células excitáveis com enorme variedade, apresentando-se em centenas de formas e funções [3]. A excitabilidade, capacidade de produzir, conduzir e transmitir para outras células impulsos elétricos, é a principal diferença entre os neurônios e as outras células. A imensa maioria dos neurônios possui além do soma (corpo celular), axônios e dendritos. No soma estão o citoplasma, as organelas e o núcleo da célula. Os axônios (geralmente um por célula) são prolongamentos nos quais os impulsos elétricos são transmitidos para outras células; a velocidade de transmissão dos impulsos aumenta com o diâmetro do axônio e com a quantidade de mielina (substância isolante de composição lipídica) que os envolve. Os dendritos (do grego déndron, que significa ramo de árvore) recebem os impulsos de outras células (figura 1.2). 


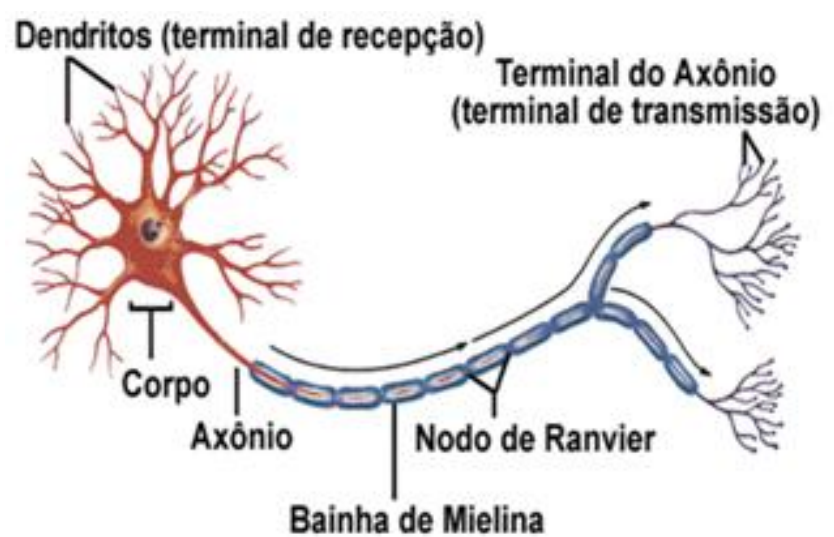

Figura 1.2: Neurônio. Adaptado de Bear et al [3].

As membranas dos neurônios, em repouso, estão a uma ddp de aproximadamente $-70 \mathrm{mV}$, essa tensão é principalmente mantida pela bomba de sódio e potássio (Bomba $\mathrm{Na}^{+} / \mathrm{K}^{+}$), com dispêndio de energia celular (por volta de $70 \%$ do ATP do encéfalo). Os impulsos elétricos gerados e conduzidos pelos neurônios são conhecidos como Potenciais de Ação (PA). Os PA são caracterizados por mudanças na tensão elétrica da membrana que se propagam pelos axônios devido a mudanças de condutividade da membrana para os íons $\mathrm{Na}^{+}$e $\mathrm{K}^{+}$.

A membrana celular dos neurônios possui canais que permitem a passagem controlada de íons. Existem muitos tipos de canais iônicos, alguns deles são específicos para um íon, uns estão sempre abertos, outros abrem apenas em uma dada faixa de voltagem e há ainda os que abrem apenas na presença de uma dada substância. É a abertura desses canais que aumenta a condutividade para um dado íon. Os canais para os íons $\mathrm{Na}^{+}$e $\mathrm{K}^{+}$envolvidos na condução dos PA são dependentes de potencial.

Os PA são gerados quando uma despolarização da membrana atinge 0 valor limiar para a abertura dos canais $\mathrm{Na}^{+}$e $\mathrm{K}^{+}$. A despolarização pode ser advinda da excitação transmitida por outro neurônio, começando no cone de implantação, ou pela transdução de um estímulo em um receptor sensorial. Devido à despolarização os canais de $\mathrm{Na}^{+}$abrem, e subitamente, há um forte influxo de $\mathrm{Na}^{+}$levando à despolarização ainda maior da membrana $(\sim+40 \mathrm{mV})$. Em seguida, os canais de $\mathrm{Na}^{+}$fecham e os canais de $\mathrm{K}^{+}$abrem e esses íons saem da célula hiperpolarizando-a para aproximadamente - $70 \mathrm{mV}$. Os íons $\mathrm{Na}^{+}$que entram na célula, durante o PA, se difundem pelo interior da 
célula conduzindo a despolarização, e consequentemente o PA, para regiões cada vez mais distantes da região onde ele foi gerado (figura 1.3).

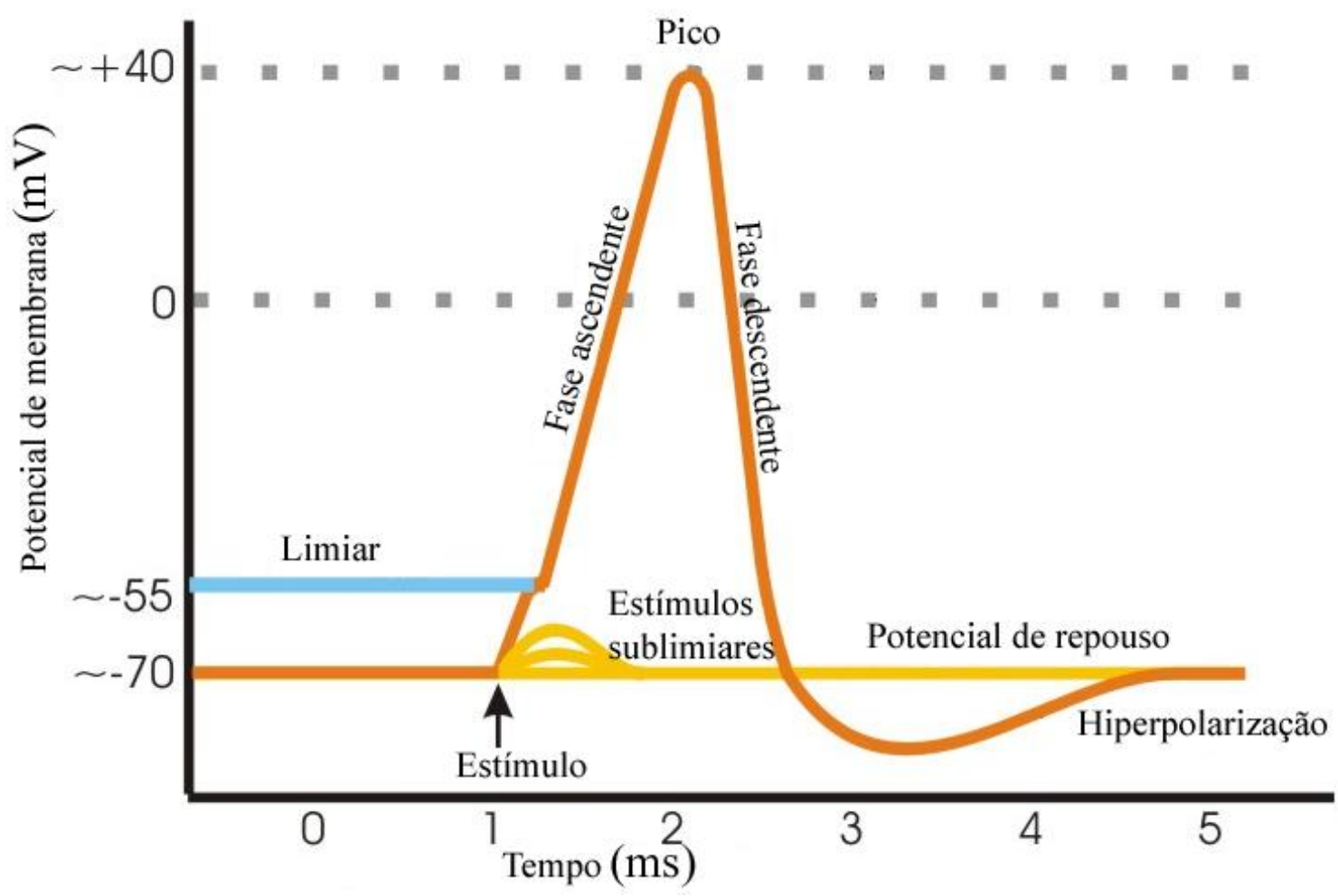

Figura 1.3: Modelo de potencial de ação. É preciso um estímulo que leve a uma despolarização igual ou maior que o limiar para iniciar um potencial de ação. A fase ascendente ocorre devido ao influxo de $\mathrm{Na}^{+}$e a fase descendente e a hiperpolarização, à saída de $\mathrm{K}^{+}$. Adaptado de Lent et al [4].

Os neurônios transmitem informações pelas sinapses. Estas podem ser elétricas ou químicas. As sinapses elétricas transmitem os PA praticamente sem alterá-los. Animais vertebrados têm esse tipo de transmissão principalmente nos estágios embrionários do desenvolvimento, pois nessa fase do desenvolvimento é necessária forte sincronia da informação conduzida pelos neurônios.

A informação nas sinapses químicas é conduzida pelos neurotransmissores, substâncias capazes de excitar neurônios. Os tipos e concentrações de neurotransmissores modulam a informação conduzida, com isso, as sinapses químicas fazem processamento de sinais. Essas sinapses são unidirecionais e geralmente o terminal pré-sináptico está em um axônio e o elemento pós-sináptico em um dendrito. A região entre os elementos sinápticos 
é conhecida como fenda sináptica. No elemento pré-sináptico estão presentes as vesículas sinápticas e os grânulos - estruturas esféricas que estão repletas de neurotransmissores. Quando os neurotransmissores são liberados na fenda sináptica eles podem excitar os receptores dos elementos pós-sinápticos.

Quando um PA chega a um terminal pré-sináptico há um forte influxo de $\mathrm{Ca}^{++}$, esse íon desencadeia reações bioquímicas que levam ao atrelamento de vesículas e grânulos à membrana pré-sináptica. Após o atrelamento, a membrana da vesícula adere à membrana neuronal levando à liberação de neurotransmissores na fenda sináptica. Em uma mesma sinapse podem ser encontrados vários tipos de neurotransmissores. A liberação dos neurotransmissores depende do padrão de PA que chega à sinapse e a informação transmitida pelo neurônio pós-sináptico depende das várias sinapses que existem entre ele e diversos outros neurônios pré-sinápticos. Portanto, as sinapses químicas são a base para a computação neural dos animais.

\subsection{Neurofisiologia da dor}

É possível identificar dois tipos de dor, uma rápida (ou aguda) que ocorre durante o estímulo lesivo e outra de caráter mais lento, que permanece após o término da lesão [5]. A dor aguda é causada pela estimulação de receptores sensíveis à dor (os nociceptores) ligados às fibras $A \delta$ (figura 1.4). Essas fibras têm diâmetro pequeno $(2,0-5,0 \mu \mathrm{m})$, velocidade de condução intermediária $(12,0-30,0 \mathrm{~m} / \mathrm{s})$ e são pouco mielinizadas; possuem poucas ramificações e, geralmente, são específicas para um determinado tipo de estímulo (pressão, temperatura, $\mathrm{pH}$, etc.). As fibras $\mathrm{A} \delta$ conduzem a informação da sensação dolorosa aguda e localizada que ocorre durante o estímulo lesivo.

Sabemos, por experiência própria, que muitas vezes a dor persiste mesmo após o término do estímulo lesivo. A sensação dolorosa continuada é transmitida através do SNP por fibras $C$ (figura 1.4). Essas fibras têm diâmetro extremamente pequeno $(0,3-1,5 \mu \mathrm{m})$ e são desmielinizadas, por isso a velocidade de transmissão de PA nessas fibras é baixa $(0,5-2,0 \mathrm{~m} / \mathrm{s})$. As fibras $C$ são muito ramificadas, portanto, a sensação dolorosa é deslocalizada 
sendo percebida não apenas na região da lesão, mas também nas regiões vizinhas (figura 1.5). Os nociceptores ligados às fibras $C$ são polimodais, ou seja, são sensíveis a vários tipos de estímulos.

A lesão de tecidos leva ao rompimento de vasos e membranas celulares. Consequentemente, há liberação de material citoplasmático e sanguíneo para o meio no qual estão os nociceptores (figura 1.5). Os leucócitos liberam substâncias algógenas como serotonina e histamina. As células dos tecidos lesados liberam substâncias fortemente algógenas como o peptídeo bradicinina, e substâncias irritantes, como os derivados do ácido araquidônico (prostaglandinas e prostaciclinas). Tanto a lesão per se quanto as substâncias algógenas liberadas ativam ou sensibilizam os nociceptores das fibras C. Devido à sensibilização, leves estímulos, os quais em tecidos sadios seriam inócuos, podem levar à dor. Esse fenômeno é conhecido como hiperalgesia. A despolarização dos nociceptores das fibras $C$ leva à liberação de prostaglandinas e neuropeptídeos de ação vasodilatadora local que exacerbam o processo inflamatório acentuando a vermelhidão e o edema, prolongando a dor.

Os neurônios primários do sistema sensório nociceptivo são do tipo pseudounipolares. A característica principal desse tipo de neurônio é que o corpo celular está fora do caminho percorrido pelo PA ao longo do axônio. Essa característica permite maior velocidade de condução e menor interferência na informação conduzida através do neurônio. Os corpos celulares dos neurônios pseudounipolares nociceptivos se agrupam nos gânglios da raiz dorsal. Os gânglios da raiz dorsal têm papel central na nocicepção uma vez que neles estão os núcleos neuronais, por tanto, é o locus da expressão dos neurotransmissores.

Os nociceptores produzem fluxos iônicos que são codificados em salvas de PA que são levados pelas fibras A $\delta$ e C (figura 1.5). Os axônios desses neurônios têm duas terminações; uma distal, na qual os PA são gerados; e uma central, que penetra na medula e lá faz sinapse com neurônios secundários. Os axônios dos neurônios secundários da dor cruzam a medula e seguem para o SNC. Os impulsos da dor rápida são veiculados ao tálamo onde fazem sinapses com neurônios que se projetam para o córtex somestésico primário $(\mathrm{S} 1)$. 
As fibras de dor lenta se projetam para o SNC no tálamo e no S1; e também para regiões que coordenam fenômenos vegetativos e emocionais. Por isso, provocam efeitos além da dor, tais como: estado fisiológico e psicológico de alerta, secreção de hormônios, e resposta emocional à dor (figura 1.5).
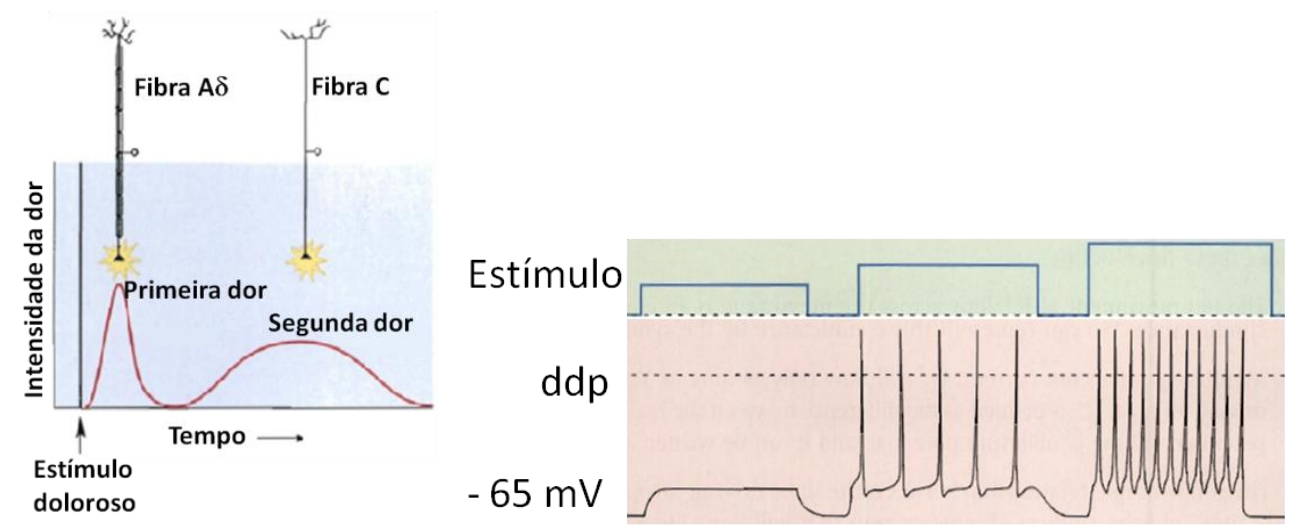

Figura 1.4: Período e intensidade da dor conduzida por fibras $A \delta$ e $C$. Codificação da intensidade do estímulo em salvas de potenciais de ação. Adaptado de Bear et al [3].

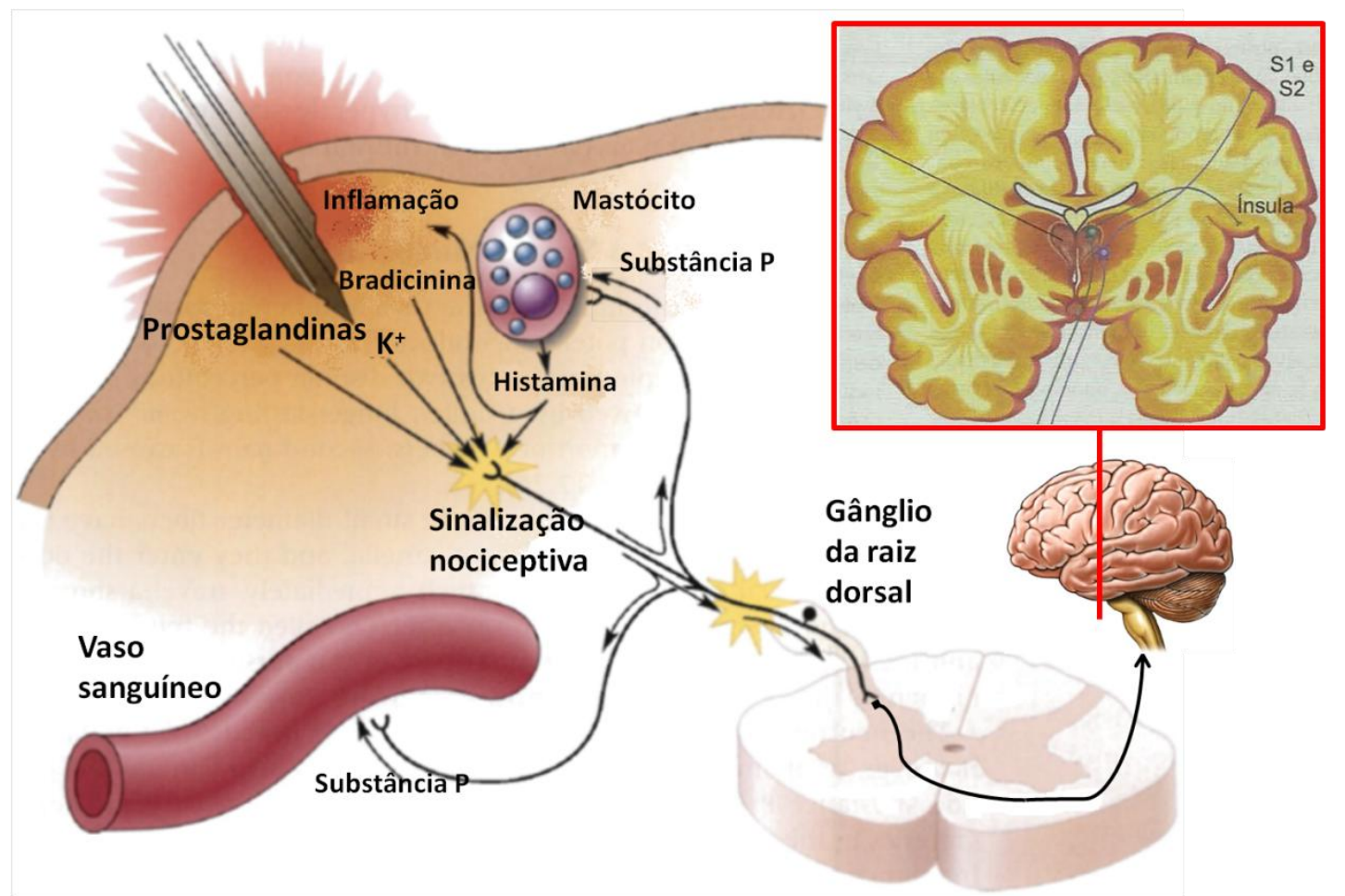

Figura 1.5: A lesão de tecidos leva à liberação de substâncias algógenas. A sinalização da dor é levada através da medula espinal até o córtex somestésico primário. Adaptado de Bear et al e Lent et al [3-4]. 
A dor pode ser autocontrolada. Isso é possível, graças às vias descendentes de modulação da dor e aos analgésicos endógenos. Essas vias originam-se no córtex somestésico e se ramificam na substância cinzenta periaquedutal. A via descendente causa inibição parcial e seletiva da dor quando os neurônios dessa via fazem sinapses com os neurônios secundários da via ascendente.

Os analgésicos endógenos (encefalinas, endorfinas e dinorfina) são peptídeos encontrados em regiões nas quais existem sinapses da via ascendente da dor (substância cinzenta periaquedutal, núcleos da rafe e corno dorsal da medula). Esses opióides naturais bloqueiam a liberação de neurotransmissores excitatórios pelos terminais pré-sinápticos e hiperpolarizam a membrana pós-sináptica. Portanto, essas substâncias fazem uma inibição sensorial total e inespecífica. Um desses analgésicos endógenos é a fosfatase ácida prostática (PAP), uma enzima responsável por hidrolisar o AMP (Monofosfato de Adenosina) extracelular em adenosina. Quando PAP é encontrado em grande quantidade, indica que houve uma supressão dos sinalizadores (AMP) que por sua vez são sensibilizadores dos neurônios condutores da sinalização nociceptiva, por isso, o PAP apresenta atividade analgésica indireta.

Há ainda um mecanismo simples, conhecido como fenômeno porta, de inibição devido à interferência de fibras $A \alpha$ ou $A \beta$ ligadas a receptores táteis. As fibras A $\alpha$ são altamente mielinizadas e têm o maior diâmetro entre as fibras axonais $(13-20 \mu \mathrm{m})$, por isso a velocidade de condução é a mais alta entre as fibras (80 - $120 \mathrm{~m} / \mathrm{s}$ ); elas são responsáveis pela propriocepção. As fibras $A \beta$ são intermediarias em mielinização, diâmetro $(6-12 \mu \mathrm{m})$ e velocidade de condução (35 - $75 \mathrm{~m} / \mathrm{s}$ ), elas se ligam a mecanorreceptores. As fibras $A \alpha$ ou $A \beta$ quando chegam à medula fazem sinapses com neurônios intermediários que por sua vez inibirão os neurônios da via ascendente da dor. Por isso, quando os impulsos táteis chegam à medula ao mesmo tempo em que os impulsos nociceptivos eles podem inibir a via ascendente da dor.

Dessa forma, a inibição da via ascendente da dor, a estimulação da via descente da dor e a estimulação da produção de analgésicos endógenos podem ser formas de reduzir, ou, até mesmo, bloquear a nocicepção. 


\subsection{Interação da luz com tecidos neurais}

Ao atravessar um meio material os fótons provenientes da fonte luminosa podem ser absorvidos ou espalhados pelos átomos ou moléculas desse meio ocorrendo atenuação da intensidade luminosa (figura 1.6). A maior parte da absorção nos tecidos biológicos é ocasionada pela água ou por macromoléculas, como proteínas e melanina. A água é a principal responsável pela absorção no infravermelho (IV) e as proteínas pela faixa ultravioleta (UV) do espectro [6].

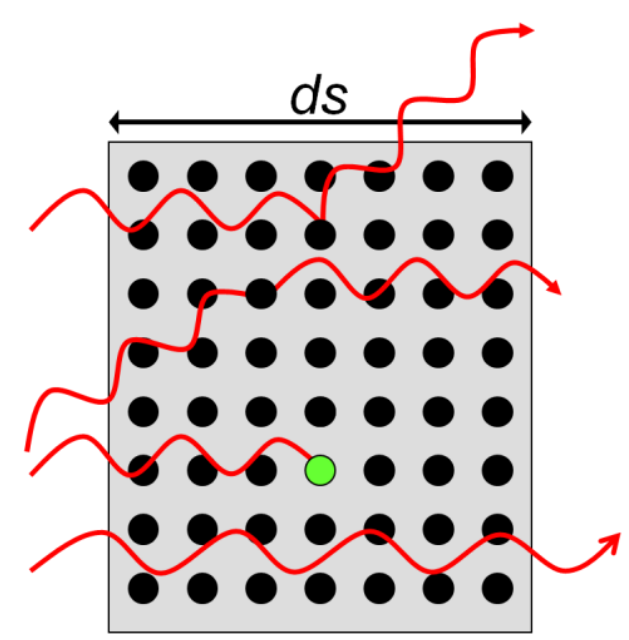

Figura 1.6: Tipos de interação que os fótons (faixa óptica) podem sofrer ao atravessar um tecido biológico. Nesse modelo esquemático as setas onduladas representam os fótons, os pontos pretos representam as moléculas, o ponto verde uma molécula depois de absorver um fóton. De cima para baixo, vemos: um espalhamento que diminui a intensidade na direção de detecção, outro que a aumenta, uma absorção e um fóton que não interage ao atravessar o meio.

$\mathrm{Na}$ faixa do vermelho e IV próximo tanto a água quanto as macromoléculas absorvem relativamente pouco, possibilitando uma maior penetração da luz nos tecidos. Por isso, a faixa entre 600 e 1200 nm é bastante empregada para tratamentos em tecidos mais profundos (até $\sim 2 \mathrm{~cm}$ ) e é, portanto, considerada como uma "janela terapêutica" para fototerapia [7].

O espalhamento ocorre devido à interação da luz com moléculas, organelas, estruturas celulares e as próprias células do tecido biológico. $O$ espalhamento pode ser dividido basicamente em dois tipos: elástico, no qual o fóton apenas muda de direção, e inelástico, onde há mudança de energia do 
fóton e da energia interna da molécula. O espalhamento Raman (processo inelástico) tem baixa probabilidade de ocorrer para tecidos biológicos iluminados com $\lambda$ na faixa de $600 \mathrm{~nm}$ a $1200 \mathrm{~nm}$. Dois modelos podem ser usados para explicar o espalhamento elástico: espalhamentos Rayleigh e Mie.

O espalhamento Rayleigh predomina quando o tamanho do centro espalhador é muito menor que o comprimento de onda $(\lambda)$ da luz incidente. Nesse modelo há uma tendência de espalhamento frontal e retroespalhamento, e uma baixa probabilidade de luz espalhada em direções perpendiculares à direção de propagação. Para esse tipo de interação o espalhamento depende do inverso da quarta potência de $\lambda$.

O espalhamento Mie acontece quando o espalhador tem dimensões da ordem de grandeza do $\lambda$ da luz incidente. A principal consequência da interação da luz com essas partículas é a atenuação da intensidade espalhada, devido à interferência entre ondas parciais de luz espalhada por diferentes pontos da partícula. O espalhamento Mie depende fracamente do comprimento de onda $\left(I \propto \lambda^{-x} \operatorname{com} 0,4<x<0,5\right)$ e é predominantemente frontal [8].

Nos tecidos do $S N$ tanto a absorção quanto o espalhamento são relevantes, por isso, eles são considerados meios turvos. No entanto, para os tecidos do SN, o principal fator de atenuação da intensidade do feixe é o espalhamento dos fótons. Solucionar analítica ou numericamente o problema da propagação da luz, através de meios turvos, utilizando as leis de Maxwell é extremamente complexo [9]. Para simular a propagação de luz em um meio turvo podem ser usadas soluções numéricas baseadas no método de Monte Carlo da equação de transporte de fótons para um meio cujas propriedades ópticas (coeficientes de absorção e espalhamento, fator de anisotropia e índice de refração) sejam conhecidas [10].

$O$ cérebro é constituído por diversos tecidos com grande especialização por isso há enorme diversidade celular. A forma, tamanho, composição bioquímica e a densidade dos neurônios afetam os padrões de espalhamento da luz. Há uma enorme variedade bioquímica das moléculas que formam os neurônios, portanto, o espectro de absorção varia entre os diversos tipos de células. As circunvoluções do córtex cerebral contribuem para reflexões e espalhamentos internos ao cérebro. A diversidade celular e a forma como as 
células estão distribuídas dentro do cérebro fazem com que a distribuição interna da luz nesse órgão seja de difícil previsão [11].

\subsection{Teoria do transporte de fótons}

Historicamente, existem duas abordagens para o problema de múltiplos espalhamentos: a abordagem analítica e a Teoria do Transporte de Fótons (TTF). A abordagem analítica parte das equações de Maxwell e das propriedades de absorção e espalhamento das partículas para obter as grandezas estatísticas como variância e função de correlação. Já a TTF lida heuristicamente com o transporte de energia por um meio turvo. Ela assume que não há correlação entre os campos, portanto, a adição de potências é tão válida quanto a adição de campos [12]. A equação diferencial básica dessa teoria é equivalente à equação de Boltzmann usada em teoria cinética de gases.

Antes de introduzir a equação básica da TTF é preciso definir algumas grandezas, tais como: intensidade especifica $I(\vec{r}, \hat{s})$, fluxo $F(\vec{r})$ e densidade de energia $u(\vec{r})$. A intensidade especifica (também chamada de radiância ou brilho) é a potência de luz com comprimento de onda entre $\lambda$ e $\lambda+d \lambda$ que atravessa uma área da, localizada em $\vec{r}$, numa direção $\hat{s}$ e é medida em $\mathrm{W} \mathrm{m}^{-}$ ${ }^{2} \mathrm{sr}^{-1} \mathrm{~nm}^{-1}$. O fluxo $F(\vec{r})$ é definido por:

$$
\vec{F}(\vec{r})=\int_{4 \pi} I(\vec{r}, \hat{s}) \hat{s} d \Omega
$$

e representa a quantidade total e a direção do fluxo de potência. A densidade de energia, definida a partir de $I(\vec{r}, \hat{s})$, é dada por:

$$
u(\vec{r})=\frac{1}{c} \int_{4 \pi} I(\vec{r}, \hat{s}) d \Omega
$$

Agora podemos introduzir a equação da TTF da intensidade especifica. Vamos considerar um elemento cilíndrico com base de área unitária e altura $d s$ com $\rho$ partículas absorvedoras e espalhadoras por unidade de volume. Cada partícula tem seção de choque de absorção, espalhamento e total dada por $\sigma_{\mathrm{a}}$, 
$\sigma_{\mathrm{s}}$ e $\sigma_{\mathrm{t}}=\sigma_{\mathrm{a}}+\sigma_{\mathrm{s}}$, respectivamente. Ao atravessar esse elemento a intensidade especifica é atenuada de:

$$
d I_{a t}(\vec{r}, \hat{s})=-\rho d s \sigma_{t} I_{a t}
$$

Mas, devido aos fótons que estavam inicialmente em direções $\hat{s}^{\prime}$ e foram espalhados para direção $\hat{s}, I(\vec{r}, \hat{s})$ aumenta de:

$$
d I_{e s p}(\vec{r}, \hat{s})=d s \frac{\rho \sigma_{s}}{4 \pi} \int_{4 \pi} p\left(\hat{s}, \hat{s}^{\prime}\right) I_{e s p}\left(\vec{r}, \hat{s}^{\prime}\right) d \Omega^{\prime}
$$

onde $p\left(\hat{s}, \hat{s}^{\prime}\right)$ é a densidade de probabilidade de um fóton ser espalhado da direção $\hat{s}^{\prime}$ para $\hat{s}$, e é conhecida como função de fase. Adicionando as contribuições para a variação de $I(\vec{r}, \hat{s})$ ao atravessar $d s$, temos:

$$
\frac{d I(\vec{r}, \hat{s})}{d s}=-\rho \sigma_{t} I(\vec{r}, \hat{s})+\frac{\rho \sigma_{s}}{4 \pi} \int_{4 \pi} p\left(\hat{s}, \hat{s}^{\prime}\right) I\left(\vec{r}, \hat{s}^{\prime}\right) d \Omega^{\prime}
$$

Essa equação pode ser resolvida de forma exata para geometrias simples e em determinadas condições de concentrações de espalhadores e absorvedores. A solução numérica dessa equação é a base para diversos softwares que calculam distribuição de luz em meios turvos, entre eles, o software MCML (Monte Carlo for Multi-Layered media) [13].

Para baixa densidade de partículas $(\rho \rightarrow 0)$ ou centros pouco espalhadores $\left(\sigma_{\mathrm{s}} \rightarrow 0\right)$, na direção do feixe colimado $(z)$, temos:

$$
\frac{d I}{d s}=-\rho \sigma_{a} I
$$

Que tem solução:

$$
I=I_{0} \exp \left(-\rho \sigma_{t} z\right)
$$

Essa equação descreve a Lei de Lambert-Beer. Geralmente, em meios biológicos o coeficiente de espalhamento não é desprezível, por isso, a lei de Lambert-Beer não descreve perfeitamente esses meios. Muitas outras aproximações podem ser feitas como as teorias de fluxos e a equação de difusão da luz. 


\subsection{Analgesia com laser de baixa intensidade.}

A eficácia da TLBI em casos clínicos de dor vem sendo corroborada em várias revisões da literatura e em estudos sistemáticos [14]. A eficácia da TLBI foi comprovada em dor crônica no pescoço [15], tendinite [16], alteração crônica em ligamentos [17], dor lombar [18] e dor crônica [19]. Para finalidades clínicas de combate à dor os comprimentos de onda usuais estão na faixa do visível ( $\lambda=632,8$ e $670 \mathrm{~nm})$ e IV ( $\lambda=780 ; 810-830 ; 904 \mathrm{~nm})$ [14].

A TLBI pode reduzir a dor por dois mecanismos: interação da luz diretamente com neurônios e ação anti-inflamatória. Luz, em comprimentos de onda e densidade de energia apropriada para tratamentos anti-inflamatórios, reduz o estresse oxidativo e aumenta a síntese de ATP. Uma cascata de efeitos metabólicos leva à redução de marcadores inflamatórios como as prostaglandinas e as interleucinas. Esses marcadores da inflamação excitam os nociceptores das fibras C podendo, portanto, inibir a produção dos marcadores, o que leva indiretamente à redução da dor.

Tratamentos com LBI, usando densidades de energia relativamente altas, são usados para desencadear efeito analgésico. Esse efeito está presente em vários órgãos do corpo, pois é a interação da luz com neurônios do SNP que desencadeia a analgesia. O efeito analgésico da TLBI é decorrente de uma inibição temporária do transporte axonal em fibras de pequeno diâmetro ( $\mathrm{A} \delta$ e $\mathrm{C}$ ). A inibição temporária (reversível) das fibras nociceptoras reduz os PA aferentes [20] responsáveis por levar a informação sobre o estímulo doloroso para o sistema nervoso central.

O mecanismo neural da TLBI para redução da dor é sustentado por evidências como:

1) Aumento da atividade sináptica da acetilcolinesterase [21]; substância que degrada o neurotransmissor nociceptivo acetilcolina.

2) Aumento da síntese de serotonina [22] e $\beta$-endorfina [14]; neurotransmissores relacionados ao alívio da dor.

3) Supressão temporária de PA evocados por bradicinina [23], substância algógena presente em processos inflamatórios.

4) Inibição da $\mathrm{Na}^{+} / \mathrm{K}^{+}$-ATPase [21], responsável por manter o potencial de repouso do neurônio. A velocidade de condução é reduzida e o período 
de latência fica aumentado em nervos iluminados de modo contínuo (CW) por laser $\operatorname{com} \lambda=830 \mathrm{~nm}[24]$.

Chow e colaboradores, em 2007 [14] propuseram que mudanças estruturais são geradas nos neurônios ao absorverem a energia de fótons. Tais mudanças na arquitetura do neurônio, observadas como formação de varicosidades, aglomeração de mitocôndrias e desorganização de microtúbulos, geram mudanças funcionais como a redução do potencial da membrana mitocondrial e o bloqueio do transporte axonal em fibras de pequeno diâmetro. O decréscimo no envio da nocicepção do SNP para o SNC resulta das mudanças funcionais citadas. Alterações morfológicas dos neurônios podem modificar a memória nociceptiva, isso está em conformidade com a permanência da analgesia decorrente da TLBI.

\subsection{Estimulação mecânica com filamentos von Frey e testes de nocicepção (placa fria, fonte radiante de calor e injeção de formalina)}

Os testes de nocicepção em animais são muito importantes para testar novos medicamentos ou procedimentos. Uma das dificuldades em avaliar a dor é que esta não pode ser quantificada diretamente - apenas pode ser estimada através da análise da resposta a um estímulo específico. Existem vários modelos nociceptivos projetados para medir resposta a diferentes tipos de estímulos ou monitorar possíveis trajetos da sinalização nociceptiva [25]. Um dos modelos mais simples para a avaliação da dor é a estimulação mecânica com filamentos von Frey [26].

O fisiologista Maximilian von Frey foi o pioneiro no estudo da dor no final do século XIX. Para desenvolver esses estudos, ele projetou um conjunto de filamentos, cada qual com uma rigidez diferente, para avaliar a sensibilidade humana à dor [27]. $O$ dispositivo baseia-se na lei de flexibilidade de materiais desenvolvida por Euler. Essa lei quando aplicada para o caso de uma haste flexível com diâmetro constante, na qual uma das extremidades é fixa e a outra está pressionada verticalmente contra uma superfície, afirma que a força exercida pela haste sobre a superfície é constante a partir do momento em que 
a haste fica flexionada. Antes do filamento se curvar a força pode aumentar, mas após a flexão, a força vertical passa a ser constante. A força é diretamente proporcional à rigidez, diretamente relacionada com a espessura do filamento $\mathrm{e}$ inversamente proporcional ao quadrado do seu comprimento [28]. Os filamentos von Frey usados neste estudo para obtenção de limiar de dor foram manufaturados especialmente por nós, para possibilitar melhor precisão na determinação desses valores. Enquanto o conjunto de filamentos comerciais variava de 0,008 até $300 \mathrm{gf}$ (grama-força), o conjunto que desenvolvemos possui 20 filamentos com forças variando de 7,6 até 117,3 gf, isso fez com que o nosso conjunto de filamentos se adequasse melhor aos nossos testes em camundongos. Os filamentos foram confeccionados com materiais de baixo custo disponíveis em lojas e mercados comuns, e as informações sobre manufatura, calibração e validação desse conjunto de filamentos foram publicadas recentemente (vide Apêndice $C$ ).

$O$ teste de placa fria tem como finalidade medir a sensibilidade dos animais experimentais a estímulos nociceptivos de natureza física, provocados por baixas temperaturas e que são capazes de ativar diferentes tipos de receptores, possibilitando a análise da potência de agentes analgésicos relacionados especificamente com os receptores sensíveis ao frio. Embora anormalidades (hipo- ou hiperalgesia) provocadas por frio sejam comorbidades comuns em neuropatias, os testes de nocicepção evocada por frio são incomuns e não possuem um método padrão [29]. O estímulo frio pode ser empregado em roedores de várias formas como: submersão do animal (ou parte dele) em água, ou álcool, ou por spray de cloreto de etila, ou ainda, o mais comum dentre esses métodos, o contato das patas ou cauda dos animais com uma placa fria. $O$ estímulo nociceptivo por frio é mais usado para avaliar hipersensibilidade provocada em modelos de dor inflamatória como injeções de formalina, bradicinina ou carragenina, do que propriamente como um estímulo nociceptivo per se.

Para avaliar o funcionamento de termorreceptores e nociceptores em dor evocada por alta temperatura é usual o emprego de uma fonte quente e a avaliação do tempo de reação do animal com o teste de retirada de cauda. $O$ teste de retirada de cauda possui duas variações principais, a primeira consiste na imersão da cauda do animal em água aquecida a uma temperatura pré- 
determinada, e a segunda usa uma fonte radiante de calor apontada para a cauda do animal. Embora essas variações do teste pareçam similares elas provocam aumentos de temperatura de forma fundamentalmente diferente e consequentemente a nocicepção e a reação a ela ocorrem de formas diversas. No caso de imersão a área afetada é maior e o aumento de temperatura é quase que instantâneo, dessa forma o tempo de reação do animal é muito curto. Por outro lado, a fonte radiante de calor, principalmente no caso de um laser de alta potência, pode ser muito bem controlada, o aumento de temperatura é localizado em uma pequena região e acontece de forma mais gradual, resultando em um maior tempo até a reação e consequentemente a quantificação desse teste é relativamente mais precisa.

A injeção intradermal de formalina é um caso particular dos modelos de dor evocada por estímulos de longa duração (de alguns minutos até poucas horas), também conhecidos como estímulos tônicos [25]. Os estímulos tônicos de um modo geral são provocados por injeção de alguma substância irritante (formalina, bradicinina, carragenina, etc.) no interior da derme, peritônio, ou cavidade; a injeção intravascular ou intradental são mais raras. A injeção intradérmica de formalina é a mais utilizada por ser uma substância comumente encontrada em laboratórios de manipulação animal, pelo procedimento ser relativamente fácil de ser executado e por gerar dois tipos de dor a partir de um mesmo procedimento. A fase inicial (0-15 min) da dor evocada pela injeção de formalina é um modelo para dor inflamatória aguda, especificamente de $(0-5 \mathrm{~min})$ é um período de dor neurogênica; e nos minutos seguintes (15 - $60 \mathrm{~min}$ ) ocorre uma fase de dor tônica.

\subsection{Imunofluorescência e microscopia confocal}

Imunofluorescência (IF) é uma técnica amplamente executada em laboratórios clínicos e de pesquisa que utiliza marcadores fluorescentes de anticorpos para detectar antígenos específicos [30]. Um anticorpo é um complexo proteico liberado pelos linfócitos B. Os anticorpos iniciam a resposta imunológica contra proteínas estranhas ao corpo, os antígenos. A organização básica de um anticorpo é feita por dois fragmentos, que juntos, lembram a letra $\mathrm{Y}$. A base do $\mathrm{Y}$ é conhecida como o fragmento que cristaliza (FC). Cada 
"braço" do $\mathrm{Y}$ forma a parte conhecida como o fragmento que contém o sítio ligante ao antígeno (FLA). Na IF o anticorpo é tratado (marcado) para receber uma molécula fluorescente, por isso, vamos chamá-lo de anticorpo fluorescente.

A técnica de IF, em sua forma mais simples, pode ser feita ligando um anticorpo fluorescente (extraído de um animal diferente do que está sendo marcado) diretamente ao antígeno no tecido alvo, isso é conhecido como imunofluorescência direta. Na IF direta apenas um anticorpo pode ligar ao antígeno, isso leva a um sinal de fluorescência fraco. Esse problema é solucionado com a técnica de IF indireta, na qual um primeiro anticorpo se liga ao antígeno e segundos anticorpos fluorescentes podem se ligar ao primeiro anticorpo. Como mais de um segundo anticorpo fluorescente está indiretamente ligado ao antígeno o sinal de fluorescência produzido é mais intenso (figura 1.7). Essa técnica é mais complexa e consome mais tempo, pois, requer dois períodos de incubação e o segundo anticorpo deve ser de um animal diferente do animal do primeiro anticorpo e do animal alvo.

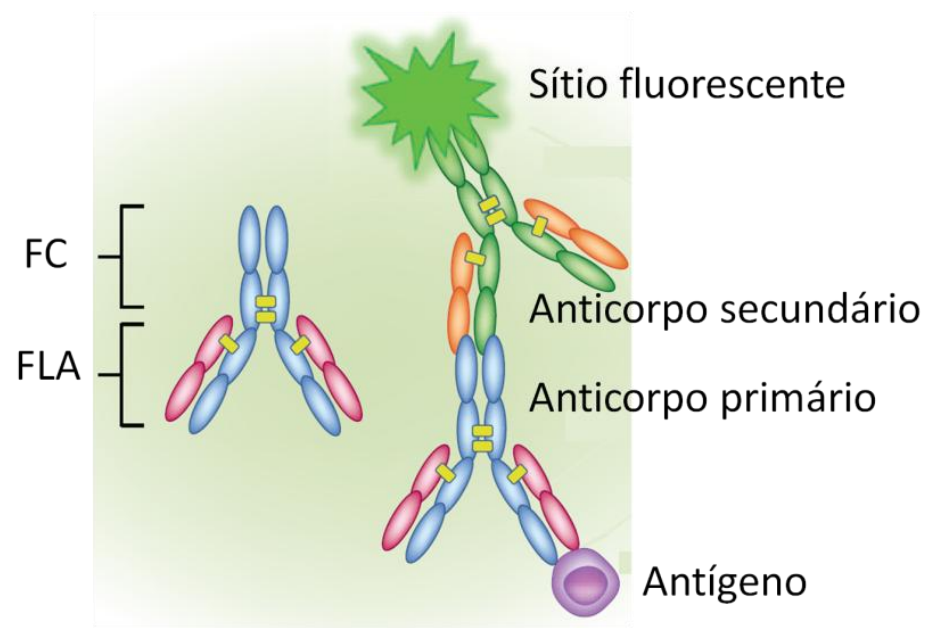

Figura 1.7: Partes do anticorpo: fragmento que cristaliza $(F C)$ e Fragmento que contem o sítio ligante ao antígeno (FLA). $\mathrm{O}$ anticorpo primário se liga ao antígeno, que faz parte do tecido. $O$ anticorpo secundário possui um sítio fluorescente e se liga ao anticorpo primário. Esse mecanismo faz o sítio fluorescente estar indiretamente ligado ao antígeno a ser visualizado. Adaptado de Odell et al [30]. 
A microscopia confocal, desenvolvida e patenteada por Marvin Minsky em 1955, utiliza imagens ópticas do interior de tecidos para criar uma amostra virtual com muitos micrometros de espessura [31]. Essa técnica produz imagens de alta qualidade e permite a reconstrução de imagens virtuais em 3 dimensões do tecido quando várias planos são combinados.

Em um microscópio óptico comum a luz é focalizada por uma lente convergente em um determinado ponto no interior da amostra. A luz será preferencialmente retroespalhada a partir desse ponto focal. Há também espalhamento em regiões vizinhas, isso gera ruído na imagem e borrão na imagem. A microscopia confocal supera esse problema, pois coloca um anteparo com um orifício, no caminho óptico entre a amostra e o detector. A luz espalhada por regiões fora do ponto focal é barrada pelo anteparo que está no plano conjugado ao ponto focal, por isso, o nome confocal (figura 1.8).

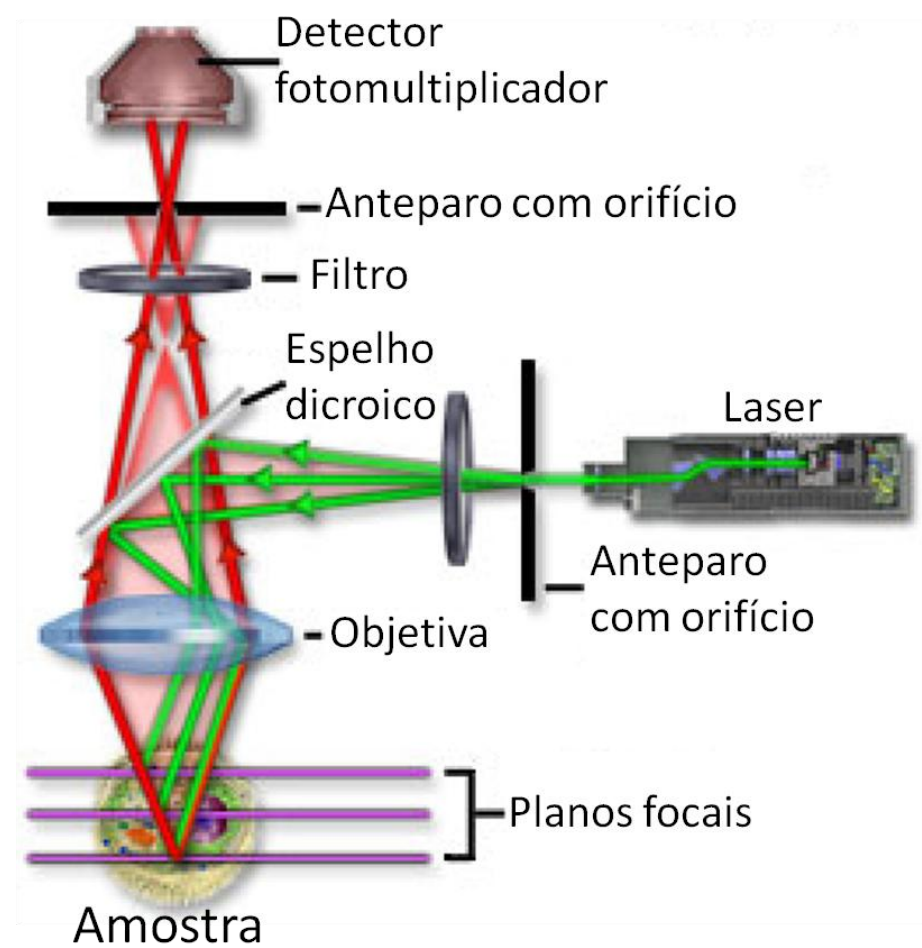

Figura 1.8: Esquema de microscopia confocal com fluorescência. A luz de excitação (verde, nesse esquema) é focalizada em um único ponto do interior da amostra. A amostra emite luz vermelha (nesse esquema) por fluorescência. $O$ espelho dicroico permite a passagem apenas da luz vermelha. $O$ anteparo impede a passagem da luz espalhada por regiões fora do ponto focal. Portanto, apenas luz produzida por fluorescência no ponto focal chega ao detector. Adaptado de Nwaneshiudu et al [31]. 
O feixe de laser de excitação vai percorrendo, ponto a ponto, todo um plano no interior da amostra. A luz retroespalhada de cada ponto da amostra vira um ponto da imagem que está sendo gerada. Todo esse processo leva frações de segundo e permite resoluções da ordem do comprimento de onda da luz excitatória. Existem algoritmos de superposição de imagens que permitem sobrepor vários planos assim formando uma imagem volumétrica, como em ressonância magnética ou tomografia computadorizada.

A microscopia confocal permite a iluminação da amostra com luz de um comprimento de onda e detecção da luz emitida por fluorescência na amostra. Essa técnica conhecida como microscopia confocal de fluorescência permite aumentar ainda mais a resolução, a intensidade do sinal, e visualizar mais de uma marcação na mesma amostra (quando a imunofluorescência é feita simultaneamente em mais de um antígeno).

\subsection{Marcação de tecido com HE}

A marcação com hematoxilina-eosina $(\mathrm{HE})$ é a mais comum das colorações em histologia [32]. Ela permite diferenciar as substâncias pelo grau de afinidade das mesmas por bases (hematoxilina) ou ácidos (eosina). Os ácidos nucleicos são corados pela hematoxilina, por isso, os núcleos ficam com cor azul-púrpura. O citoplasma é corado pela eosina e passa a ter um tom avermelhado.

Essa técnica pode ser usada para quantificar a regeneração celular uma vez que pode marcar a quantidade de ácidos nucleicos e consequentemente novos núcleos celulares [33]. No sistema nervoso hematoxilina marca astrócitos, mioglia e fibroglia. Por isso, a marcação com HE pode ser usada para quantificar a proporção entre neurônios e células da glia. Algumas substâncias liberadas em tecidos em processos inflamatórios podem ser marcadas por HE. 


\section{2. ÓPTICA DE TECIDOS BIOLÓGICOS}

Devido ao grande número de aplicações da terapia com laser de baixa intensidade (TLBI) no Sistema Nervoso Central (SNC), o estudo da penetração e difusão da luz no cérebro torna-se extremamente importante. Neste capítulo, apresentaremos experimentos de iluminação transcraniana e mapeamento de propriedades ópticas em cérebros de ratos Wistar (Rattus novergicus) com luz laser vermelho $(\lambda=660 \mathrm{~nm})$ e infravermelho $(\lambda=808 \mathrm{~nm})$. Quantificamos a penetração e distribuição de luz em uma iluminação transcraniana e comparamos as propriedades ópticas das estruturas cerebrais no experimento de transmissão de luz laser através de amostras de cérebro. Os dados aqui apresentados corroboram a TLBI transcraniana em ratos e apontam para a possibilidade de ampliação das aplicações de TLBI transcraniana em seres humanos.

\subsection{Introdução}

As interações dos tecidos com luz dão origem a um grande número de efeitos físicos, químicos ou biológicos. Alguns desses efeitos, como os fototérmicos, fotoacústicos, reações fotoquímicas, fotobiomodulação, fosforescência, fluorescência e perda de coerência óptica são usados para terapia e diagnóstico e são a base científica da Fotomedicina.

Quantificar a penetração e distribuição de luz no cérebro de rato pode ampliar nosso conhecimento acerca dos mecanismos de fototerapias, como TLBI e terapia fotodinâmica (PDT), uma vez que estimaremos melhor a fluência de luz em cada região. Medidas das propriedades ópticas de cérebro de rato podem aprimorar as pesquisas sobre diagnósticos por imagens obtidas por tomografia por coerência óptica (OCT) e tomografia optoacústica (OAT) [34].

\subsection{Material e métodos}

\section{Animais}

Todos os procedimentos com animais foram aprovados pelo Subcomitê de Pesquisa Animal do Hospital Geral de Massachusetts (protocolo 
\# 2010N000220) e seguiram as diretrizes do National Institutes of Health. Foi utilizado tecido ex-vivo de dois ratos Wistar (Rattus novergicus, machos, pesando aproximadamente $300 \mathrm{~g}$, obtidos no Charles River Laboratories (Wilmington - Massachusetts - EUA).

\section{Laser, detectores de luz e software para análise de imagens}

Os experimentos descritos nesse capítulo usaram fontes de laser, equipamentos de detecção de luz e software para análise de imagens. Os dois feixes de laser usados foram gerados pelo mesmo equipamento (DMC, modelo Photon Lase III), de forma contínua (modo CW). As principais características desses feixes de laser estão na tabela 2.1. As aberturas angulares dos feixes são $30^{\circ}$, por isso, geram uma geometria de feixe largo (figura 2.1).

Tabela 2.1: Características dos lasers.

\begin{tabular}{cccccc}
\hline $\begin{array}{c}\text { Tipo de } \\
\text { laser }\end{array}$ & $\begin{array}{c}\text { Meio } \\
\text { ativo }\end{array}$ & $\lambda(\mathbf{n m})$ & $\begin{array}{c}\text { Potência } \\
(\mathbf{m W})\end{array}$ & $\begin{array}{c}\text { Abertura } \\
\text { do feixe }\left(^{\circ}\right)\end{array}$ & $\begin{array}{c}\text { Diâmetro da } \\
\text { ponteira }(\mathbf{m m})\end{array}$ \\
\hline $\begin{array}{c}\text { Diodo } \\
\text { Vermelho }\end{array}$ & InGaAIP & 660 & 30 & 30 & 1,40 \\
$\begin{array}{c}\text { Diodo IV } \\
\text { AsGaAl }\end{array}$ & 808 & 30 & 30 & 1,40 \\
\hline
\end{tabular}
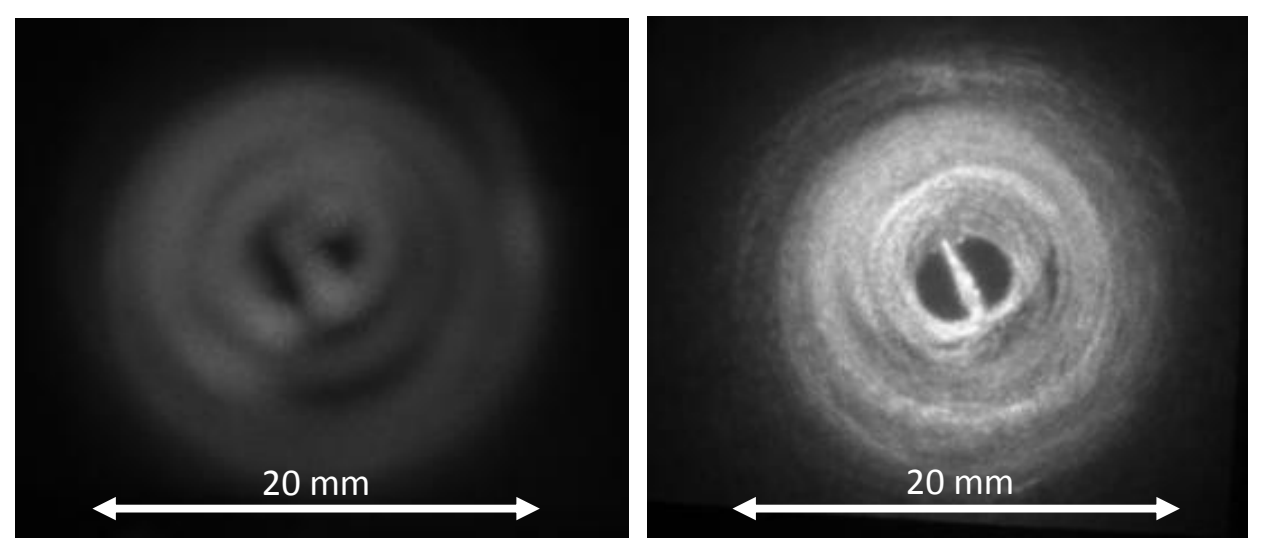

Figura 2.1: Imagem do feixe largo sem amostra, $600 \mathrm{~nm}$ (esquerda), $808 \mathrm{~nm}$ (direita). $O$ feixe infravermelho aparenta ser mais intenso devido à diferença no tempo de exposição para gerar essas imagens.

Imagens da luz laser transmitida através das amostras ou espalhada por elas foram obtidas com uma câmera digital (Câmera Digital Canon PowerShot G10, 14.7 megapixels) com lentes manualmente ajustáveis. As lentes eram 
ajustadas com o objetivo de possibilitar máxima nitidez da superfície da amostra. Na mesma configuração em que foram obtidas essas imagens, uma imagem com paquímetro na posição da amostra mostrou que uma linha de $1 \mathrm{~mm}$ tem 56 pixels. Um filtro de transmitância variável (Round Variable ND Filter, Thorlabs, Newton, NJ, USA) foi usado para regular a intensidade luminosa do feixe que incidia nas amostras. O tempo de captura para formar as imagens foi de 4,0 s para luz infravermelha e de 0,01 s para luz vermelha.

As imagens foram adquiridas em formato de 8-bits, por isso, elas têm $256=2^{8}$ níveis de cinza (nc). As intensidades luminosas, nas imagens, variam de 0 , nenhum fóton detectado em um dado pixel; até 255 , detecção máxima da câmera e valor dado a todas as intensidades acima desta. A transmitância do filtro e o tempo de aquisição da câmera possibilitaram que intensidade luminosa na imagem fosse maior que o valor de fundo $(\sim 5 \mathrm{nc})$ e menor que $o$ limite de saturação da imagem (255 nc).

\subsubsection{Iluminação transcraniana do encéfalo de rato}

Estudamos a distribuição e a penetração da luz durante a iluminação transcraniana em um modelo ex-vivo. Para isso, um rato Wistar (Rattus Novergicus) adulto foi sacrificado por overdose de anestésico e sua cabeça foi tricotomizada. A cabeça foi seccionada cirurgicamente por um corte sagital a 2,3 mm de distância do plano médio. Esta seção da cabeça de rato foi iluminada com laser vermelho e IV em pontos acima de três estruturas anatômicas: hipocampo, cerebelo e córtex frontal (posições relativas ao bregma foram: $-3,3 \mathrm{~mm},-6,0 \mathrm{~mm},+2,5 \mathrm{~mm}$, respectivamente). A iluminação foi feita com a ponteira em contato com a pele e os pontos de iluminação estavam a 2,0 $\mathrm{mm}$ do plano do corte. Um corte coronal (-3,3 mm do bregma) também foi feito para permitir a visualização do hipocampo através de outra direção e a iluminação foi a 2,0 mm do plano de corte da superfície de saída dos fótons (figura 2.2). 


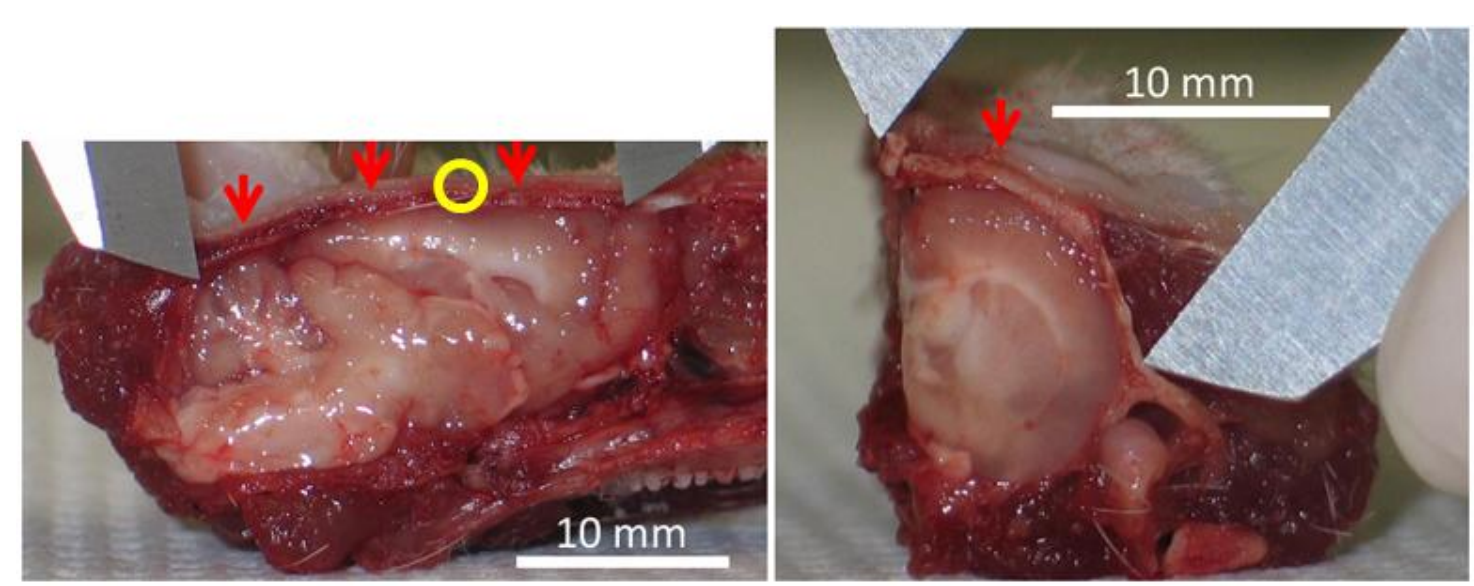

Figura 2.2: cortes sagital (à esquerda) e coronal (direita) de uma cabeça de rato. O círculo em amarelo indica a posição do bregma e as setas indicam os pontos de iluminação (esquerda: hipocampo, cerebelo e córtex frontal; direita: hipocampo; sempre a $2 \mathrm{~mm}$ da superfície aqui fotografada).

A luz atenuada pelo filtro e espalhada pela amostra foi captada pela câmera digital. A câmera estava posicionada a $2,5 \mathrm{~cm}$ da amostra e estava perpendicular à direção do feixe laser (figura 2.3). As imagens produzidas pela luz espalhada e captadas pela câmera foram analisadas com o software ImageJ [35]. Perfis de intensidade, na direção do feixe de laser, fornecem informações sobre as propriedades ópticas do tecido.

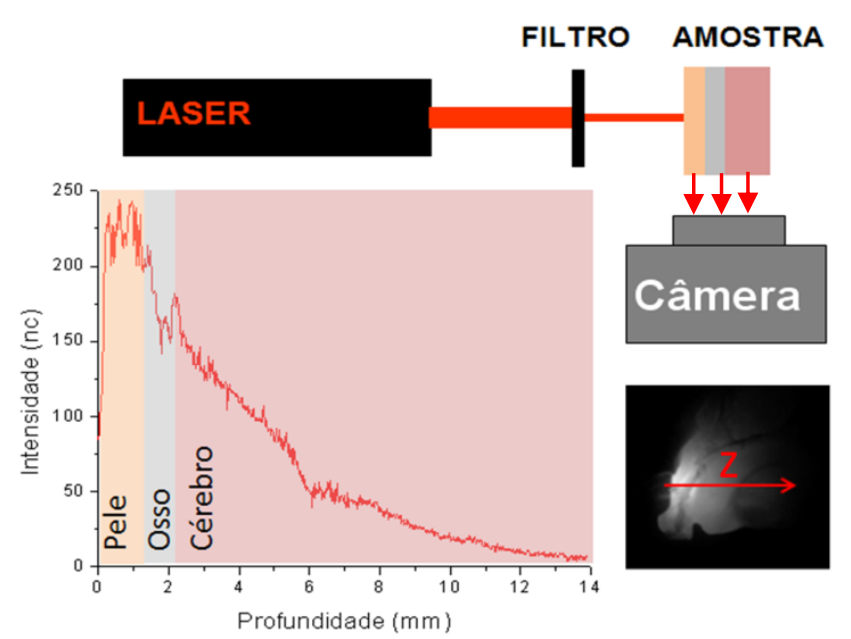

Figura 2.3: A luz do laser, atenuada pelo filtro, ilumina a amostra. A luz espalhada pela amostra é capturada pela câmera formando uma imagem. A seta na imagem indica a posição e a direção usadas para traçar o perfil de intensidade da luz visto no gráfico à esquerda $(z)$. 


\subsubsection{Mapeamento óptico do encéfalo de rato}

Um rato foi sacrificado por overdose de anestésico e seu cérebro foi removido. $O$ cérebro foi seccionado por corte sagital produzindo duas amostras com espessura de $2,0 \mathrm{~mm}$. A amostra $A$ vai desde o plano médio $(\mathrm{z}=0)$ até $\mathrm{z}=2,0 \mathrm{~mm}$ e a amostra $\mathrm{B}$ vai de $\mathrm{z}=2,0 \mathrm{~mm}$ até $\mathrm{z}=4,0 \mathrm{~mm}$ de distância a partir do plano médio (figura 2.4). É possível distinguir na amostra $A$, o cerebelo (aproximadamente $-10<\mathrm{x}<-5 \mathrm{~mm},-10<\mathrm{y}<-5 \mathrm{~mm}$ ), o tronco encefálico anterior ao cerebelo, o bulbo olfatório anterior à ponte encefálica e uma estreita camada de córtex na superfície superior da amostra. Na amostra B é possível visualizar, na região mais à esquerda, o cerebelo; na parte inferior, uma pequena região de troco encefálico; ao centro, substância cinzenta e na parte superior uma camada mais espessa ( 2 mm) de córtex.

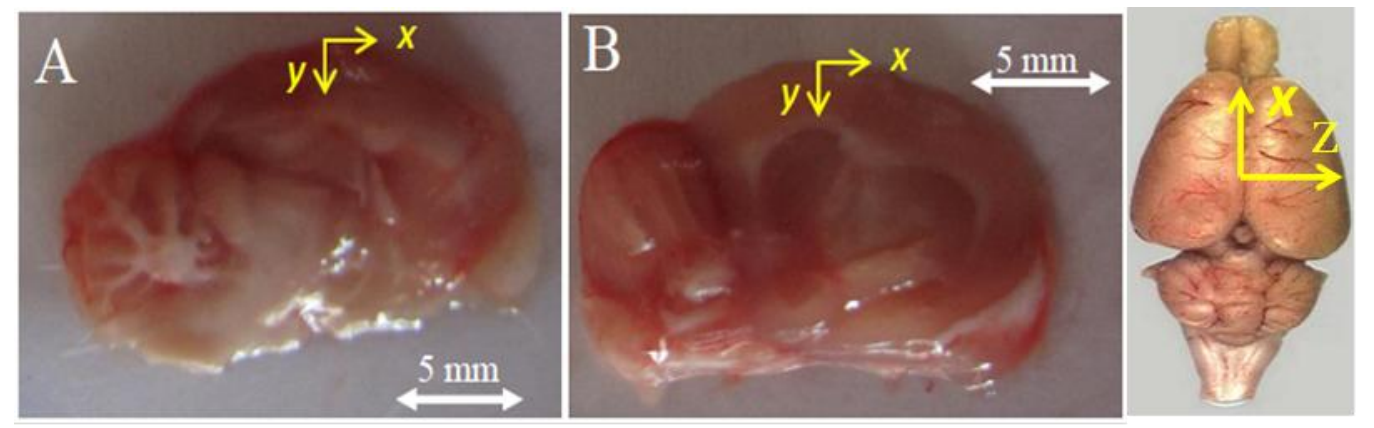

Figura 2.4: As amostras e o sistema de eixos para orientação. $O$ corte foi feito no plano perpendicular à $z$ de tal forma que a amostra $A$ vai desde o plano médio $(\mathrm{z}=0)$ até $\mathrm{z}=2,0 \mathrm{~mm}$ e a amostra $B$ vai de $\mathrm{z}=2,0 \mathrm{~mm}$ até $\mathrm{z}=4,0 \mathrm{~mm}$ de distância a partir do plano médio

Cada amostra foi iluminada por inteiro pelo feixe largo de laser. A luz transmitida através das amostras foi capturada pela câmera, que estava alinhada com o feixe de raios laser (figura 2.5) e posicionada longe da amostra $(20 \mathrm{~cm})$. As imagens produzidas por luz atenuada ao passar pela amostra foram analisadas com o software ImageJ. Perfis de intensidade (em níveis de cinza) da luz transmitida ao longo da direção $x$ foram traçados a cada 2,0 mm. $O$ feixe de laser e a espessura da amostra não foram perfeitamente uniformes. 


\section{Filtro Amostra}

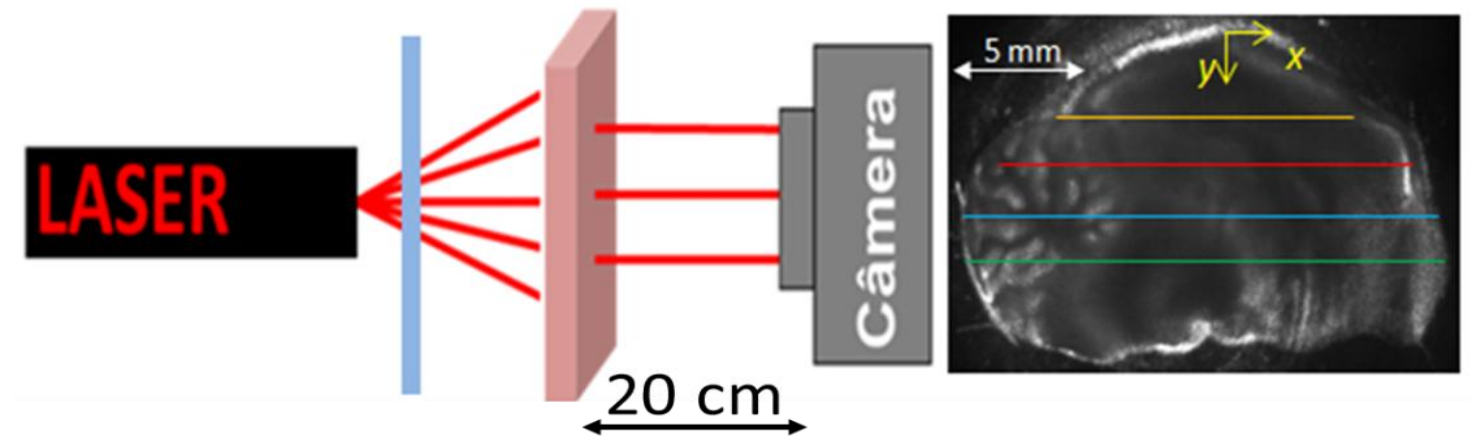

Figura 2.5: A luz do laser, atenuada pelo filtro, atravessa a amostra e é capturada pela câmera posicionada a $20 \mathrm{~cm}$ da amostra. A luz capturada pela câmera forma imagens nas quais serão traçados perfis de intensidade nos locais indicados pelas linhas.

\subsection{Resultados e discussão}

As técnicas simples de imageamento que descrevemos produziram resultados inovadores uma vez que pela primeira vez esse tipo de técnica foi usado para estimar a distribuição de luz com finalidades dosimétricas em iluminação transcraniana característica de TLBI e para caracterizar diferenças ópticas entre os tecidos encefálicos.

\subsection{1. lluminação transcraniana do encéfalo de rato}

Essa seção apresenta os resultados dos experimentos descritos na seção 2.2.1. As imagens apresentadas na figura 2.6 foram produzidas com luz espalhada infravermelha (linha superior de imagens), e vermelha (linha inferior de imagens). A irradiação das amostras com laser foi feita acima da região do: hipocampo, cerebelo, córtex frontal e coronal de hipocampo (da esquerda para a direita). Como se vê na figura 2.6, para os mesmos tecidos, a luz IV alcança estruturas mais profundas, justificando o maior emprego desse comprimento de onda para terapias em estruturas mais internas do encéfalo. Os limites entre tecidos (pele, crânio, encéfalo) são visíveis nas imagens uma vez que as propriedades ópticas desses tecidos são muito distintas. As diferenças de atenuação dentro do encéfalo geram diferentes intensidades nas imagens. Especificamente, podemos ver a camada granular do cerebelo mais escura, 
evidenciando uma maior atenuação (ou menor espalhamento lateral) devido a um maior empacotamento celular nessa região. Os neurônios do córtex são mais mielinizados, por isso, espalham luz com maior intensidade que outras regiões do encéfalo (imagem maior da figura 2.6).
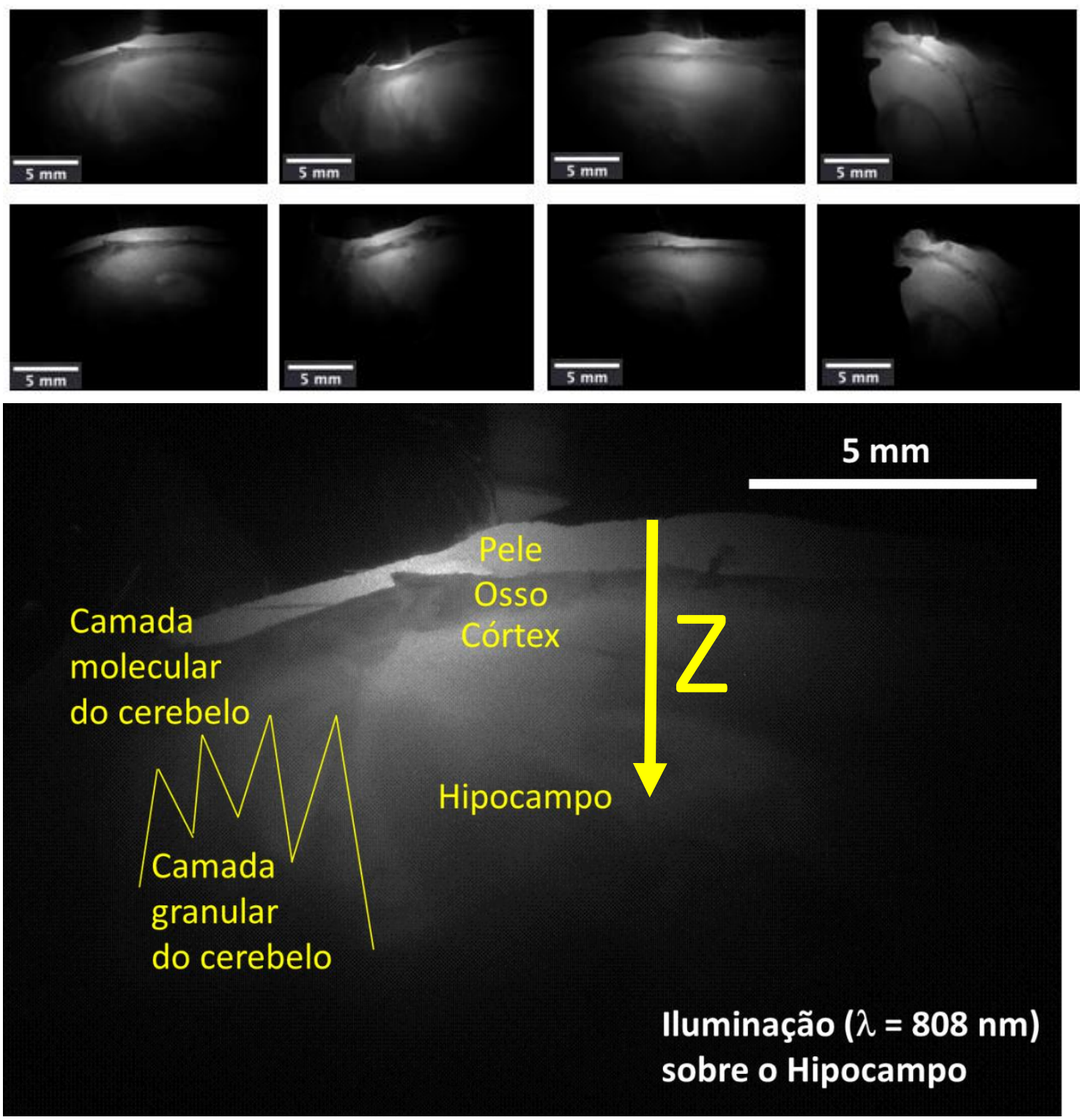

Figura 2.6: Imagens menores das amostras iluminadas com luz espalhada infravermelha (linha superior de imagens), e vermelha (linha inferior de imagens). A irradiação das amostras com laser foi feita acima da região do: hipocampo, cerebelo, córtex frontal e coronal de hipocampo (da esquerda para a direita). Em destaque: iluminação sobre o hipocampo com luz infravermelha evidenciando os diferentes tecidos biológicos. A direção Z é a mesma descrita na Figura 2.3. 
A luz espalhada a $90^{\circ}$ pelas amostras tem perfil de intensidade, que de um modo geral, apresentam um pico inicial de espalhamento na pele seguido por um vale na região óssea. Na região do encéfalo há um novo pico seguido de decréscimo da intensidade nas regiões mais profundas (figuras 2.7 e 2.8). Os perfis possibilitam quantificar parâmetros ópticos dos diferentes tecidos. Neste experimento a luz atravessa três órgãos diferentes: pele, osso craniano e encéfalo. Os perfis de intensidade foram traçados na direção de propagação do laser (z) e mostram picos após cada limite entre tecidos (figuras 2.7 e 2.8). A intensidade desses picos é proporcional à quantidade de luz que eles dispersam.
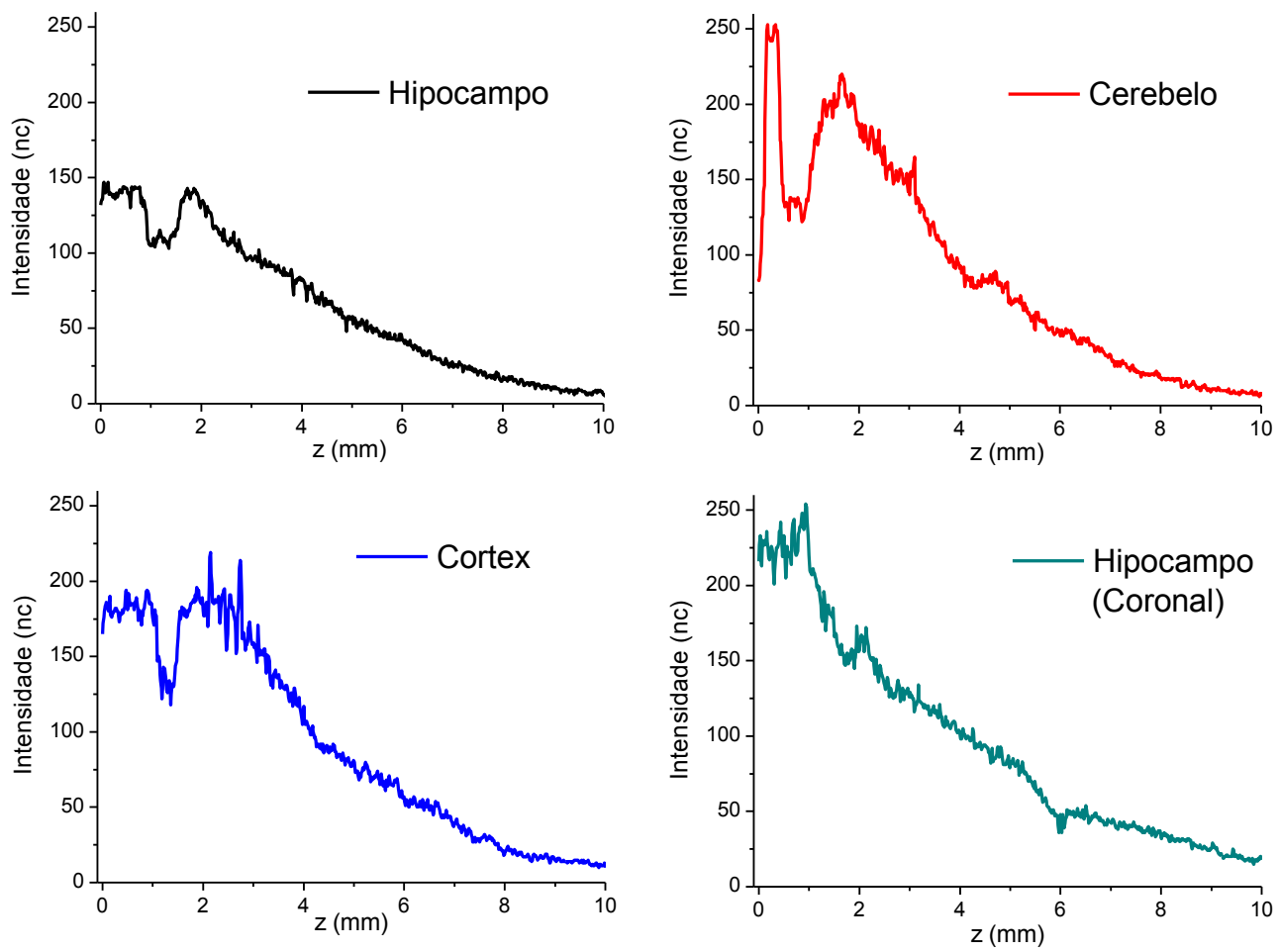

Figura 2.7: Perfis das imagens das amostras irradiadas com laser infravermelho $(\lambda=808 \mathrm{~nm})$. 

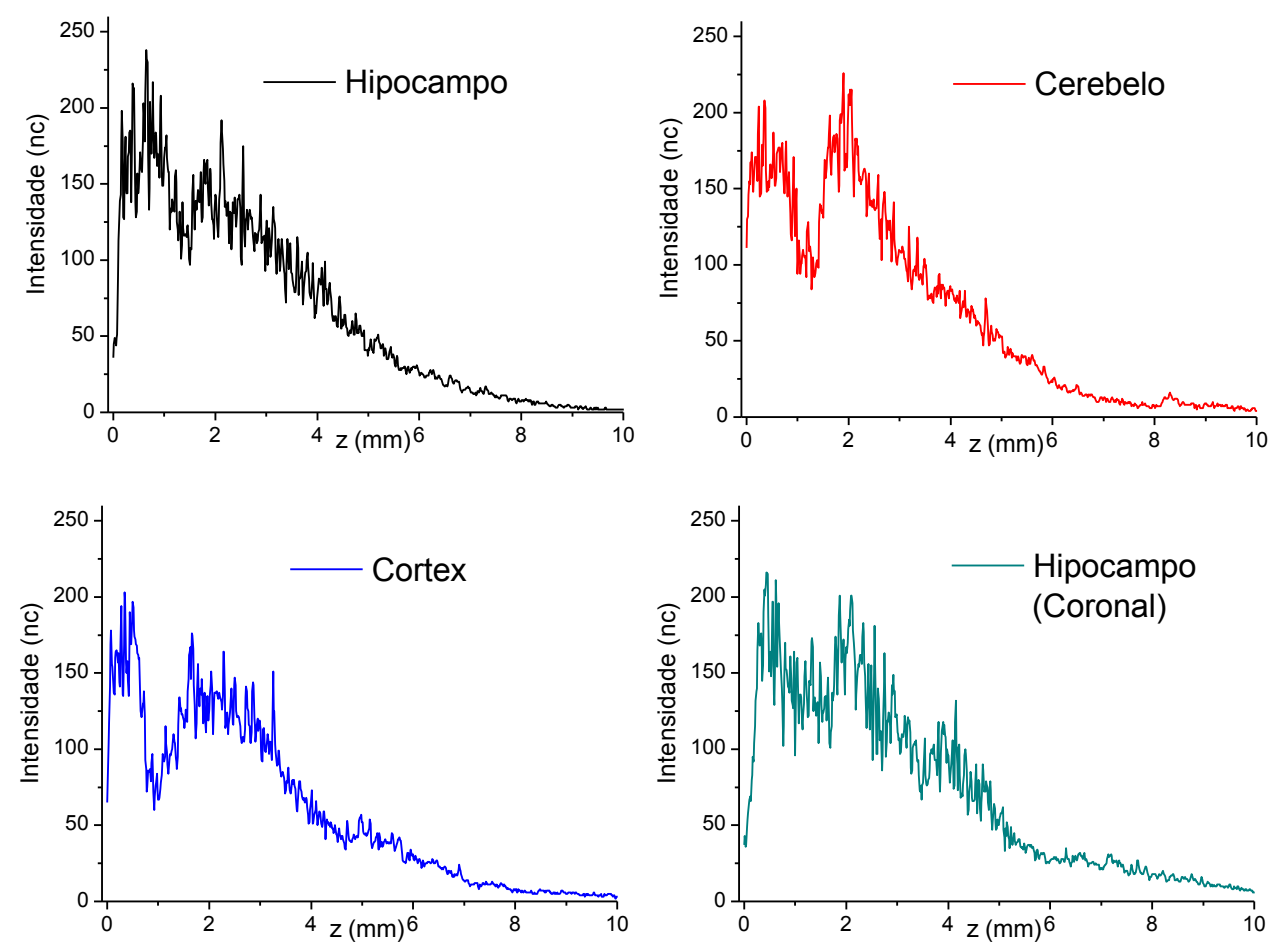

Figura 2.8: Perfis das imagens das amostras irradiadas com laser vermelho $(\lambda=660 \mathrm{~nm})$.

Longe da superfície de incidência do laser, a atenuação da luz espalhada a $90^{\circ}$ é aproximadamente exponencial (figuras 2.9 e 2.10 ):

$$
I(z)=I_{0} e^{-\mu_{a e^{Z}}}
$$

Logo, podemos obter $\mu_{\mathrm{ae}}$ fazendo:

$$
\mu_{a e}=-\frac{\ln \left(\frac{I(z)}{I_{0}}\right)}{z}
$$

Nessas equações $I(z)$ representa a intensidade espalhada a $90^{\circ}$ no ponto $z, I_{0}$ é a intensidade inicial do feixe e $\mu_{a e}$ é o coeficiente de atenuação da luz espalhada a $90^{\circ}$. Esse coeficiente é uma medida da atenuação total que 0 feixe sofre ao atravessar um tecido biológico.

Em uma amostra isotrópica de tecido podemos assumir que a quantidade de fótons espalhados a $90^{\circ}$ a partir de um dado ponto da amostra é proporcional à intensidade de luz que incide nesse dado ponto. A espessura de 
tecido biológico que os fótons devem atravessar até saírem da amostra, após o espalhamento $90^{\circ}$, é relativamente pequena e uniforme. Por isso, podemos considerar que a atenuação nesse caminho óptico é, proporcionalmente, a mesma para todos os pontos. Levando em consideração tais hipóteses é plausível dizer que o coeficiente de atenuação da luz espalhada a $90^{\circ}\left(\mu_{a e}\right)$ é numericamente igual ao coeficiente de atenuação total $\left(\mu_{t}\right)$, que é uma propriedade do tecido biológico.

As regiões do encéfalo têm propriedades ópticas específicas, portanto, os $\mu_{a e}$ devem diferir de uma região para outra. Comparando os perfis no interior do encéfalo, longe das interfaces entre diferentes tecidos $(z=3,5$ $10,0 \mathrm{~mm}$ ), encontramos diferenças no coeficiente exponencial para cada ponto de iluminação (hipocampo, cerebelo e no córtex frontal), no corte sagital (figura 2.9), e diferenças para cada direção (sagital e coronal) no hipocampo (figura 2.10).

O coeficiente do ajuste exponencial e a incerteza desse coeficiente de cada perfil de intensidade foram obtidos a partir de ajustes exponenciais (equação 2.2) usando o software Origin 8. Os coeficientes dos ajustes exponenciais e as incertezas desses coeficientes possibilitam comparar estatisticamente os $\mu_{a e}$ com o auxílio do software Graphpad Prism 5. Os oito conjuntos de valores usados para calcular os oito $\mu_{a e}$ foram comparados para verificar possíveis correlações entre cada um dos grupos. O teste estatístico usado para isso foi a Análise de Variância Simples (one way ANOVA). Uma vez encontradas diferenças significativas, foi conduzido o teste pos-hoc de Tukey HSD. Para todas as análises foi estabelecido um valor de alfa de 0,05 (significância de 95\%).

Normalizamos $\mu_{a e}$ fazendo com que o valor mais elevado fosse igual a um, em unidades arbitrárias (u.a.). Verificamos que quase todos os valores de $\mu_{a e}$ são diferentes, mostrando a forte dependência de $\mu_{a e}$ com a região do cérebro (figura 2.11). No entanto, $\mu_{a e}$ são estatisticamente iguais $\left(^{*}\right)$ para cerebelo e hipocampo (coronal), iluminados com luz vermelha. A razão entre os $\mu_{a e}$ no vermelho em relação aos de IV para os tecidos de hipocampo, cerebelo, córtex e hipocampo (corte sagital) é respectivamente: 1,63; 2,27; 1,13; 1,66. A média para essas razões de $\mu_{a e}$ é 1,67 ; isso mostra que a luz vermelha é mais 
atenuada, portanto, penetra menos nos tecidos encefálicos que a luz infravermelha (figura 2.11).
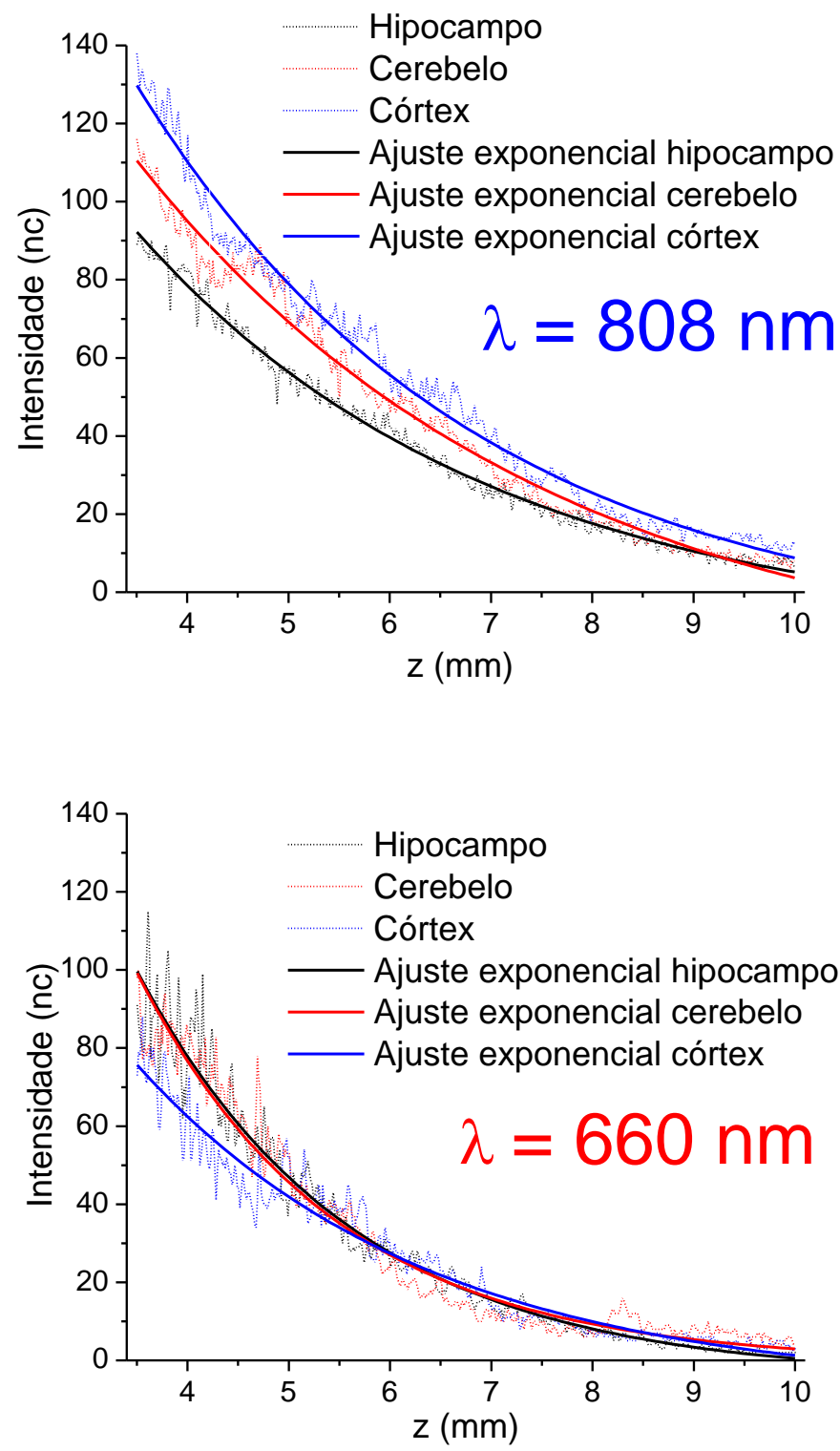

Figura 2.9: Ajustes exponenciais dos perfis das imagens das amostras com cortes sagitais irradiadas com laser infravermelho $(\lambda=808 \mathrm{~nm})$ e vermelho $(\lambda=660 \mathrm{~nm})$. 

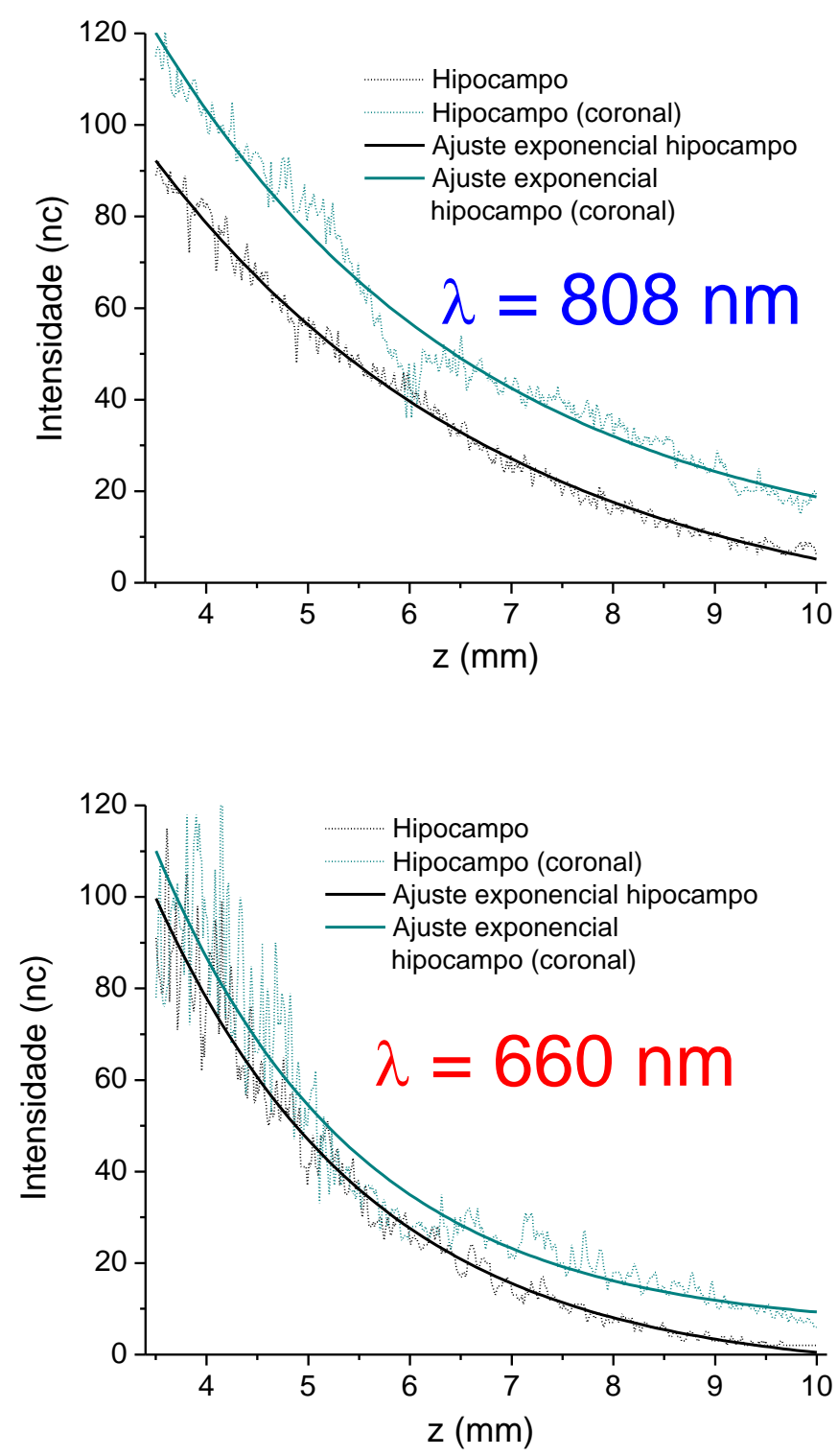

Figura 2.10: Ajustes exponenciais dos perfis das imagens irradiadas no hipocampo com laser infravermelho $(\lambda=808 \mathrm{~nm})$ e vermelho $(\lambda=660 \mathrm{~nm})$. 


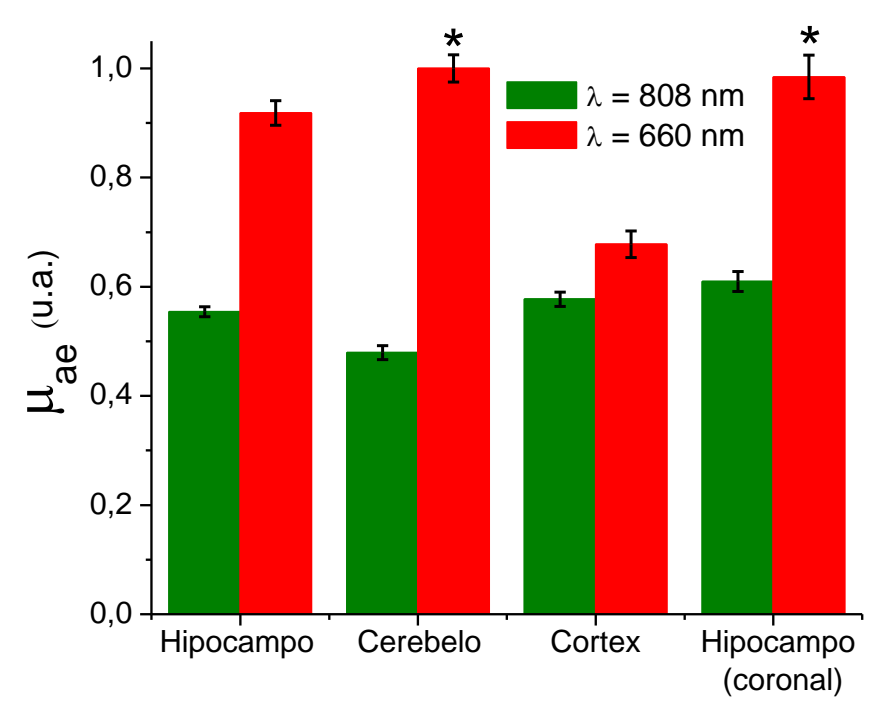

Figura 2.11: Coeficientes de atenuação da luz espalhada a $90^{\circ}\left(\mu_{a e}\right)$ normalizados de diferentes regiões do tecido encefálico. Apenas os $\mu_{a e}$ da luz vermelha no cerebelo e no hipocampo (coronal) são estatisticamente iguais $\left({ }^{*}\right)$.

\subsubsection{Mapeamento óptico do encéfalo de rato}

Essa seção apresenta os resultados dos experimentos descritos na seção 2.2.2. As imagens mostradas na figura 2.12 correspondem à luz transmitida de ambos os lasers infravermelho $(\lambda=808 \mathrm{~nm})$ e vermelho $(\lambda=660$ $\mathrm{nm})$ através das amostras A e B. Os limites entre tecidos e as diferenças de atenuação no interior do cérebro são qualitativamente evidenciadas nas imagens. Os picos (vales) nos perfis de intensidade das imagens são áreas de menor (maior) atenuação e mostram que há grande diferença nas propriedades ópticas de diferentes regiões do cérebro de rato.

Uma vez que a distância entre a amostra e câmera $(20 \mathrm{~cm})$ foi muito maior que as dimensões da amostra $(\sim 2 \mathrm{~cm})$ a intensidade de luz, $I(x, y)$, pode ser considerada proporcional à intensidade irradiada a partir da posição $(x, y)$ da superficie da amostra. Traçamos perfis de intensidade luminosa na imagem, variando $x$ e mantendo $y$ constante. Fizemos isso para quatro posições de $y$ (2, 4, 6, $8 \mathrm{~mm}$, a partir do topo da amostra) em cada imagem. A espessura das bordas das amostras não é uniforme, por isso, as intensidades dessa região não são confiáveis e não estão presentes nos gráficos. 

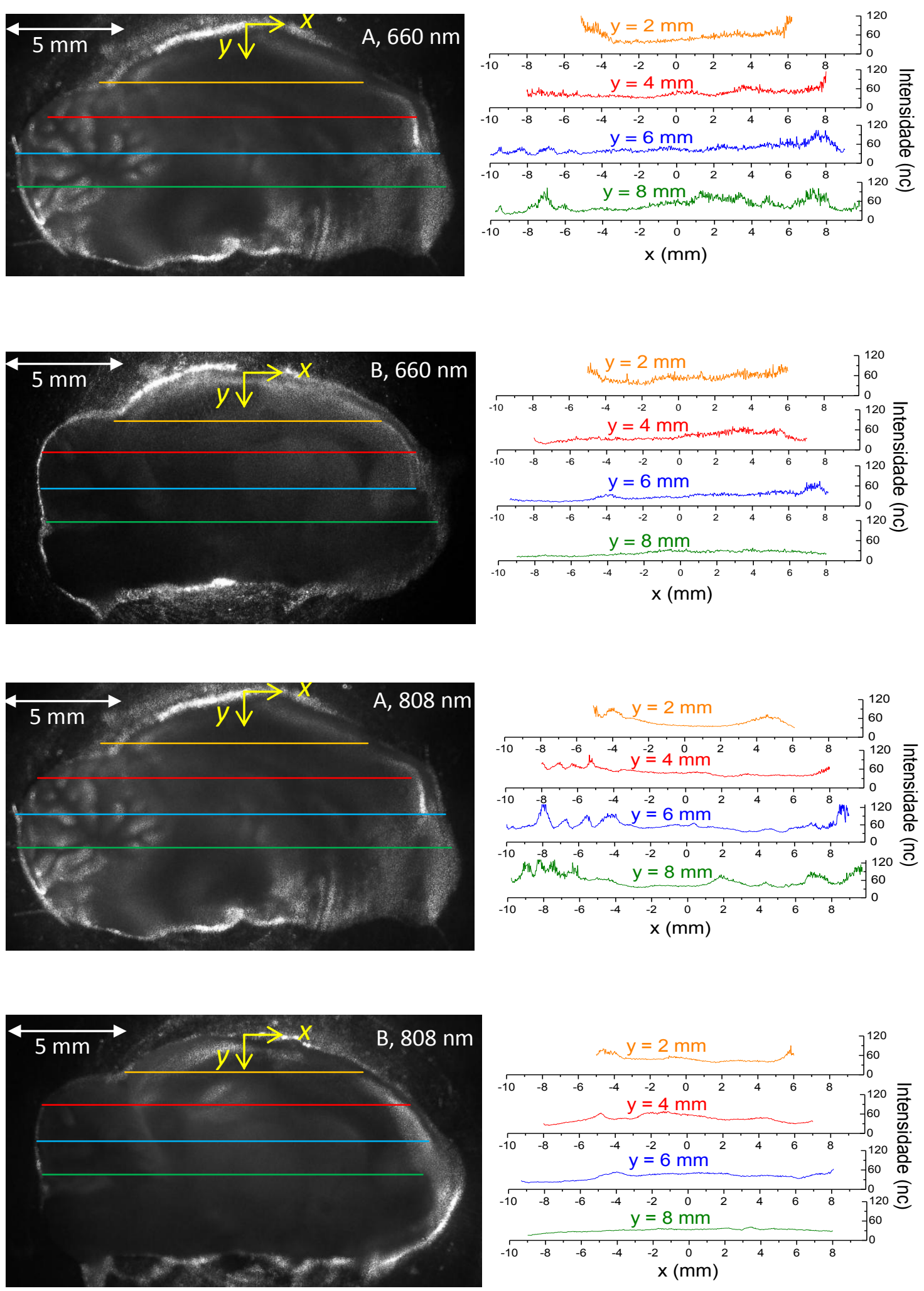

Figura 2.12: Imagens de luz laser transmitida através das amostras (esquerda) e perfis de intensidade (direita) ao longo das linhas marcadas nas imagens. De cima para baixo: $660 \mathrm{~nm}$ e amostra A; $660 \mathrm{~nm}$ e amostra B; $808 \mathrm{~nm}$ e amostra A; $808 \mathrm{~nm}$ e amostra B. 
Podemos ver claramente que a intensidade de luz muda em cada região do cérebro. Em particular no cerebelo há variações bruscas de intensidade ponto por ponto que podem ser explicadas porque essa região possui substância cinzenta (neurônios pequenos, não mielinizados) e substância branca (neurônios mielinizados). Estas diferenças são evidenciadas por picos nos perfis de intensidade na amostra $A$, na região do cerebelo, tanto com luz vermelha quanto infravermelha. A diferença de composição do cérebro também é responsável pela atenuação na amostra $B$ ser em média maior que na amostra $A$, nos dois comprimentos de onda estudados.

$\mathrm{Na}$ figura 2.12 vemos, por exemplo, que a imagem $(B, 660 \mathrm{~nm})$ tem sua parte frontal $(x>0)$ intensidades mais elevadas que na região posterior $(x<0)$. Isso é um indício de que a região frontal do cérebro de rato atenua menos a luz vermelha. Portanto, experimentos de TLBI transcraniana ou o imageamento com luz (e.g. OCT) com intenção de iluminar regiões profundas do cérebro desse animal podem ser realizados com iluminação preferencialmente frontal partindo das laterais.

A iluminação pelo topo e centro da cabeça $(x=y=z=0)$, comumente realizada em experimentos de TLBI transcraniana [36-38], pode não ser a mais eficiente para iluminar regiões profundas do cérebro uma vez que há forte absorção nas camadas mais superficiais do cérebro nessa região. Isso fica evidenciado ao observarmos que na região superior central do encéfalo $I(x=0$, $y=2,0<z<2)=40$ nc. Uma alternativa poderia ser iluminação frontal uma vez que $I(x=6, y=2,0<z<2)=80 \mathrm{nc}$.

O hipocampo é uma subestrutura do cérebro com grande relevância para fotoneuromodulação por TLBI para doenças como Alzheimer, Parkinson e esquizofrenia. $A$ imagem $(B, 808 \mathrm{~nm})$ mostra uma fraca atenuação na região do hipocampo $(-2<x<0, y=4,2<z<4)$. Estudar as propriedades ópticas da região do hipocampo pode incrementar as ferramentas de diagnóstico óptico das doenças degenerativas dessa região.

A área sob o perfil de intensidade, ou seja, a integral da curva é a transmissão total da luz na camada y do tecido. Nomeamos essa grandeza como: $T_{y}$, e definimo-la como: 


$$
T_{y}=\int_{x_{i}}^{x_{f}} I(x, y) d x
$$

Os $T_{y}$ para as amostras $\mathrm{A}$ e $\mathrm{B}$, nas coordenadas $\mathrm{y}=2,4,6,8 \mathrm{~mm}$, para os comprimentos de onda 660 e $808 \mathrm{~nm}$ foram calculados.

A média de $T_{y}$, para cada comprimento de onda, é dada por:

$$
\left\langle T_{y}\right\rangle=\frac{T_{2}+T_{4}+T_{6}+T_{8}}{4}
$$

Os valores de $T_{y}$ e $\left\langle T_{y}\right\rangle$ são mostrados na figura 2.13. A transmissão média é maior para luz infravermelha $(808 \mathrm{~nm})$ e para da amostra $A$. No entanto, próximo ao topo $(y=2 \mathrm{~mm})$ das duas amostras, a transmissão é ligeiramente maior para luz vermelha do que para luz IV. A amostra A tem tendência de apresentar maiores valores de transmissão que a $B$, principalmente para valores maiores de $\mathrm{y}$, o que pode ser atribuído à menor atenuação da luz na região do cerebelo.

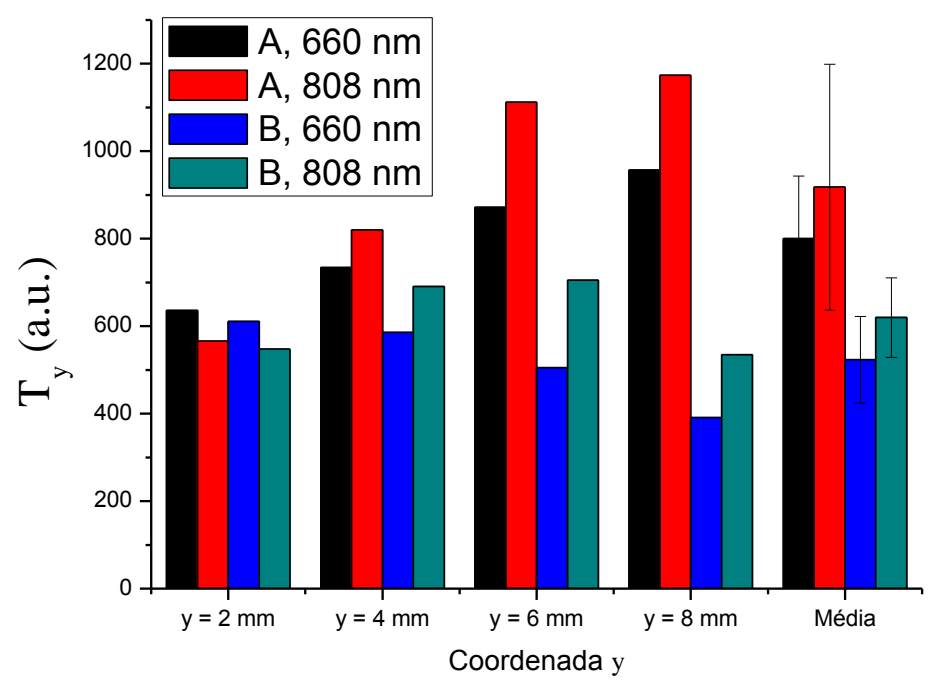

Figura 2.13: valores de $T_{y}$ e $\left\langle T_{y}\right\rangle$. As médias, $\left\langle T_{y}\right\rangle$, para cada amostra e comprimento de onda, foram calculadas a partir dos quatro valores de áreas sob os perfis, $T_{y}$, de cada amostra. 


\subsection{CONCLUSÃO:}

O experimento de iluminação transcraniana mostrou que a Luz infravermelha penetra mais profundamente em tecido cerebral do que a luz vermelha. O tecido ósseo do crânio não é um forte atenuador de luz vermelha ou infravermelha uma vez que, nessas condições, a absorção é pequena e o espalhamento frontal predomina. Os coeficientes de atenuação são diferentes para as áreas do encéfalo (hipocampo, córtex e cerebelo) e podem caracterizar tais tecidos. Estes resultados foram obtidos com o registro de imagens de espalhamento da luz no encéfalo de animais, técnica inédita com essa finalidade.

Mapeando as propriedades ópticas do cérebro de rato concebemos novas possibilidades de iluminação para fototerapia e diagnóstico por imagem formada por métodos ópticos. Tais concepções estão fundamentadas em conhecimento de áreas e comprimentos de onda que são menos atenuados pelo tecido cerebral. Em particular ressaltamos a iluminação com luz IV frontal e lateral como uma possível técnica ainda não explorada de iluminação que foi ressaltada pelo mapeamento óptico aqui realizado.

$O$ estudo de perfis de intensidade em imagens de luz espalhada ou transmitida através de amostras biológicas é uma técnica de baixo custo e muito eficiente para adquirir insight sobre a óptica de tecidos. Os experimentos aqui descritos tiveram resultados satisfatórios e que podem levar a descobertas futuras. Esses experimentos podem ainda ser melhorados com fontes de luz e amostras mais uniformes. 


\section{FOTONEUROMODULAÇÃO DA DOR.}

Os efeitos da TLBI implicam em conversão de energia luminosa em energia metabólica com uma subsequente modulação das funções celulares. Por isso, as TLBI são comumente conhecidas como fotobiomodulação. Quando as células alvo são neurônios, é ainda mais apropriado designar a TLBI como fotoneuromodulação. Nesse capítulo mostraremos que a fotoneuromodulação no SNC, devido à iluminação transcraniana, altera a liberação de substâncias mediadoras da nocicepção resultando na redução da dor.

Recentemente resultados notáveis foram encontrados em Neurologia, usando TLBI transcraniana, um tratamento não invasivo para ferimentos ou doenças cerebrais. A TLBI transcraniana melhora a recuperação motora após acidente vascular cerebral em ratos [36] e em humanos [39]; reduz significativamente o tempo de recuperação em traumatismos cranioencefálicos (TCE) [37], com pouca evidência de efeitos colaterais [38]. Resultados encorajadores foram obtidos para algumas doenças degenerativas do sistema nervoso central como a esclerose lateral amiotrófica familiar [40], a doença de Parkinson [41], a doença de Alzheimer [42].

\subsection{Material e métodos}

\section{Animais}

Todos os procedimentos com animais foram aprovados pelo Subcomitê de Pesquisa Animal do Hospital Geral de Massachusetts (protocolo \# 2014N000040) e seguiram as diretrizes do National Institutes of Health. Camundongos da linhagem BALB/c adultos, machos, pesando entre 20 e $24 \mathrm{~g}$, obtidos no Charles River Laboratories (Wilmington-Massachusetts - EUA) foram usados neste estudo. Os camundongos foram alocados em cinco por gaiola, ciclo claro/escuro de 12/12 horas, com água e comida ad libitum.

\section{Parâmetros da iluminação com laser}

A iluminação foi feita usando um laser de diodo de $810 \mathrm{~nm}$ (DioDent Micro 810, Hoya ConBio, Fremont, CA) equipado com fibra de quartzo-sílica. Os camundongos foram posicionados em um imobilizador transparente (Flat 
Bottom Rodent Holders, Kent Scientific, Torrington - Connecticut - EUA). A iluminação transcraniana do encéfalo foi realizada com a ponta da fibra óptica em contato com a pele do animal e posicionada perpendicularmente sobre o bregma. O laser era configurado em modo contínuo (CW), com área irradiada de $1 \mathrm{~cm}^{2}$ e potência de $300 \mathrm{~mW}$, no entanto, outros parâmetros da iluminação como: tempo, energia e densidade de energia, tiveram variações que estão explicitadas na tabela 3.1. Não há parâmetros bem estabelecidos para TLBI transcraniana em camundongos. Escolhemos parâmetros que levaram em consideração a atenuação da luz ao atravessar as camadas de pele e osso do crânio conforme conhecimento adquiro nos experimentos apresentados no capítulo 2.

Os grupos experimentais foram separados de acordo com a dose de luz que cada animal recebeu. Dessa forma os animais tratados com iluminação transcraniana durante $24 \mathrm{~s}\left(7,2 \mathrm{~J} / \mathrm{cm}^{2}\right)$ serão designados como grupo tratado com laser \#1 (GL24); por sua vez, os animais tratados com iluminação transcraniana durante $120 \mathrm{~s}\left(36 \mathrm{~J} / \mathrm{cm}^{2}\right)$ serão designados como grupo tratado com laser \#2 (GL120) e os que não receberam iluminação fazem parte do grupo controle $(\mathrm{GC})$. Para o $\mathrm{GC}$ foi feito todo o procedimento de imobilização do animal e a ponteira do laser foi posicionada em contato com a cabeça do animal durante $120 \mathrm{~s}$, no entanto, o laser não foi acionado. Cada grupo era composto por 15 animais, subdivididos de forma que: 5 animais foram usados para quantificar o limiar de dor; 5 para os testes de nocicepção; e 5 para os ensaio de quantificação de ATP, imunofluorescência e marcação com HE.

Tabela 3.1: Parâmetros da TLBI.

\begin{tabular}{lccc}
\hline Grupos & GC & GL24 & GL120 \\
\hline Local da aplicação & \multicolumn{3}{c}{ Cabeça, transcraniana } \\
Forma da aplicação & \multicolumn{3}{c}{ Pontual com contato } \\
Área iluminada $\left(\mathbf{c m}^{2}\right)$ & 0 & 1,0 & 1,0 \\
Potência (mW) & 0 & 300 & 300 \\
Tempo de iluminação (s) & 0 & 24 & 120 \\
Energia (J) & 0 & 7,2 & 36 \\
Densidade de Energia $\left(\mathbf{J} / \mathbf{c m}^{2}\right)$ & 0 & 7,2 & 36 \\
\hline
\end{tabular}




\section{Avaliação do limiar de dor}

Os camundongos foram transferidos, para gaiolas individuais $(10 \times 20 \times$ $15 \mathrm{~cm}$ ) com base de malha de arame metálico (orifícios de $5 \times 5 \mathrm{~mm}$ ). O estímulo nociceptivo foi obtido com um conjunto de filamentos von Frey manufaturados para aplicar forças entre 10 e $120 \mathrm{gf}$. Para evocar dor o filamento era pressionado perpendicularmente contra a região plantar de uma das patas traseiras do camundongo por cerca de $3 \mathrm{~s}$.

A estimulação era iniciada com o filamento de menor força $e$ sucessivamente repetida com filamentos de maior força até o momento em que o camundongo reagia com um flinch (reflexo autônomo de dor caracterizado por espasmos) ou lambendo a pata. A força do último filamento usado era considerada o limiar de nocicepção daquele animal. A média dos limiares de cada animal foi considerada como o limiar de nocicepção para o grupo $(n=5)$.

Mais informações sobre como manufaturar e calibrar filamentos von Frey, bem como, sobre como compará-los aos filamentos comerciais e sobre os testes que podem ser feitos usando tais filamentos podem ser obtidas no Apêndice C.

Testes de nocicepção: placa fria, fonte radiante de calor e injeção de formalina

Os testes de nocicepção foram realizados nos grupos $(n=5)$ de animais que receberam iluminação transcraniana de 24 e 120 s e no grupo controle. Esses testes foram executados duas horas após a iluminação, em dias consecutivos, na seguinte ordem: placa fria, fonte radiante de calor, injeção de formalina.

O teste da placa fria evoca dor moderada no animal, devido à baixa temperatura $\left(4 \pm 1^{\circ} \mathrm{C}\right)$ e a avaliação da nocicepção pode ser indiretamente mensurada pelo tempo de latência até a reação do animal. A placa fria utilizada nesse experimento consistia em uma camada de gelo recoberta por uma folha de papel alumínio dentro de uma caixa de isopor. Os camundongos foram confinados em uma região de $10 \times 10 \times 10 \mathrm{~cm}$ no interior da caixa. A temperatura desse aparato foi constantemente monitorada por um termômetro na superfície de alumínio na região em que os camundongos estavam confinados, e os experimentos foram conduzidos apenas quando a temperatura estava entre 3 e $5{ }^{\circ} \mathrm{C}$. Quando a temperatura passava de $5^{\circ} \mathrm{C}$ o gelo era substituído e esperávamos alguns minutos até que a temperatura ficasse novamente entre 3 e $5{ }^{\circ} \mathrm{C}$. No momento em que os animais foram colocados 
em contato com a superfície da placa fria o cronômetro manual foi acionado. $O$ teste foi encerrado quando os animais reagiam lambendo a pata ou com um flinch nas patas dianteiras. O tempo até a reação do animal foi cronometrado e usado para calcular o tempo de latência médio para o grupo.

$O$ teste de retirada da cauda de uma fonte radiante de calor caracterizase por elevação da temperatura no tecido que está sendo alvo do aquecimento da irradiação térmica. Para esse teste, foi usado um laser de alta potência $\left(1 \mathrm{~W}, 1 \mathrm{~mm}^{2}, 730 \mathrm{~nm}\right.$ ) com feixe apontado para o ponto médio das caudas dos camundongos que foram posicionados em um imobilizador transparente (Flat Bottom Rodent Holders, Kent Scientific, Torrington - Connecticut - EUA) que permitia o movimento apenas da cauda do animal. $O$ tempo até que o animal retirasse a cauda do feixe foi contabilizado com um cronômetro manual e foi usado para calcular o tempo de latência médio para o grupo.

Para avaliação da nocicepção por substância irritante, uma injeção de 10 $\mu \mathrm{L}$ de formalina a $2 \%$ foi aplicada na pata traseira direita, levando a dor inflamatória em duas fases. A primeira fase é de dor aguda (0 - 15 minutos após a injeção), caracterizada por curta duração e visível inflamação da pata. A segunda fase é de dor tônica (15 - 60 minutos após a injeção), em que a duração é maior que nos modelos de dor aguda, no entanto não pode ser classificada como dor crônica, pois tem duração e apenas algumas dezenas de minutos. Após a fase tônica espera-se que não haja mais dor evocada pela formalina e o animal apresente comportamento semelhante ao de um animal no qual não houve injeção de substância algógena. Para a medição da nocicepção nas fases aguda e tônica cronometramos o tempo total (soma de todos os momentos) em que o animal permaneceu com a pata traseira direita levantada. Para a fase aguda levamos em consideração o período de observação de cinco minutos ( 0 - 5 min após a injeção de formalina), e para fase tônica o período de cinco minutos $(15-20$ min após a injeção de formalina).

A tabela 3.2 sumariza as informações sobre a avaliação do limiar de dor e os testes de nocicepção.

Tabela 3.2: Informações sobre os experimentos realizados.

\begin{tabular}{|c|c|c|}
\hline Experimento & Limiar de dor & Testes de nocicepção \\
\hline Estímulo nociceptivo & $\begin{array}{l}\text { Filamentos von } \\
\text { Frey }\end{array}$ & $\begin{array}{l}\text { Placa fria, fonte radiante de } \\
\text { calor e injeção de formalina }\end{array}$ \\
\hline Resposta ao estímulo & Flinch & Tempo de reação \\
\hline $\begin{array}{l}\text { Cronograma dos } \\
\text { estímulos }\end{array}$ & $\begin{array}{c}\text { Antes da TLBI, } \\
1,2,3,6 \text { e } 24 \text { h } \\
\text { após TLBI }\end{array}$ & 2 h após TLBI \\
\hline
\end{tabular}




\section{Fixação e extração de tecido}

As extrações dos tecidos foram realizadas $3 \mathrm{~h}$ após a iluminação transcraniana, em grupos $(n=5)$ de animais que não participaram de qualquer estimulação nociceptiva. Para proceder com a extração, 0 animal foi anestesiado por injeção intramuscular de $30 \mu \mathrm{L}$ de solução de cetamina e xilazina (proporção de 10:1). O coração do animal foi acessado por uma rápida cirurgia para abrir a caixa torácica. Para que a fixação ocorresse internamente aos tecidos foram realizadas duas perfusões transcardíacas, a primeira com $10 \mathrm{~mL}$ de solução salina tamponada com fosfato e a segunda com $10 \mathrm{~mL}$ de paraformaldeído $4 \%$. O coração do camundongo bombeia a solução tampão e o paraformaldeído para o interior dos tecidos promovendo a fixação interna dos mesmos, levando ao óbito do animal. Após a eutanásia do animal, o encéfalo do camundongo foi extraído por inteiro e preservado por $48 \mathrm{~h}$ em paraformaldeído a $4 \%$.

\section{Imunofluorescência e marcação com HE}

Após a fixação os encéfalos foram cortados na fissura medial e os hemisférios direitos foram embebidos em blocos de parafina e seccionados em cortes sagitais na região medial, produzindo oito amostras de $5 \mu \mathrm{m}$ de espessura para cada encéfalo. Dessa forma, o encéfalo de cada animal gerou quatro pares de amostras e cada par de amostras foi marcado com um dos três antígenos ou com HE (marcações em duplicata). As imagens de tecido encefálico marcados com HE foram usadas para verificar a presença possíveis lesões ou inflamação decorrentes da iluminação transcraniana. As fatias foram aderidas às lâminas transparentes e receberam o protocolo padrão de imunohistoquímica para fluorescência ou marcação com HE praticado no Photopathology Laboratory, Wellman Center for Photomedicine, Massachusetts General Hospital [Anexo A].

Nos experimentos apresentados nesse trabalho, as IF foram indiretas com tecido alvo de camundongo e os antígenos foram: tubulina, para verificar alterações no citoesqueleto, como as descritas por Chow et al [14]; canais de glutamato tipo 1 (Gl1), pois esse é um neurotransmissor envolvido na condução da informação nociceptiva; e fosfatase ácida prostática (PAP deriva de prostatic acid phosphatase), um analgésico endógeno. Os anticorpos primários usados 
foram de galinha e atacavam especificamente cada um dos antígenos. Os anticorpos secundários foram de cabra anti-galinha com sítio fluorescente de fluoresceína. A fluoresceína tem pico de excitação em 494 nm e emite em $521 \mathrm{~nm}$.

\section{Microscopia}

As amostras marcadas com tubulina, Gl1 e PAP foram fotografadas digitalmente com microscópio confocal (Olympus FV1000 - multi-photon confocal microscope, Olympus Corporation of the Americas) usando a técnica de fluorescência. A resolução dessas imagens foi suficiente para observar alterações nas quantidades de Gl1, PAP e tubulina.

As amostras marcadas com HE foram fotografadas digitalmente com o equipamento NanoZoomer (Hamamatsu, Japão) para formar imagens digitais com ampliação de 40 vezes em cada dimensão, ou seja, 1600 vezes em área.

\section{Quantificação de ATP}

O hemisfério esquerdo do encéfalo (complementar ao hemisfério que foi usado para imageamento de tecidos) recém-extraído foi macerado e centrifugado (4000 rpm, 15 min). Após a centrifugação houve separação entre dois meios: o sobrenadante líquido e translúcido; e o soluto turvo. O soluto foi descartado e o sobrenadante foi congelado em nitrogênio líquido para preservar as características bioquímicas.

O ATP presente no hemisfério esquerdo do encéfalo dos camundongos foi quantificado com a técnica de fotometria da reação de luciferina com ATP. A luminescência decorrente da reação de luciferina com ATP acontece em três fases:

$$
\begin{gathered}
\text { luciferina }+ \text { ATP } \rightarrow \text { adenilato de luciferil }+ \text { pirofosfato } \\
\text { adenilato de luciferil }+\mathrm{O}_{2} \rightarrow \text { oxiluciferina }^{*}+\text { AMP } \\
\text { oxiluciferina }^{*} \rightarrow \text { oxiluciferina }+ \text { luz }
\end{gathered}
$$

O símbolo $*$ denota que a oxiluciferina está em um estado eletrônico excitado. 
Quando a oxiluciferina volta para o estado fundamental (reação 3.3) a energia é liberada na forma de fótons. O conjunto de reações (3.1 - 3.3) mostra que a concentração de ATP pode ser estimada a partir da luminescência provocada pela desexcitação da oxiluciferina.

Para a quantificação da concentração de ATP, misturamos $10 \mu \mathrm{L}$ do sobrenadante de cada amostra com $40 \mu \mathrm{L}$ da solução de luciferina e essa mistura foi incubada (temperatura ambiente, placa coberta por alumínio, $10 \mathrm{~min}$ ) nos poços de uma placa de microtitulação (Promega, CellTiter-Glo® Luminescent kit). Após incubação a placa foi lida no luminômetro (GloMax®Multi+ Microplate Multimode Reader) a emissão com comprimento de onda de $570 \mathrm{~nm}$ foi quantificada para cada poço.

\section{Análise estatística}

Inicialmente todos os dados passaram pelos testes de Shapiro-Wilk e Levene, que comprovaram as hipóteses de normalidade da distribuição e de homocedasticidade (homogeneidade da variância), respectivamente. As comparações entre os grupos (GC versus GL24; GC versus CG120; GL24 versus CG120) (controle versus $24 \mathrm{~s}$ versus $120 \mathrm{~s}$ ) em cada tempo de avaliação foram realizadas por análises de variância (ANOVA) simples. Uma vez encontrada diferenças significativas, foi conduzido o teste pos-hoc de Tukey DHS (Diferença Honestamente Significante). Para todas as análises foi estabelecido um valor de $5 \%$ para a significância do teste, ou seja, uma confiança de $95 \%$ de que a diferença ocorreu de fato e não por coincidência.

\subsection{Resultados e discussão}

Nessa seção apresentaremos os resultados do comportamento dos animais em relação à estimulação nociceptiva mecânica para avaliar o limiar de dor e de outros estímulos térmicos ou inflamatórios. Discutiremos como essas alterações comportamentais podem ser explicadas por alterações bioquímicas resultantes do processo de fotoneuromodulação. 


\subsubsection{Limiar de dor}

O limiar de dor foi avaliado imediatamente antes $(0 \mathrm{~h})$ e depois $(1,2,3,6,24 \mathrm{~h})$ da iluminação e constatamos que os dois grupos que receberam iluminação transcraniana apresentaram aumento do limiar de dor, entretanto, o limiar de dor do grupo controle permaneceu inalterado (figura 3.1). Nota-se nesse gráfico que o efeito da iluminação não é imediato, pois se verifica um aumento do limiar de dor com o tempo após a iluminação. O limiar de dor médio para GC, GL24 e GL120, imediatamente antes da iluminação com laser (808 nm), foi respectivamente de 21,5, 17,8 e 24,4 gf; no entanto, essa diferença não foi significativa. A segunda medida foi realizada $1 \mathrm{~h}$ após a iluminação transcraniana e os dois grupos iluminados apresentavam aumento do limiar em relação aos seus valores pré-iluminação e em relação ao grupo controle. O maior valor do limiar de dor para GL24 foi de 38,3 gf, $3 \mathrm{~h}$ depois da iluminação; e para GL120 foi de 65,2 gf, 2 h depois da iluminação. A medida $6 \mathrm{~h}$ após a iluminação mostra que GL24 voltou a apresentar resposta aos estímulos mecânicos similares às apresentadas pelo grupo controle, no entanto, GL120 continuou com o limiar de dor aumentado. A última medida da série mostra que, $24 \mathrm{~h}$ depois da iluminação, todos os grupos voltaram a responder à estimulação mecânica de forma semelhante à inicial $(0 \mathrm{~h})$, mostrando um caráter temporário para os efeitos da iluminação transcraniana.

Houve diferença significativa $(p \leq 0,05)$ nos limiares de dor entre os grupos GL120 e GC nas medidas realizadas 1, 2, 3 e 6 h após a iluminação transcraniana; entre GL120 e GL24 nas medidas realizadas 1, 2, 3 e 6 h após a iluminação transcraniana. Entre GL24 e GC não houve diferenças significativas. 


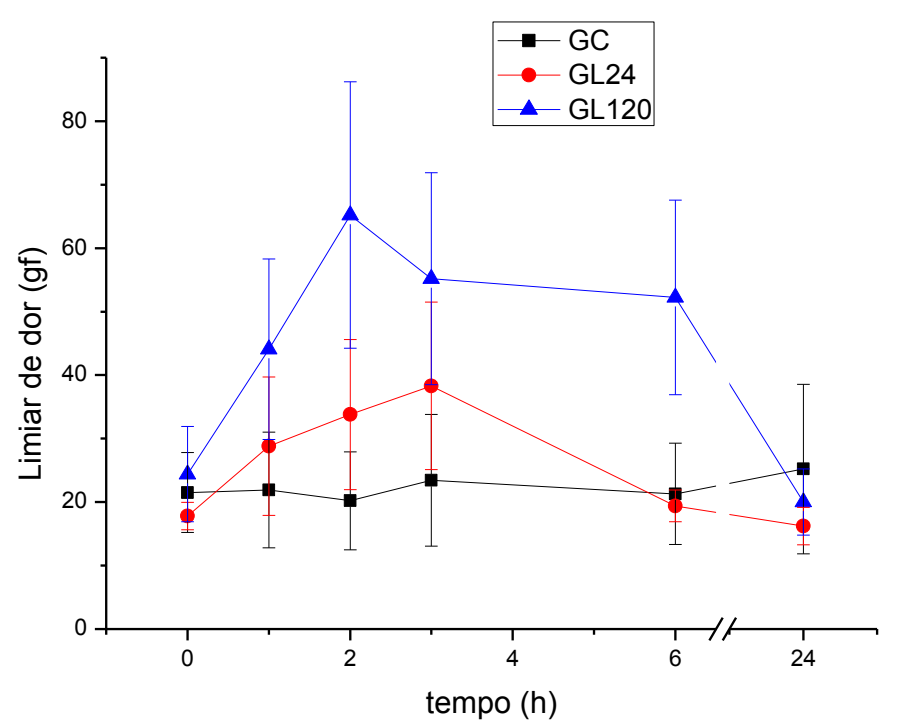

Figura 3.1: Limiar de dor médio e desvios padrão (DP) antes da iluminação e 1, $2,3,6,24 \mathrm{~h}$ depois da iluminação para os grupos controle e os que receberam iluminação transcraniana de 7,2 ou $36 \mathrm{~J}$. O maior aumento do limiar acontece entre 2 e $3 \mathrm{~h}$ e depois de $24 \mathrm{~h}$ o limiar de todos os grupos volta a ser semelhante.

\subsubsection{Testes de nocicepção}

\section{Placa fria}

O tempo de latência até a reação do animal em resposta à estimulação térmica de baixa temperatura foi avaliado $2 \mathrm{~h}$ após a aplicação do laser e as médias e DP dos grupos $(n=5)$ são apresentadas na figura 3.2. Os animais do GC levaram em média $30 \mathrm{~s}$ para reagir à nocicepção evocada pelo frio lambendo as patas dianteiras. Os animais do GL24 demoraram mais para reagir a nocicepção evocada pelo frio (72 s), no entanto, essa diferença não é estatisticamente significativa quando comparada ao grupo controle. O GL120 apresentou uma latência média de $161 \mathrm{~s}$, que foi significativamente maior que a dos outros dois grupos. 


\section{Placa Fria}

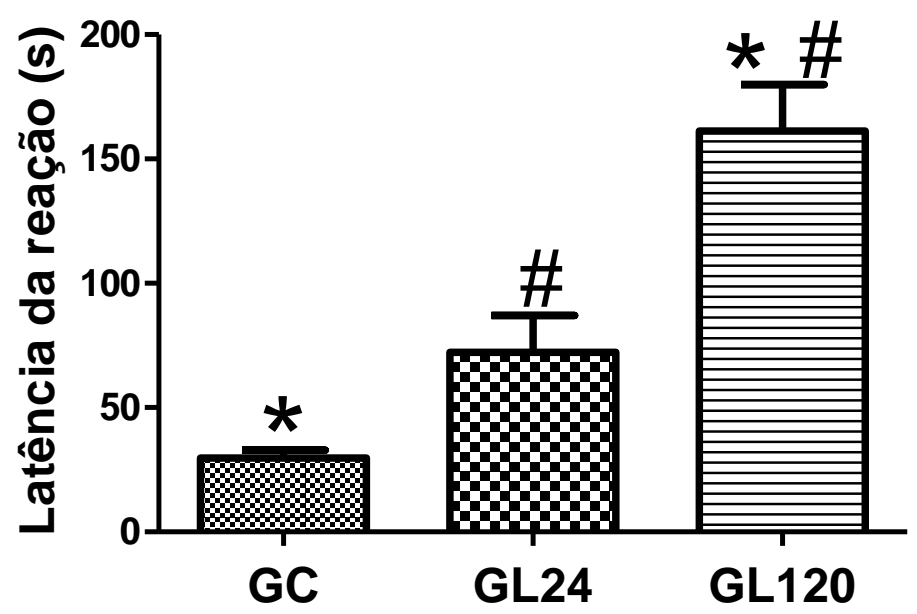

Figura 3.2: Média e desvio padrão (DP) dos grupos $(n=5)$ para o tempo de latência até a reação do animal em resposta à estimulação térmica de baixa temperatura. Os símbolos * e \# marcam os pares de grupos estatisticamente diferentes, $p \leq 0,05$.

\section{Retirada da cauda de uma fonte radiante de calor}

Os animais do grupo controle demoraram menos que os que foram iluminados para retirar a cauda de uma fonte radiante de calor, isso atesta, indiretamente, que a tolerância desses animais para a dor evocada pelo aumento de temperatura no tecido está mais baixa que nos outros dois grupos. O grupo controle levou em média 4,1 s para retirar a cauda enquanto GL24 e GL120 levaram 9,0 e 30,1 s para retirar a cauda, respectivamente. O GL120 apresentou uma latência significativamente maior que a dos outros dois grupos (figura 3.3). 


\section{retirada da cauda de uma fonte radiante de calor}

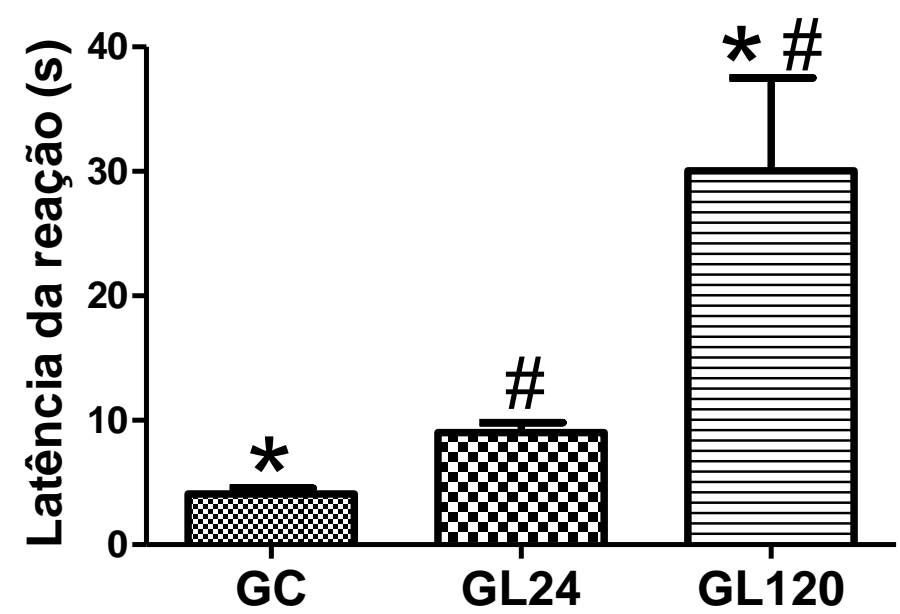

Figura 3.3: Média e DP dos grupos $(n=5)$ para o tempo de latência até a retirada da cauda em resposta à estimulação térmica de alta temperatura. Os símbolos * e \# marcam os pares de grupos estatisticamente diferentes, $p \leq 0,05$.

\section{Injeção de formalina}

Durante a fase aguda da dor inflamatória provocada pela injeção de formalina na pata traseira direita dos animais o tempo que o animal permanece com a pata levantada, evitando o contato da mesma com o chão, é um indicativo da hiperalgesia sentida pelo animal. Nos cinco primeiros minutos (300 s) depois da injeção, o grupo controle permanece em média 155,4 s com a pata inflamada levantada. A duração da resposta à dor inflamatória no grupo controle foi significativamente maior que a duração dessa resposta para os grupos que foram iluminados que foram de $53,4 \mathrm{~s}$ para GL24 e 73,6 s para GL120 (figura 3.4). 
Injeção de formalina: dor aguda

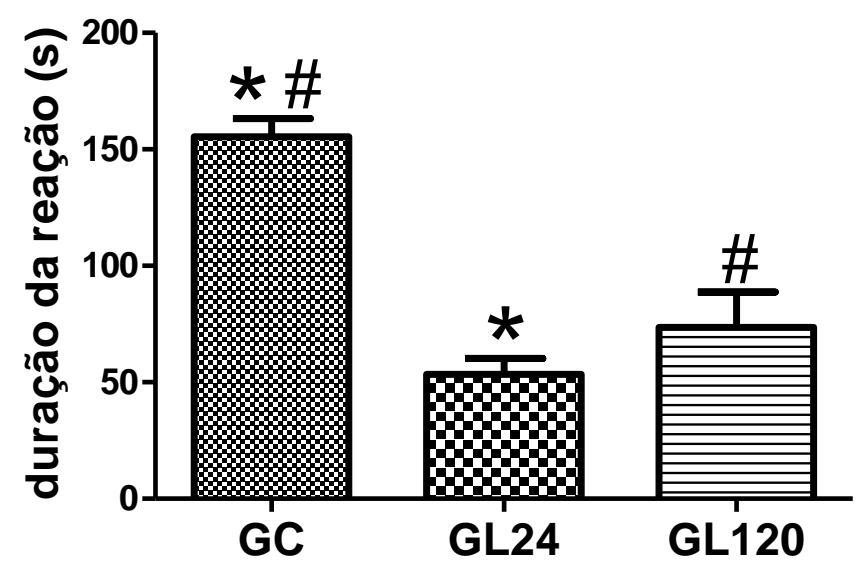

Figura 3.4: Média e DP dos grupos $(n=5)$ para a duração da reação do animal em resposta à inflamação provocada pela injeção de formalina. Os símbolos * e \# marcam os pares de grupos estatisticamente diferentes, $p \leq 0,05$.

Durante a fase tônica o GL120 praticamente não manifestou comportamento que indicasse dor. O tempo médio que esse grupo passou com a pata levantada foi de apenas $1,2 \mathrm{~s}$, um resultado compatível com a inexistência de dor. O GC e o GL24 ficaram 35,3 e 21,2 s com a pata levantada e a diferença foi significativa apenas entre GC e GL120 (figura 3.5).

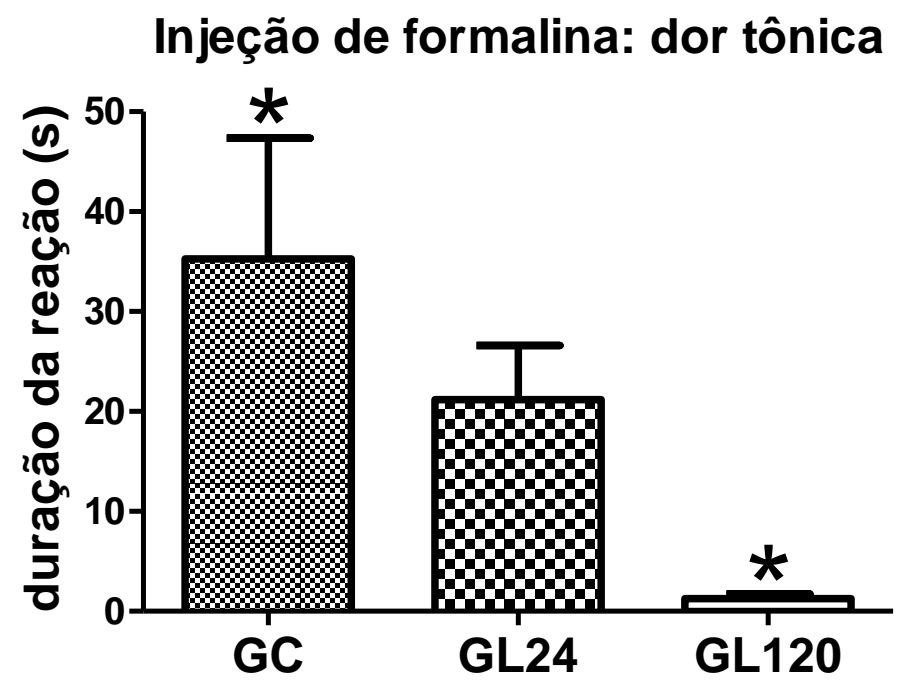

Figura 3.5: Média e DP para a duração da reação do animal, durante a fase tônica, em resposta à inflamação provocada pela injeção de formalina. Os símbolos * e \# marcam os pares de grupos estatisticamente diferentes, $p \leq 0,05$. 


\subsubsection{Alterações bioquímicas no encéfalo}

ATP

A concentração de ATP nas amostras de hemisfério cerebral foi quantificada e normalizada pela concentração do grupo controle. A concentração de ATP do GL24 foi $27 \%$ maior que a concentração no grupo controle, no entanto essa diferença não foi estatisticamente significativa. $O$ GL120 apresentou uma concentração de ATP 90\% maior que a concentração no grupo controle, diferença estatisticamente significativa (figura 3.6).

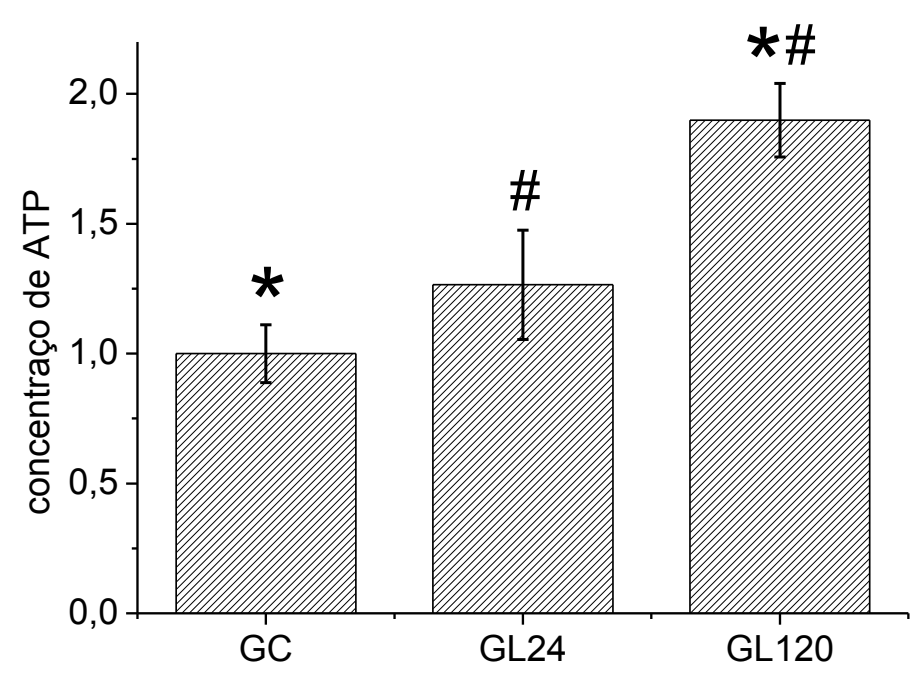

Figura 3.6: Média e DP para a concentração de ATP no hemisfério esquerdo, normalizada pela concentração de ATP do grupo controle. Os símbolos * e \# marcam os pares de grupos estatisticamente diferentes, $p \leq 0,05$.

\section{Concentrações de glutamato, PAP e tubulina por Imunofluorescência}

As imagens de imunofluorescência captadas por microscopia confocal apresentadas nesse trabalho são de regiões do córtex. As imagens tiveram as regiões de luminescência coloridas digitalmente e as cores foram escolhidas de forma arbitrária tal que vermelho, amarelo, verde, e azul representassem, respectivamente, Gl1, PAP, tubulina e o corante artificial DAPI, um marcador de núcleos celulares usados para facilitar a quantificação e proliferação de células (figura 3.7). 
A quantificação dos antígenos foi realizada indiretamente pela intensidade da fluorescência nas imagens. Como essas imagens são da superfície do tecido há uma determinada área da imagem sem tecido e por isso, sem fluorescência. Para possibilitar a comparação de várias imagens independente da quantidade de tecido que a imagem mostra, a quantificação da fluorescência foi efetuada em uma região quadrada $(0,2 \times 0,2 \mathrm{~mm})$ no centro das imagens (figura 3.8). Todas as imagens possuem as mesmas dimensões $(1 \times 1 \mathrm{~mm})$, mesma resolução (tamanho do pixel) e a região usada para quantificação sempre apresenta tecido biológico.

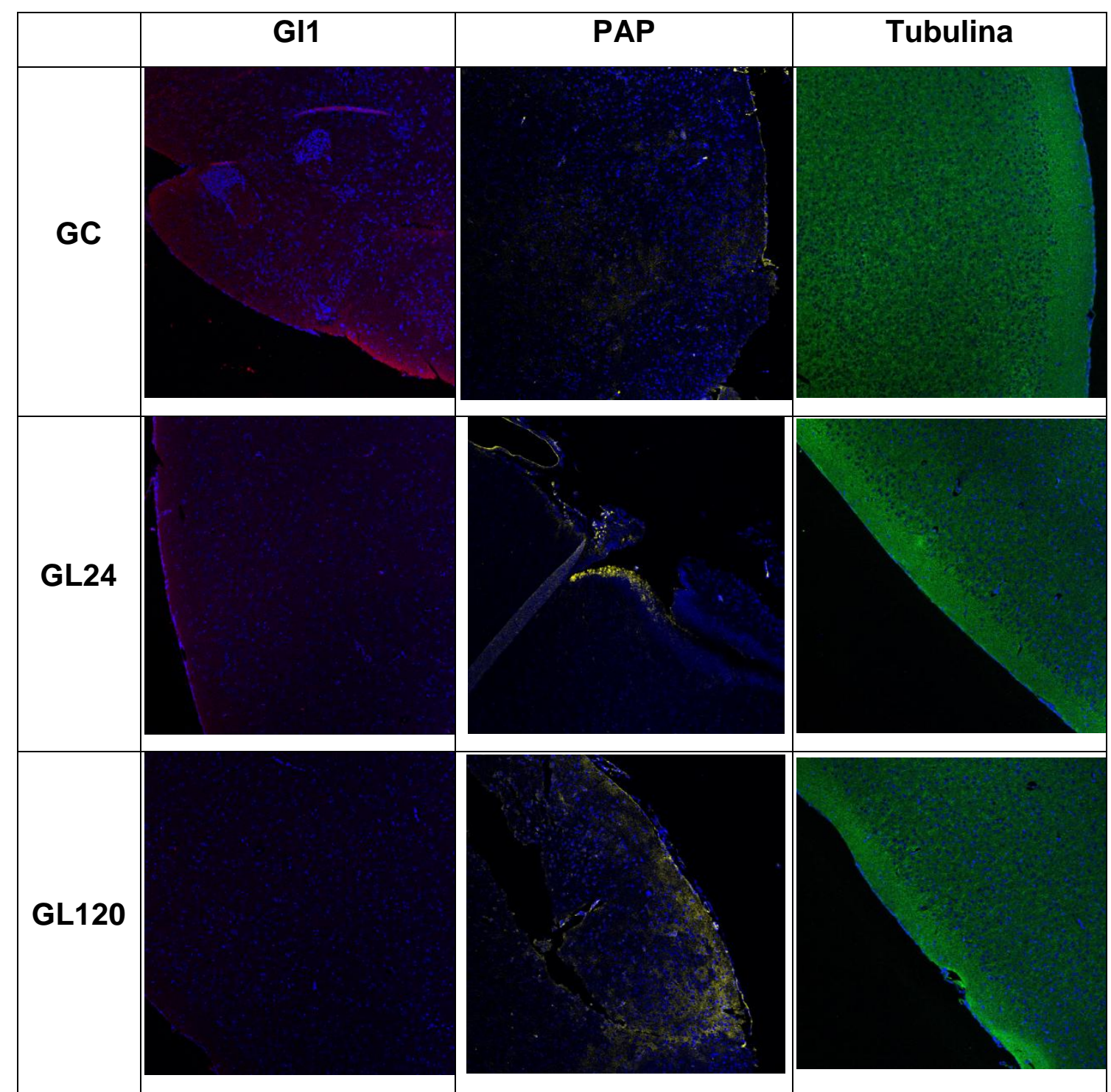

Figura 3.7: Exemplos de imagens de cada um dos grupos com cada um dos antígenos marcados: tubulina (verde), PAP (amarelo) Gl1 (vermelho) e os núcleos celulares (azul). 


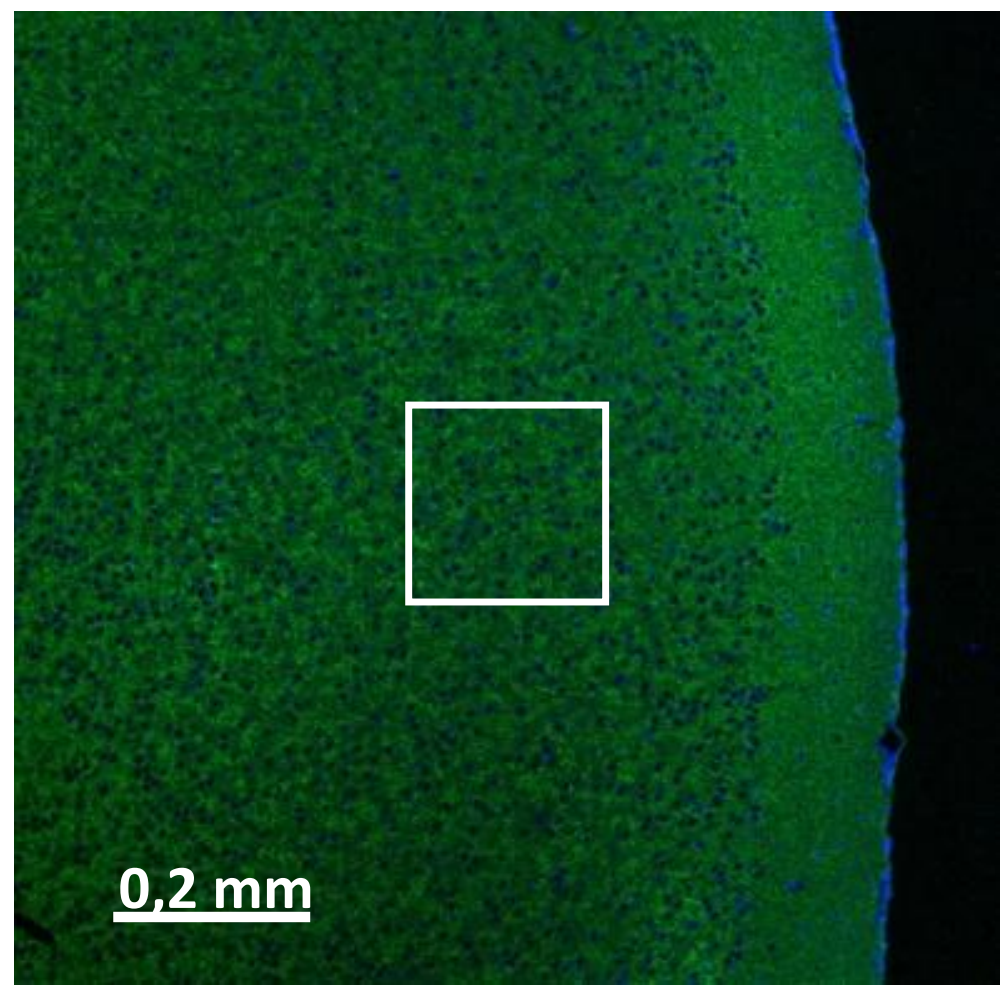

Figura 3.8: Tecido cerebral com antígeno tubulina (verde) e núcleos celulares (azul) marcados pela técnica de imunofluorescência. O quadrado central de $(200 \times 200 \mu \mathrm{m})$ é a região onde as imagens são analisadas para a quantificação da fluorescência.

\section{Glutamato}

O glutamato é um neurotransmissor excitatório da sinalização nociceptiva. A diminuição da concentração de glutamato no tecido leva à diminuição da condução de estímulos nociceptivos devido à diminuição de disparos de potencial de ação.

A quantidade de glutamato (Gl1) é significativamente maior no grupo controle em relação aos grupos que receberam iluminação transcraniana (figura 3.9). Este efeito pode explicar o aumento do limiar de dor observado nos grupos GL24 e GL120 quando comparados ao GC. 


\section{Glutamato}

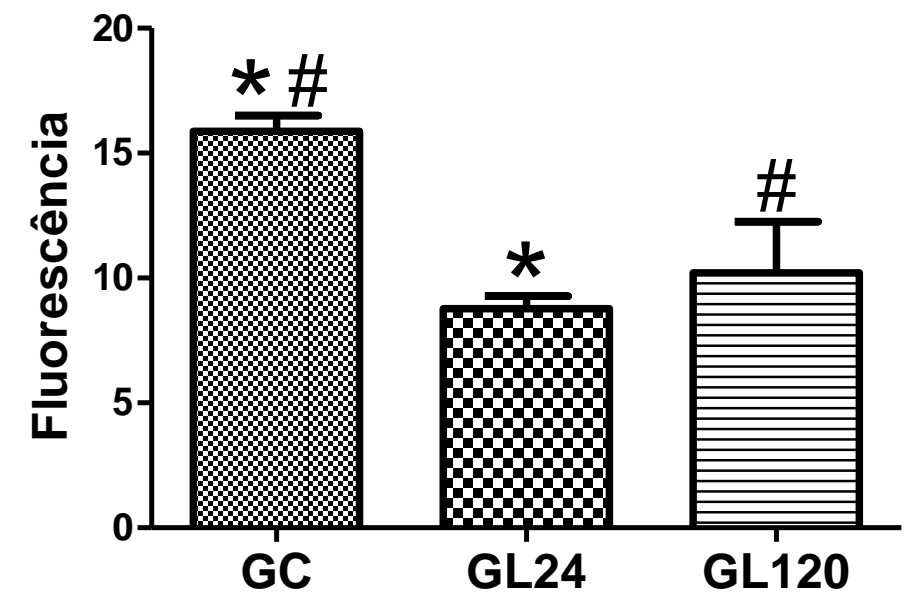

Figura 3.9: Média e DP para a intensidade da fluorescência de Gl1 no hemisfério direito. Os símbolos * e \# marcam os pares de grupos estatisticamente diferentes, $p \leq 0,05$.

\section{PAP}

O PAP é uma enzima responsável por hidrolisar o AMP (Monofosfato de Adenosina) extracelular em adenosina. Quando PAP é encontrado em grande quantidade, indica que houve uma supressão dos sinalizadores (AMP) que por sua vez são sensibilizadores dos neurônios condutores da sinalização nociceptiva, por isso, o PAP apresenta atividade analgésica indireta [43-44].

A quantidade de PAP no córtex cerebral dos camundongos do GL120 foi significativamente maior que no GL24. A quantidade mais elevada desse analgésico endógeno em GL120 pode explicar o limiar de dor elevado para esse grupo $3 \mathrm{~h}$ depois da iluminação (figura 3.10). 


\section{Analgésico endógeno PAP}

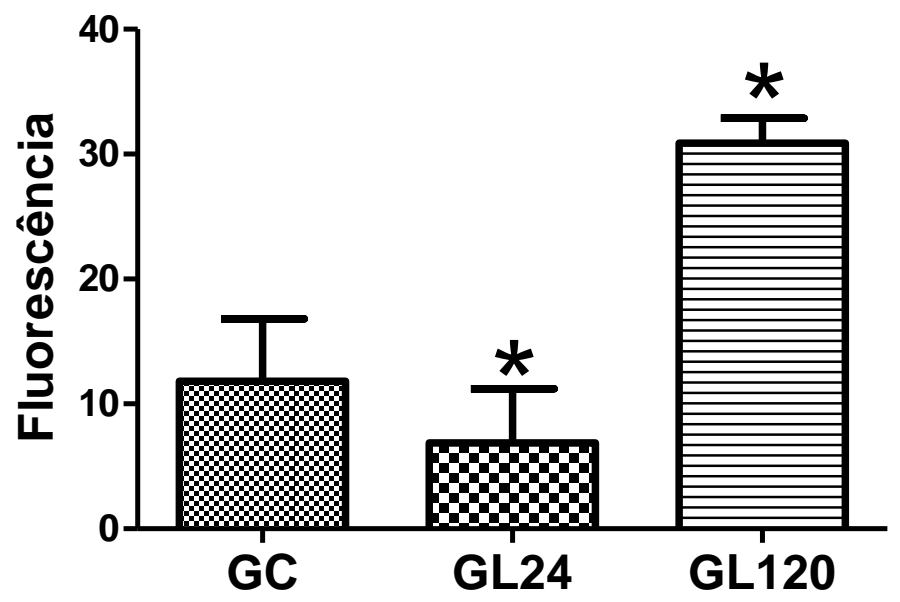

Figura 3.10: Média e DP para a intensidade da fluorescência de PAP no hemisfério direito. Os símbolos * e \# marcam os pares de grupos estatisticamente diferentes, $p \leq 0,05$.

\section{Tubulina}

Não há variação significativa na quantidade de tubulina após a iluminação transcraniana (figura 3.11) e não há formação de varicosidades (aglomerados de tubulina) como as que Chow et al [14] acharam em neurônios de gânglio da raiz dorsal in vitro. As varicosidades foram definidas em termos de tamanho e formato dos aglomerados de tubulina de tal forma que fossem compatíveis com as achadas por Chow et all, para isso, usamos a análise de imagens com o software imageJ. Não foram identificadas aglomerações de tubulina com intensidades de fluorescência maiores que 20 e tamanhos maiores que $150 \mu \mathrm{m}^{2}$.

A não formação de varicosidades é mais um indício de que a analgesia por terapia com luz pode ter mais de um mecanismo de ação dependendo das células e tecidos iluminados. Outra explicação para a não formação de varicosidades é que a fluência luminosa que efetivamente atinge os neurônios na iluminação transcraniana que executamos nesse trabalho in vivo seja muito menor que a fluência usada in vitro no trabalho de Chow et al [14]. 


\section{Tubulina}

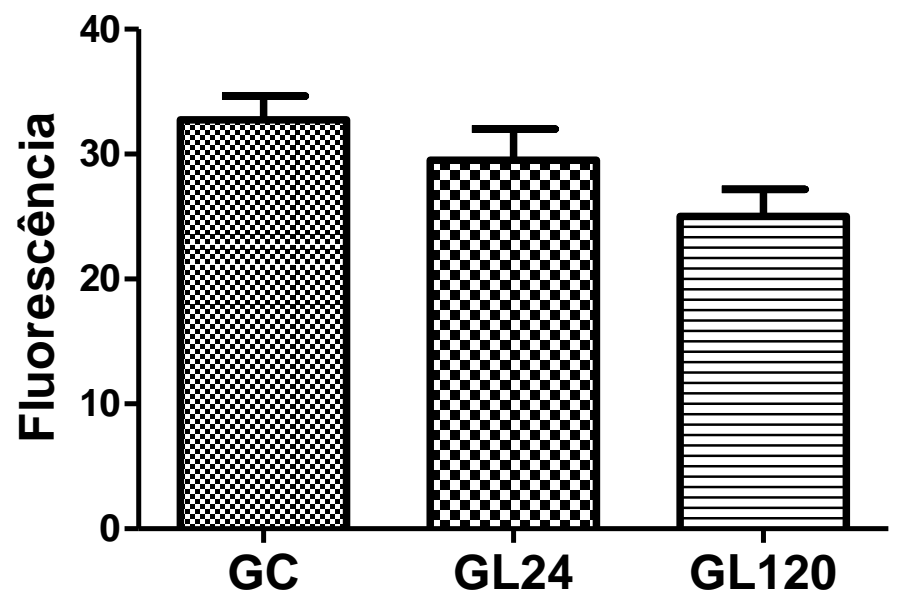

Figura 3.11: Média e DP para a intensidade da fluorescência de tubulina no hemisfério direito. Os símbolos * e \# marcam os pares de grupos estatisticamente diferentes, $p \leq 0,05$.

\section{Marcação de tecido por Hematoxilina-Eosina}

As imagens digitais obtidas das amostras de tecidos marcados com $\mathrm{HE}$ possibilitam avaliar a morfologia dos tecidos, alterações como queimaduras, inflamações e deformações que fossem causadas pela iluminação transcraniana ficariam claramente expostas com essa técnica. No entanto, como podemos observar nas imagens da figura 3.12 não verificamos alterações morfológicas provocadas pela iluminação transcraniana. Essas imagens atestam que as doses usadas nesses experimentos foram suficientes para produzir fotoneuromodulação sem, no entanto, lesionar o tecido biológico.

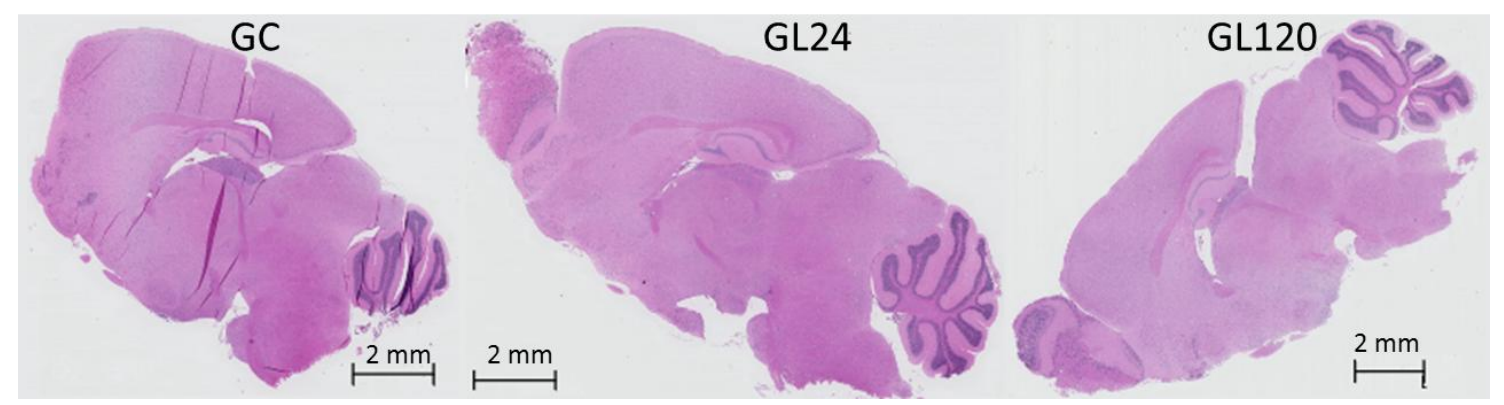

Figura 3.12: Amostras de tecido marcado com HE. Corte sagital do hemisfério direito de encéfalo de camundongos. 


\subsection{Conclusão}

Os experimentos descritos nesse capítulo atestam a relevância e eficácia da fotoneuromodulação proveniente de iluminação transcraniana com laser de $\lambda=808 \mathrm{~nm}$ para suprimir a nocicepção em camundongos. O teste para avaliação do limiar de dor em camundongos mostrou que a fotoneuroinibição da dor é um processo temporário e reversível, com pico entre 2 - $3 \mathrm{~h}$, e que cessa $24 \mathrm{~h}$ depois da iluminação transcraniana. Os demais testes de nocicepção mostraram que a atenuação da dor devido à fotoneuromodulação no SNC acontece em várias regiões do corpo do animal (patas dianteiras, traseiras e cauda) e para vários tipos de estímulos como pressão, frio, calor e inflamação.

Os mecanismos para a supressão da nocicepção podem ser explicados pelas mudanças bioquímicas iniciadas pela absorção de fótons. Observamos 0 aumento da síntese de ATP, que como já foi bem explicado acontece devido à absorção de fótons na cadeia de respiração celular [45-46]. O aumento da quantidade de ATP pode ser responsável por indiretamente aumentar a liberação do analgésico endógeno PAP já que o processo de síntese dessa substância requer energia para ser iniciado. Uma maior quantidade de analgésicos endógenos (PAP) reduz a condução da sinalização de dor, e em decorrência disso, o número de neurotransmissores da dor (Gl1) diminui também.

A fotoneuromodulação depende da dose usada na iluminação transcraniana isso é evidenciado em muitos experimentos quando GL24 apresenta resultados intermediários entre GC e GL120. Os efeitos da iluminação transcraniana levam certo tempo para ocorrer e existe a possibilidade que o momento da extração do tecido não fosse o momento ideal para observar uma determinada manifestação de alterações bioquímicas.

Outro mecanismo que avaliamos para a supressão da nocicepção foi à formação de varicosidade de tubulina. Nesse teste não verificamos alteração significativa nos níveis de concentração de tubulina e nem mesmo formação de aglomerados dessa substância. Isso reforça a ideia que a fotoneuromodulação da dor pode acontecer por mais de um mecanismo e que há diferenças fundamentais na fotoneuromodulação do SNC e do SNP e ainda na quantidade 
de energia luminosa necessária para que ocorra a fotoneuromodulação in vivo ou in vitro.

A densidade de potência de $300 \mathrm{~mW} / \mathrm{cm}^{2}$ usada para a iluminação trascraniana nesse trabalho é relativamente alta quando comparada à densidade de potência usada em outros estudos de terapia com laser de baixa intensidade, mesmo assim não causou aumento de temperatura do tecido encefálico a ponto de queimar ou causar um processo inflamatório local. Isso é evidenciado pala análise das imagens desses tecidos marcados com HE, pois, nenhuma dessas amostras mostrou lesões ou marcadores inflamatórios. 


\section{CONSIDERAÇÕES FINAIS E PERSPECTIVAS FUTURAS}

Uma das principais dificuldades para fototerapia ou fotodiagnóstico por via transcraniana é a impossibilidade de iluminação de áreas profundas do SNC. No capítulo 2 desse trabalho dirimimos esse problema mostrando que a luz infravermelha $(808 \mathrm{~nm})$ passa pela pele, crânio e chega a regiões relativamente profundas $(\sim 1 \mathrm{~cm})$ dentro do tecido encefálico. Além disso, mapeamos características de atenuação óptica desses tecidos possibilitando uma dosimetria mais precisa para fototerapia transcraniana em roedores.

A fotoneuromodulação do SNC realizada por iluminação transcraniana foi efetivamente provada como uma forma de suprimir a nocicepção em camundongos. A hiponocicepção causada pela fotoneuromodulação foi generalizada, pois se estendeu por várias regiões do corpo dos animais, e inespecífica, pois suprimiu dores evocadas por diferentes estímulos.

A fotoneuromodulação transcraniana nos próximos anos poderá ser estudada e desenvolvida como uma modalidade complementar para tratar diversos tipos de dores em humanos e animais. Acreditamos que esse trabalho possa servir de fundamentação teórica para diversos estudos científicos, translacionais e clínicos sobre fototerapia. Infelizmente o conhecimento e prática em fototerapia ainda são restritos a poucos pesquisadores, clínicos e entusiastas. Esperamos que esse trabalho possa auxiliar na disseminação dessas terapias, e se isso ocorrer, tudo terá valido a pena. 


\section{REFERÊNCIAS:}

1. de Mello Moreira, M., O envelhecimento da população brasileira: intensidade, feminização e dependência. Revista Brasileira de Estudos de População, 2014. 15(1): p. 79-94.

2. Chow, R., et al., Inhibitory effects of laser irradiation on peripheral mammalian nerves and relevance to analgesic effects: a systematic review. Photomedicine and Laser Surgery, 2011. 29(6): p. 365-381.

3. Bear, M.F., B.W. Connors, and M.A. Paradiso, Neuroscience. 2007: Wolters Kluwer Health.

4. Lent, R., Cem Bilhões de Neurônios? Conceitos Fundamentais de Neurociência-2 ${ }^{a}$ edição. Brasil: Editora Atheneu, 2001.

5. Kandel, E.R., J.H. Schwartz, and T.M. Jessell, Principles of neural science. Vol. 4. 2000: McGraw-Hill New York.

6. Niemz, M.H., Laser-tissue interactions. 1996: Springer Berlin.

7. Chavantes, M.C., Laser em bio-medicina: Princípios e prática. São Paulo: Ed Atheneu, 2009: p. 87.

8. Sousa, M.V.P., et al. Phantoms of fingers with various tones of skin for LLLT dosimetry. in SPIE BiOS. 2011: International Society for Optics and Photonics.

9. Cheong, W.-F., S.A. Prahl, and A.J. Welch, A review of the optical properties of biological tissues. Quantum Electronics, IEEE Journal of, 1990. 26(12): p. 2166-2185.

10. Ramos, A.L.O., et al. Monte Carlo simulations combined with experimental measurements: a new possibility of study of the light distribution in fat emulsions. in BiOS. 2010: International Society for Optics and Photonics.

11. Sousa, M.V.P., et al. Laser scattering by Transcranial rat brain illumination. in Proc. of SPIE Vol. 2012.

12. Ishimaru, A., Wave propagation and scattering in random media. Volume I-Single scattering and transport theory. Research supported by the US Air Force, NSF, and NIH. New York, Academic Press, Inc., 1978. 267 p., 1978. 1.

13. Ramella-Roman, J., S. Prahl, and S. Jacques, Three Monte Carlo programs of polarized light transport into scattering media: part I. Optics Express, 2005. 13(12): p. 44204438.

14. Chow, R.T., M.A. David, and P.J. Armati, $830 \mathrm{~nm}$ laser irradiation induces varicosity formation, reduces mitochondrial membrane potential and blocks fast axonal flow in small and medium diameter rat dorsal root ganglion neurons: implications for the analgesic effects of $830 \mathrm{~nm}$ laser. Journal of the Peripheral Nervous System, 2007. 12(1): p. 28-39.

15. Chow, R.T. and L. Barnsley, Systematic review of the literature of low-level laser therapy (LLLT) in the management of neck pain. Lasers in Surgery and Medicine, 2005. 37(1): p. 46-52.

16. Bjordal, J.M., et al., A systematic review with procedural assessments and metaanalysis of low level laser therapy in lateral elbow tendinopathy (tennis elbow). BMC Musculoskeletal Disorders, 2008. 9(1): p. 75.

17. Bjordal, J.M., et al., A systematic review of low level laser therapy with location-specific doses for pain from chronic joint disorders. Australian Journal of Physiotherapy, 2003. 49(2): p. 107-122.

18. Basford, J.R., C.G. Sheffield, and W.S. Harmsen, Laser therapy: a randomized, controlled trial of the effects of low-intensity $\mathrm{Nd}$ : YAG laser irradiation on musculoskeletal back pain. Archives of Physical Medicine and Rehabilitation, 1999. 80(6): p. 647-652. 
19. Enwemeka, C.S., et al., The efficacy of low-power lasers in tissue repair and pain control: a meta-analysis study. Photomedicine and Laser Therapy, 2004. 22(4): p. 323329.

20. Wakabayashi, H., et al., Effect of irradiation by semiconductor laser on responses evoked in trigeminal caudal neurons by tooth pulp stimulation. Lasers in Surgery and Medicine, 1993. 13(6): p. 605-610.

21. Navratil, L. and I. Dylevsky, Mechanisms of the analgesic effect of therapeutic lasers in vivo. Laser Therapy, 1997. 9: p. 33-40.

22. Walker, J., Relief from chronic pain by low power laser irradiation. Neuroscience Letters, 1983. 43(2): p. 339-344.

23. Jimbo, K., et al., Suppressive effects of low-power laser irradiation on bradykinin evoked action potentials in cultured murine dorsal root ganglion cells. Neuroscience Letters, 1998. 240(2): p. 93-96.

24. Cambier, D., et al., The influence of low intensity infrared laser irradiation on conduction characteristics of peripheral nerve: a randomised, controlled, double blind study on the sural nerve. Lasers in Medical Science, 2000. 15(3): p. 195-200.

25. Le Bars, D., M. Gozariu, and S.W. Cadden, Animal models of nociception. Pharmacological Reviews, 2001. 53(4): p. 597-652.

26. Pitcher, G.M., J. Ritchie, and J.L. Henry, Paw withdrawal threshold in the von Frey hair test is influenced by the surface on which the rat stands. Journal of Neuroscience Methods, 1999. 87(2): p. 185-193.

27. Schmidt, R., et al., Innervation territories of mechanically activated C nociceptor units in human skin. Journal of Neurophysiology, 1997. 78(5): p. 2641-2648.

28. Fruhstorfer, H., W. Gross, and O. Selbmann, von Frey hairs: new materials for a new design. European Journal of Pain, 2001. 5(3): p. 341-342.

29. Jasmin, L., et al., The cold plate as a test of nociceptive behaviors: description and application to the study of chronic neuropathic and inflammatory pain models. Pain, 1998. 75(2): p. 367-382.

30. Odell, I.D. and D. Cook, Immunofluorescence Techniques. Journal of Investigative Dermatology, 2013. 133(1): p. e4.

31. Nwaneshiudu, A., et al., Introduction to confocal microscopy. Journal of Investigative Dermatology, 2012. 132(12): p. e3.

32. Avwioro, G., Histochemical uses of haematoxylin-a review. Journal of Pharmacy and Clinical Sciences (JPCS), 2011. 1: p. 24-34.

33. Pascoe, S. and D. Gatehouse, The use of a simple haematoxylin and eosin staining procedure to demonstrate micronuclei within rodent bone marrow. Mutation Research/Environmental Mutagenesis and Related Subjects, 1986. 164(4): p. 237-243.

34. Cox, B., et al., Quantitative spectroscopic photoacoustic imaging: a review. Journal of Biomedical Optics, 2012. 17(6): p. 0612021-06120222.

35. Abràmoff, M.D., P.J. Magalhães, and S.J. Ram, Image processing with ImageJ. Biophotonics International, 2004. 11(7): p. 36-43.

36. Lampl, Y., Laser treatment for stroke. Expert Review of Neurotherapeutics, 2007. 7(8): p. 961-965.

37. Oron, A., et al., Low-level laser therapy applied transcranially to mice following traumatic brain injury significantly reduces long-term neurological deficits. Journal of Neurotrauma, 2007. 24(4): p. 651-656.

38. Hamblin, M., et al., Low-level light therapy aids traumatic brain injury. SPIE Newroonm, 2011.

39. Lampl, Y., et al., Infrared Laser Therapy for Ischemic Stroke: A New Treatment Strategy Results of the NeuroThera Effectiveness and Safety Trial-1 (NEST-1). Stroke, 2007. 38(6): p. 1843-1849. 
40. Moges, H., et al., Light therapy and supplementary Riboflavin in the SOD1 transgenic mouse model of familial amyotrophic lateral sclerosis (FALS). Lasers in Surgery and Medicine, 2009. 41(1): p. 52-59.

41. Trimmer, P.A., et al., Reduced axonal transport in Parkinson's disease cybrid neurites is restored by light therapy. Molecular Neurodegeneration, 2009. 4: p. 26.

42. Zhang, L., et al., Low-power laser irradiation inhibiting A625-35-induced PC12 cell apoptosis via PKC activation. Cellular Physiology and Biochemistry, 2008. 22(1-4): p. 215-222.

43. Hurt, J.K. and M.J. Zylka, PAPupuncture has localized and long-lasting antinociceptive effects in mouse models of acute and chronic pain. Molecular Pain, 2012. 8: p. 28-28.

44. Zylka, M.J., et al., Prostatic acid phosphatase is an ectonucleotidase and suppresses pain by generating adenosine. Neuron, 2008. 60(1): p. 111-122.

45. Karu, T., Primary and secondary mechanisms of action of visible to near-IR radiation on cells. Journal of Photochemistry and Photobiology B: Biology, 1999. 49(1): p. 1-17.

46. Lapchak, P.A. and L. De Taboada, Transcranial near infrared laser treatment (NILT) increases cortical adenosine-5'-triphosphate (ATP) content following embolic strokes in rabbits. Brain Research, 2010. 1306: p. 100-105. 


\title{
Laser scattering by Transcranial rat brain illumination
}

\author{
Marcelo V. P. Sousa ${ }^{*}{ }^{\text {, }}$, Renato Prates ${ }^{\mathrm{b}}$, Ilka T Kato ${ }^{\mathrm{b}}$, Caetano P. Sabino ${ }^{\mathrm{b}}$, Luis C. \\ Suzuki $^{\mathrm{b}}$, Martha S. Ribeiro ${ }^{\mathrm{b}}$, Elisabeth M. Yoshimura ${ }^{\mathrm{a}}$. \\ ${ }^{a}$ Institute of Physics, University of São Paulo, São Paulo, Brazil; ${ }^{\mathrm{b}}$ Center for Laser and \\ Applications, IPEN-CNEN/SP, Brazil
}

ABSTRACT

Due to the great number of applications of Low-Level-Laser-Therapy (LLLT) in Central Nervous System (CNS), the study of light penetration through skull and distribution in the brain becomes extremely important. The aim is to analyze the possibility of precise illumination of deep regions of the rat brain, measure the penetration and distribution of red $(\lambda=660 \mathrm{~nm})$ and Near Infra-Red (NIR) $(\lambda=808 \mathrm{~nm})$ diode laser light and compare optical properties of brain structures. The head of the animal (Rattus Novergicus) was epilated and divided by a sagittal cut, $2.3 \mathrm{~mm}$ away from mid plane. This section of rat's head was illuminated with red and NIR lasers in points above three anatomical structures: hippocampus, cerebellum and frontal cortex. A high resolution camera, perpendicularly positioned, was used to obtain images of the brain structures. Profiles of scattered intensities in the laser direction were obtained from the images. There is a peak in the scattered light profile corresponding to the skin layer. The bone layer gives rise to a valley in the profile indicating low scattering coefficient, or frontal scattering. Another peak in the region related to the brain is an indication of high scattering coefficient $\left(\mu_{\mathrm{s}}\right)$ for this tissue. This work corroborates the use of transcranial LLLT in studies with rats which are subjected to models of CNS diseases. The outcomes of this study point to the possibility of transcranial LLLT in humans for a large number of diseases.

Keywords: LLLT dosimetry, rat brain illumination, Nervous System, Biophotonics, Near Infra-Red laser, Transcranial Illumination, Hippocampus, Neurology, LLLT animal model, Neurophotonics.

\section{INTRODUCTION}

Just few years after Theodore Maiman [1] developed the first laser in 1960, it was used by Mester [2] to promote wound healing, and this is probably the first Low Level Laser Therapy (LLLT). The mechanisms of LLLT is based in photon absorption by molecules, it was first explained by Karu [3]. Laser illumination promotes DNA and RNA synthesis [4], lead protein production and increase mitochondrial production of ATP accelerating cell metabolism [5]. Nowadays LLLT is being used in branches of medicine that require reduction of inflammation, pain relief, healing, tissue regeneration or prevention of tissue death [6].

Recently remarkable results have been found in Neurology, using Transcranial LLLT, a noninvasive treatment for serious brain diseases or injuries. Transcranial LLLT improves motor recovery after strokes in rats [7] and in humans [8]; reduces significantly the recovery time in Traumatic Brain Injury (TBI) [9] with little evidence of side effects [10]. Encouraging results were obtainded for some degenerative CNS diseases as familial amyotrophic lateral sclerosis [11], Parkinson disease [12], Alzheimer disease [13] with this technique. Additionally, single neuron light stimulation [14] is connected to pain relief.

Light crossing the interior of biological tissue interacts, basically, in two ways: absorption and scattering [15]. The absorption occurs when a photon interacts with an atom or molecule and the entire energy of the photon is transferred to the atom or molecule. Absorption is quantified by the absorption coefficient $\left(\mu_{\mathrm{a}}\right)$, which is related to the probability of this interaction in a unit of length. The scattering interactions can change both direction and energy of photons (inelastic), or only the direction (elastic scattering). Visible and near IR light interacting with biological tissue give rise mainly to elastic scattering. The scattering depends on size, shape and refraction index of the scattering center and on the wavelength of the incident light. To quantify elastic scattering two parameters are necessary: the scattering coefficient $\left(\mu_{\mathrm{s}}\right)$, which express the probability that scattering occurs, and the anisotropy factor $(\mathrm{g})$, which is defined as the average cosine of the scattering angle. The total attenuation coefficient is $\mu_{\mathrm{t}}=$ $\mu_{\mathrm{a}}+\mu_{\mathrm{s}}$.

Knowledge of the penetration and distribution of light inside biological tissues is a hard problem because absorption and scattering depend on wavelength, tissue biochemistry and anatomy [16]. Numerical methods as Monte Carlo simulation [17] can be used to calculate light distribution inside tissues. Due to inhomogeneity of biological tissues, transport theory, a heuristic approach based on energy conservation, is more useful than Maxwell equations to analyze light distribution inside biological medium [16]. The amount of photons in a position $\vec{r}$ propagating in a given direction $\vec{s}$ is described by the radiative transport equation:

Biophotonics: Photonic Solutions for Better Health Care III, edited by Jürgen Popp,

Wolfgang Drexler, Valery V. Tuchin, Dennis L. Matthews, Proc. of SPIE Vol. 8427, 842728

(C) 2012 SPIE · CCC code: 1605-7422/12/\$18 - doi: 10.1117/12.912616

Proc. of SPIE Vol. 8427 842728-1 


$$
\overline{d L(\vec{r}, \vec{s})}=-\mu_{t} L(\vec{r}, \vec{s})+\mu_{s} \int_{4 \pi} p(\vec{s}, \vec{s},) L(\vec{r}, \vec{s},) d \Omega
$$

where $L(\vec{r}, \vec{s})$ is the radiance and $p\left(\vec{s}, \overrightarrow{s^{\prime}}\right)$ is the phase function that describes the angular distribution for a single scattering event.

Here we present an experimental study that was carried out to determine light penetration and distribution inside the animal heads, during transcranial rat brain illumination. The imaging technique allows us to determine light fluence inside skin, bone, brain and to obtain a relative attenuation coefficient for each tissue [18].

\section{MATERIAL AND METHODS}

Two diode laser sources were used in this experiment $(\lambda=808 \mathrm{~nm}$ e $\lambda=660 \mathrm{~nm})$, main characteristics of these sources are presented in table 1. A neutral variable filter was used to regulate light intensity and a high resolution camera (14.7 Mega pixels) captured photons scattered from the sample. The camera lenses were adjusted to focus in the surface of the sample. As the sensitivity of the camera is very low for NIR, exposure time was $4.0 \mathrm{~s}$ for NIR light and $10 \mathrm{~ms}$ for red light. Short period illumination generated speckle patterns to red illuminations.

Table 1: Characteristics of laser sources.

\begin{tabular}{ccccc}
\hline Source & $\boldsymbol{\lambda}(\mathbf{n m})$ & Power $(\mathbf{m W})$ & $\begin{array}{c}\text { Angular } \\
\text { aperture of the } \\
\text { beam }\left({ }^{\circ}\right)\end{array}$ & Spot size (mm) \\
\hline Red & 660 & 30 & 30 & 1.40 \\
NIR & 808 & 30 & 30 & 1.40 \\
\hline
\end{tabular}

Adult rats (Rattus Novergicus) were anesthetized, decapitated and their heads were shaved. The heads were surgically sectioned by a sagittal cut, $2.3 \mathrm{~mm}$ away from mid plane. This section of rat's head was illuminated with red and NIR lasers in points above three anatomical structures: hippocampus, cerebellum and frontal cortex (positions relative to the bregma were: $-3.3 \mathrm{~mm},-6.0 \mathrm{~mm},+2.5 \mathrm{~mm}$, respectively). The illumination spots were $2.0 \mathrm{~mm}$ away from the plane surface of the sagittal cut. A coronal cut of the heads (-3.3 mm from bregma) was also made to allow the visualization of hippocampus through another direction. Illumination spots to coronal sever were $2.3 \mathrm{~mm}$ away from the mid plane and 2.0 away from visualized surface (figure 1).

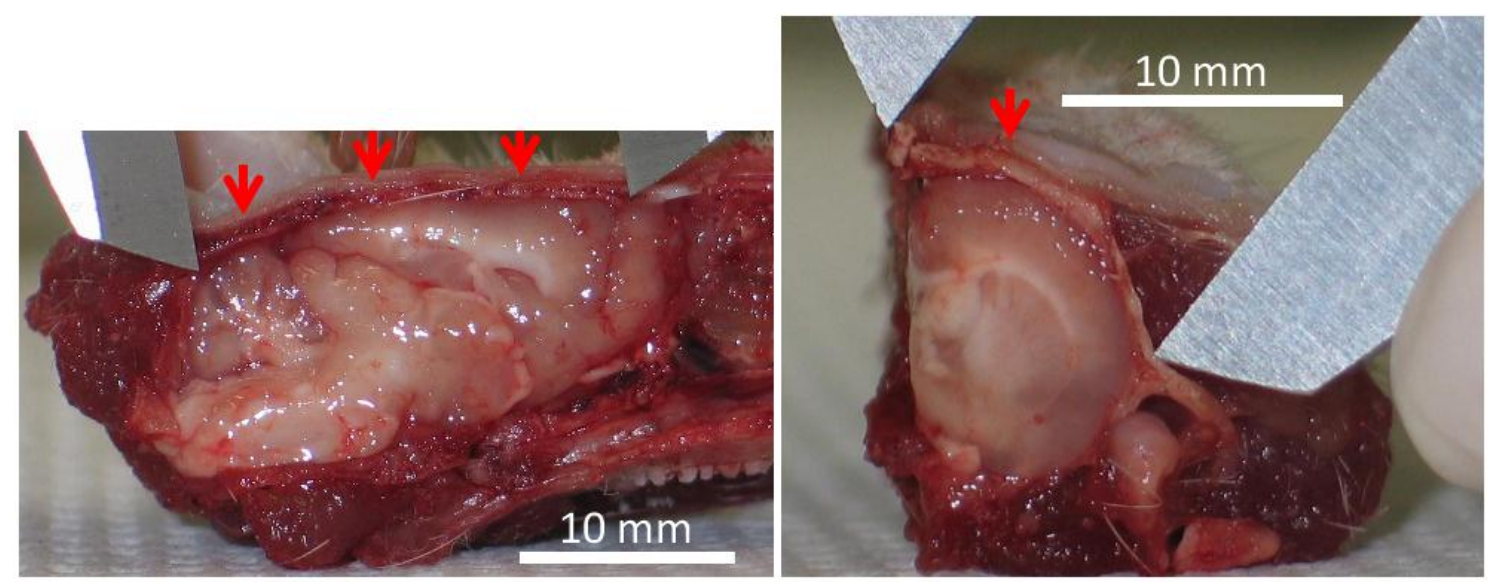

Figure 1: Sagittal (left) and coronal (right) cuts of a rat head. The arrows indicate illumination spots (left: hippocampus, cerebellum and frontal cortex, and right: hippocampus).

\subsection{Experimental method}

The light scattered by each sample passed through the filter and was captured by the high resolution camera which was positioned perpendicularly to the laser beam (figure 2). The images produced by the scattered light and captured by the camera were analyzed with the software ImageJ 1.44. Intensity profiles, in laser beam direction $(z)$, provide information about tissue optical properties. Profiles of scattered intensities in the laser direction were obtained from the images which are in 8-bits format, so they have 256 gray-levels (gl). 


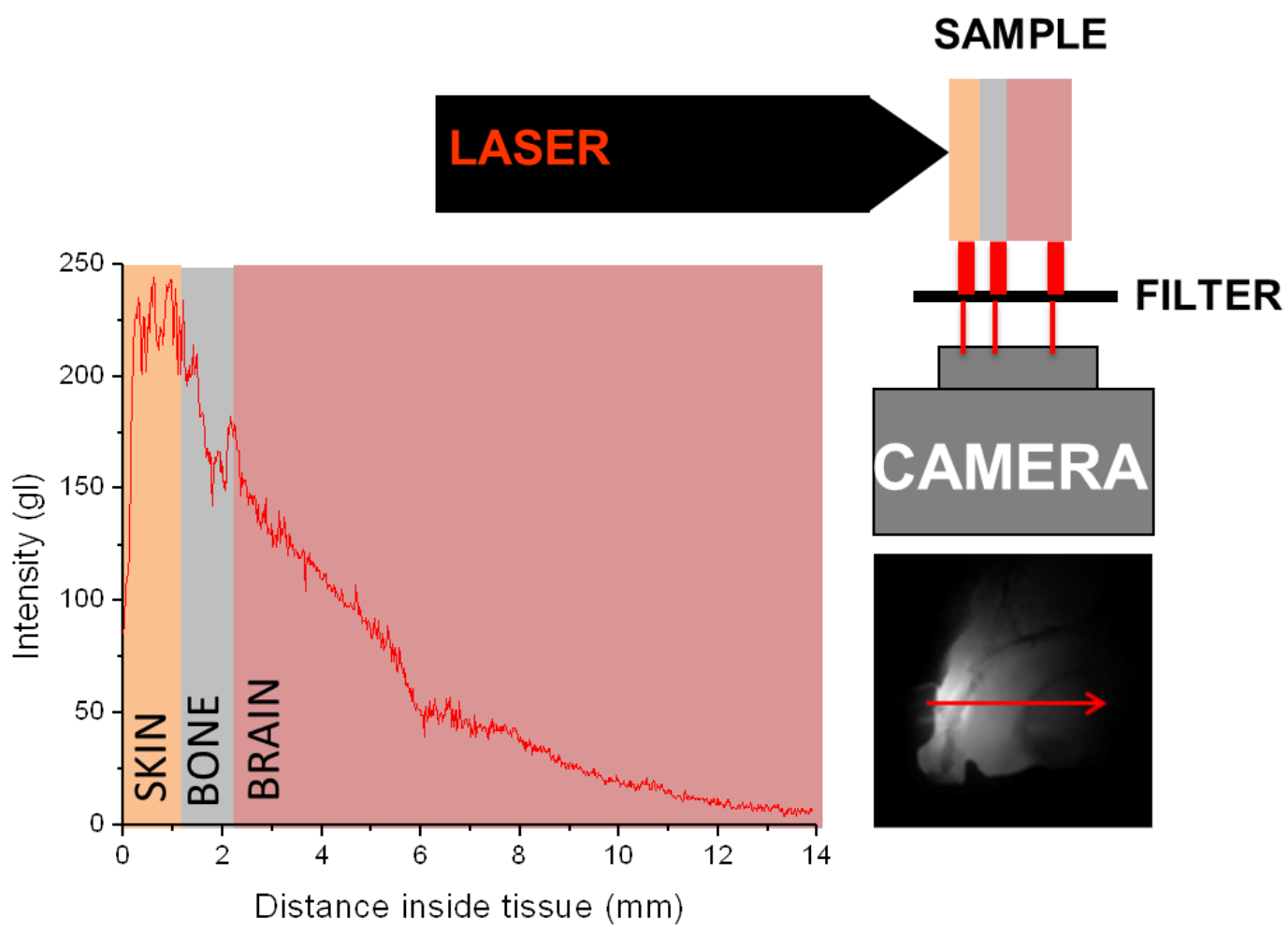

Figure 2: Set up of the experiment, laser illuminates the sample and scattered light is captured by the camera. Arrow in the image indicates where the light intensity (measured in gray levels in the image - gl) profile shown in the graph was measured.

\subsection{Analyzing the images}

Light scattered at $90^{\circ}$ by homogeneous samples shows an intensity profile with a steep growth near the illumination spot, followed by an exponential attenuation [19]. In this experiment we illuminated three different tissues: skin, cranial bone and brain. The profiles of scattered intensities in the laser direction show peaks after each tissue boundary and, far from the edges, they show an approximately exponential attenuation. The peaks are higher for tissues that scatter more light. This way, one can scale tissue scattering coefficients with the corresponding peak intensity. We calculated the exponential coefficients for brain tissue profiles.

Brain is a complex organ with different kinds of neurons and glia. Shape, density, myelination and biochemical composition of cells exert major influence on brain tissue optical parameters. Profiles helped us to identify different brain regions allowing us to make a map of brain tissue optical parameters. It is possible to extract iso-intensity curves from the images.

\section{RESULTS AND DISCUSSION}

The images shown in figure 3 were produced with scattered light: NIR $(\lambda=808 \mathrm{~nm})$ at top, red $(\lambda=660 \mathrm{~nm})$ at bottom; and from left to right: hippocampus, cerebellum, frontal cortex and coronal view of hippocampus. Comparing images produced with NIR and red light one is able to notice that NIR penetrates deeper than red light. It suggests that NIR is more indicated to LLLT in inner parts of the brain. The tissue boundaries and the differences of attenuation inside the brain are qualitatively clear in the pictures.

Analyzing intensities profiles of NIR-light images (figure 4) one can see that there is a peak in the scattered light profile corresponding to the skin layer. The peak width depends on the thickness of skin in that point, and indicates the high scattering coefficient of skin. The bone layer gives rise to a valley in the profile indicating low scattering coefficient, or frontal scattering. The valley width is proportional to cranial thickness in that point. The following peak in the region related to the brain is an indication of high scattering coefficient $\left(\mu_{\mathrm{s}}\right)$ for this tissue. Profiles of red-light (figure 5) images are similar to NIRlight ones but attenuation is larger and speckle pattern of the images diminishes the smoothness of the profiles. 

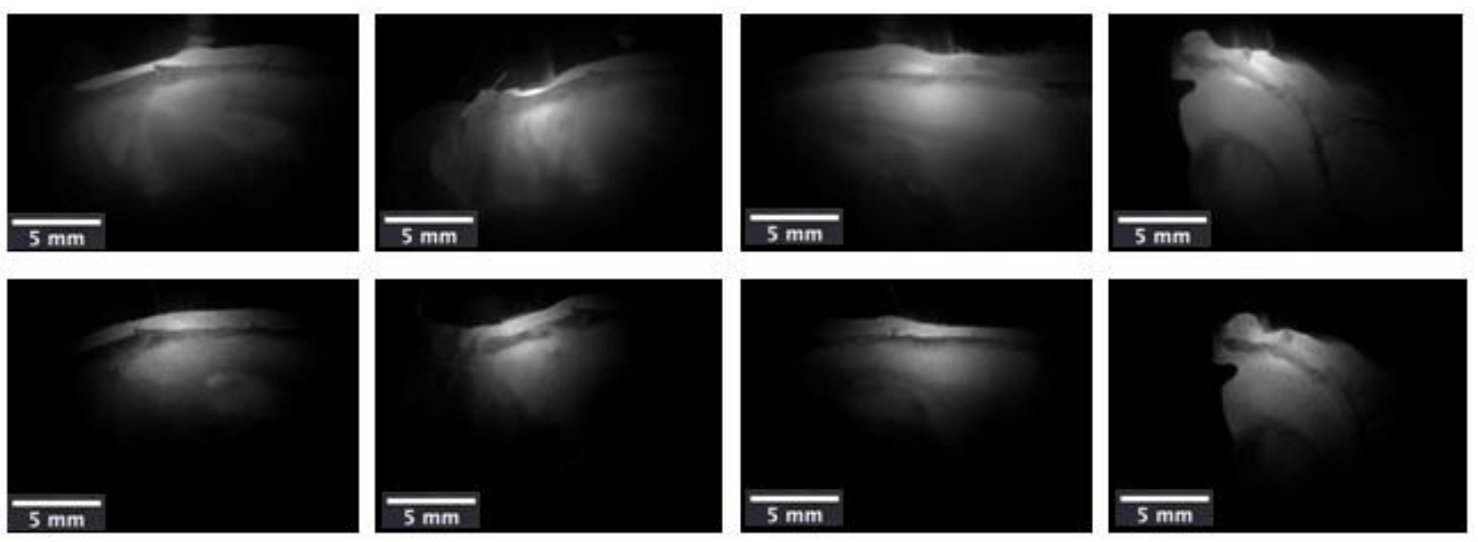

Figure 3: Images of transcranial illumination. Images of NIR illumination are at the top and red illumination ones are at the bottom. From left to right: hippocampus, cerebellum, frontal cortex and coronal view of hippocampus.
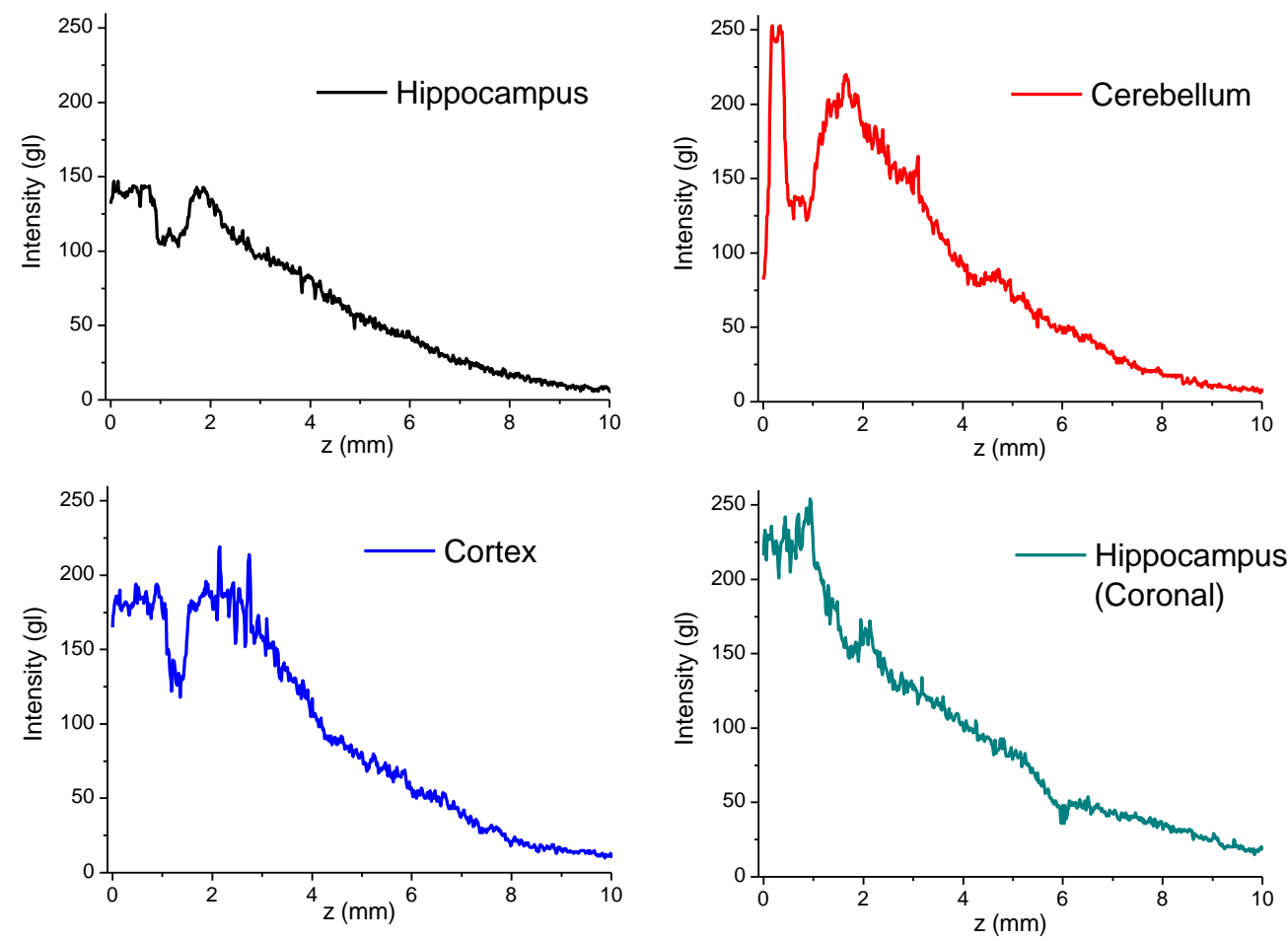

Figure 4: Profiles of transcranial illumination in different point. NIR $(\lambda=808 \mathrm{~nm})$ illumination.

Far from the entrance, light attenuation is approximately exponential:

$$
I(z)=I_{0} e^{-\mu_{t} z}
$$

So, we can obtain $\mu_{\mathrm{t}}$ by:

$$
\mu_{t}=-\frac{\ln \left(\frac{I(z)}{I_{0}}\right)}{z}
$$

The light captured by the camera, at $z$, is proportional to $I(z)$.. Each region of the brain has specific optical properties, so it changes the exponential coefficient. Comparing profiles, far from boundaries $(z$ from 3.5 to $10.0 \mathrm{~mm}$ ), we found differences in exponential coefficient for each point (hippocampus, cerebellum and frontal cortex), in sagittal cuts (figure 6); and differences for each direction (sagittal and coronal) in hippocampus (figure 7). As $\mu_{\mathrm{t}}$ are proportional to exponential coefficients, we normalized them, making the highest value to be equal to 1 , in arbitrary units (a.u.). Almost all values of $\mu_{t}$, are independent, showing the strong dependence of $\mu_{\mathrm{t}}$ with brain's region. Nevertheless, $\mu_{\mathrm{t}}$ are statistically 
equal $(*)$ to cerebellum and hippocampus (coronal). Comparing $\mu_{t}$, to red and NIR illuminations, we can see clearly that red light is more attenuated to all these brain's sub-structures (figure 8).
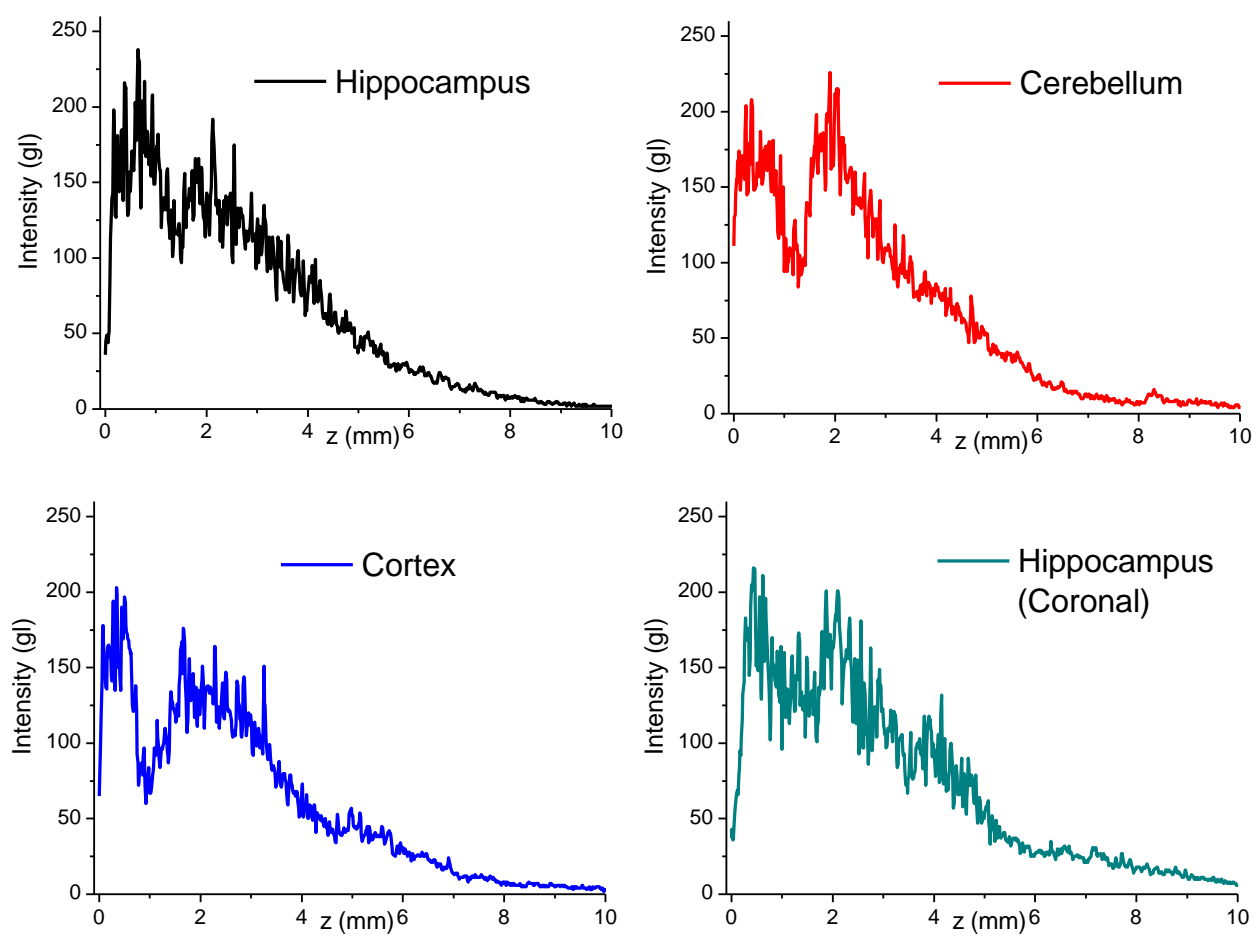

Figure 5: Profiles of transcranial illumination in different spots. Red $(\lambda=660 \mathrm{~nm})$ illumination.
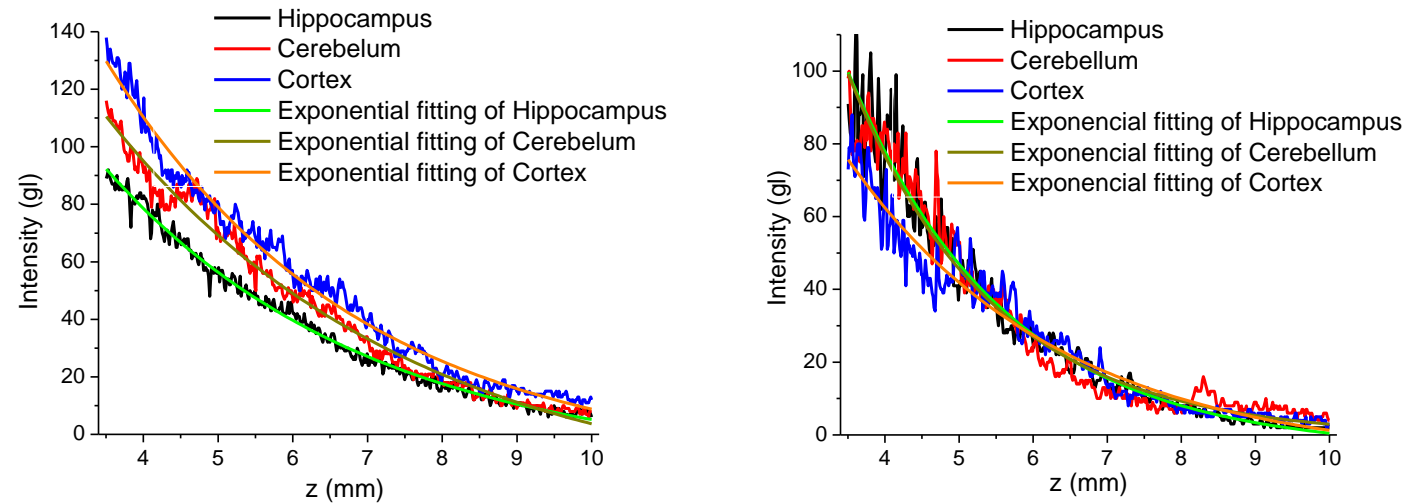

Figure 6: Exponential fitting of profiles far from boundaries to obtain $\mu_{\mathrm{t}}$ (sagittal cuts). 

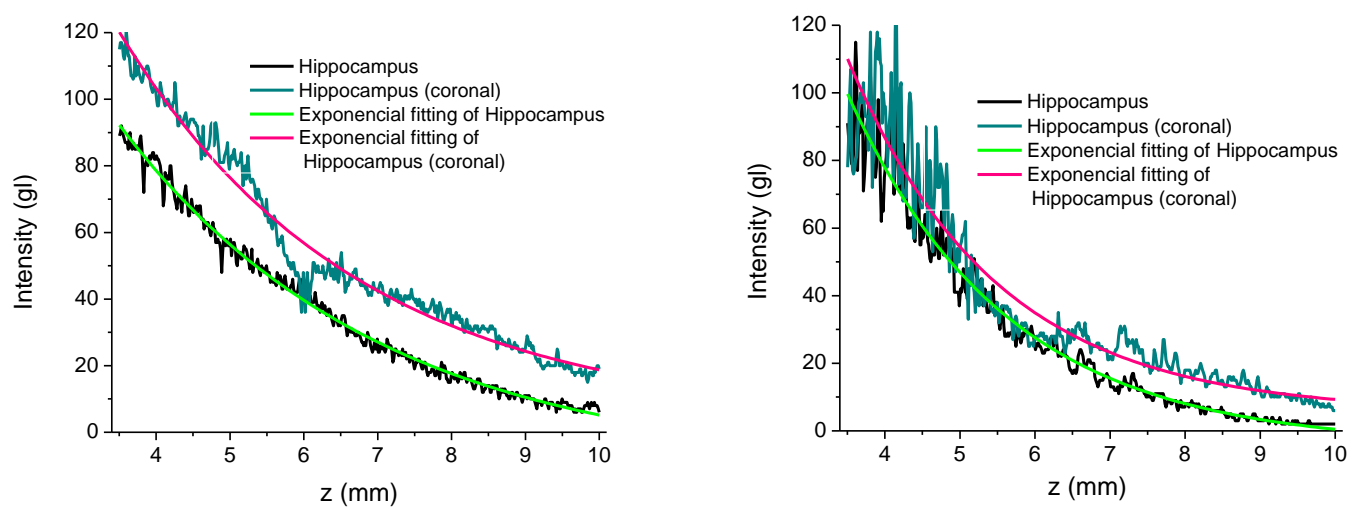

Figure 7: Exponential fitting of profiles far from boundaries to obtain $\mu_{\mathrm{t}}$ (hippocampus).

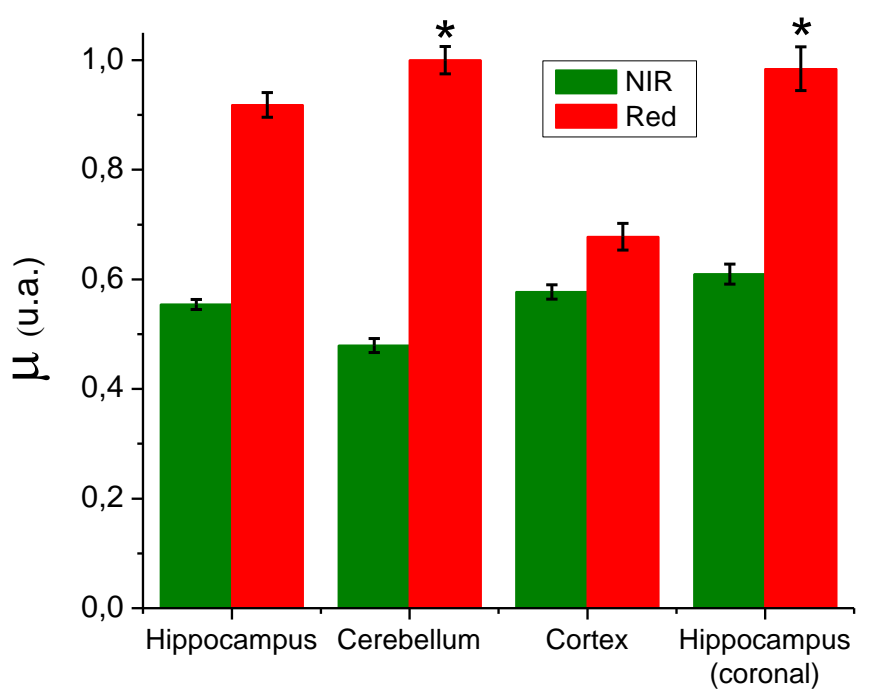

Figure 8: Normalized $\mu_{\mathrm{t}}$ for red and NIR wavelengths in different brain spots. Attenuation is statistically the equal (*) for red light in cerebellum and hippocampus (coronal),

\section{CONCLUSIONS}

NIR penetrates deeper in a transcranial illumination, skull is not a major attenuator tissue, different parts of brain have different attenuation coefficient; these are useful information to trancranial LLLT. Analyze intensity profiles of images from tissues is a simple and powerful method to study quantitatively and qualitatively optical properties.

\section{ACKNOWLEGEMENTS}

The authors thank to CNPq and SPIE Student Chapter for financial support (Officer Travel Grant).

\section{REFERENCES}

[1] Perkowitz, "From ray-gun to Blu-ray", Physics World, 23 (5): 16-20, (2010).

[2] Mester E., Spiry T., et al, "Effect of laser rays on wound healing", Am J Surg,122:532-535, (1971).

[3] Karu T., "Primary and secondary mechanisms of action of visible to near-IR radiation on cells". Journal Photochem Photobiol B; 49:1-17, (1999).

[4] Kam T., Kalendo G., Lethokov V., "Biostimulation of HeLa cells by low-intensity visible light II. Stimulation of DNA and RNA synthesis in a wide spectral range", Nuevo Cimento;309-318, (1984).

[5] Baxter G. D. "Therapeutic Lasers: Theory and Practice", London, England: Churchill Livingstone; 89$138,(1984)$.

[6] J. T. Hashmi, et al., "Role of Low-Level Laser Therapy in Neurorehabilitation", Phys. Med. \& Rehab. 2, pp. S292-S305, (2010). 
[7] Lampl Y. "Laser treatment for stroke", Expert Rev Neurother; 7:961-965, (2007).

[8] Lampl Y., Zivin J. A., Fisher M., et al. "Infrared laser therapy for ischemic stroke: a new treatment strategy: results of the NeuroThera Effectiveness and Safety Trial-1 (NEST-1)", Stroke; 38:1843-1849, (2007).

[9] Oron A., Oron U., Streeter J., et al. "Low-level laser therapy applied transcranially to mice following traumatic brain injury significantly reduces longterm neurological deficits", J Neurotrauma; 24:651-656, (2007).

[10] Hamblin M., Huang Y. Y., et al., "Low-level light therapy aids traumatic brain injury", SPIE Newroonm. (2011)

[11] Moges H., Vasconcelos O. M., Campbell W. W., et al. "Light therapy and supplementary riboflavin in the SOD1 transgenic mouse model of familial amyotrophic lateral sclerosis (FALS)", Lasers Surg Med; 41:52-59, (2009).

[12] Trimmer P. A., Schwartz K. M., Borland M. K., et al. "Reduced axonal transport in Parkinson's disease cybrid neurites is restored by light therapy", Mol Neurodegener; 4:26, (2009).

[13] Zhang L., Xing D., Zhu D., et al. "Low-power laser irradiation inhibiting Abeta25-35-induced PC12 cell apoptosis via PKC activation”, Cell Physiol Biochem; 22:215-222, (2008).

[14] Hirase H., Yuste R., et al. "Multiphoton Stimulation of Neurons", Inc. J Neurobiol 51: 237-247, (2002).

[15] Sousa M. V. P., Yoshimura E. M., et al. "Phantoms of fingers with various tones of skin for LLLT dosimetry", Proceedings of SPIE 7906, 79060U (2011)

[16] Cheong W., Prahl S. A., Welch A. J., "A review of the optical properties of the biological tissues", Jornal of Quantum Eletronics, 26 (12): 2166 - 2185, (1990).

[17] Ramos A. Sousa M. V. P. Yoshimura E. M., et al, "Monte Carlo simulations combined with experimental measurements: a new possibility of study of the light distribution in fat emulsions." proceedings SPIE 7567, 756709 (2010).

[18] Silva D.F.T, Ribeiro M.S. "Light attenuation in rat skin following low level laser therapy on burn healing process", Proceedings SPIE 7715, 77151O-1 (2010).

[19] SOUSA, M. V. P., Ramos A. L. O, Magalhães A. C., Saito M. T., Yoshimura E. M., Light distribution in phantoms, Brazilian Journal of Medical Physics, 2011. v.5. p.70.

*contact: marcelovictor@usp.br 


\title{
Inhomogeneity in optical properties of rat brain: a study for LLLT dosimetry
}

\author{
Marcelo V. P. Sousa ${ }^{* a}$, Renato Prates ${ }^{\mathrm{b}}$, Ilka T Kato ${ }^{\mathrm{b}}$, Caetano P. Sabino ${ }^{\mathrm{b}}$, Tania M. \\ Yoshimura $^{\mathrm{b}}$, Luis C. Suzuki ${ }^{\mathrm{b}}$, Ana C Magalhães ${ }^{\mathrm{a}}$, Elisabeth M. Yoshimura ${ }^{\mathrm{a}}$, Martha S. \\ Ribeiro ${ }^{\mathrm{b}}$. \\ ${ }^{a}$ Institute of Physics, University of São Paulo, São Paulo, Brazil; ${ }^{b}$ Center for Laser and \\ Applications, IPEN-CNEN/SP, Brazil
}

\begin{abstract}
Over the last few years, low-level light therapy (LLLT) has shown an incredible suitability for a wide range of applications for central nervous system (CNS) related diseases. In this therapeutic modality light dosimetry is extremely critical so the study of light propagation through the CNS organs is of great importance. To better understand how light intensity is delivered to the most relevant neural sites we evaluated optical transmission through slices of rat brain point by point. We experimented red $(\lambda=660 \mathrm{~nm})$ and near infrared $(\lambda=808 \mathrm{~nm})$ diode laser light analyzing the light penetration and distribution in the whole brain. A fresh Wistar rat (Rattus novergicus) brain was cut in sagittal slices and illuminated with a broad light beam. A high-resolution digital camera was employed to acquire data of transmitted light. Spatial profiles of the light transmitted through the sample were obtained from the images. Peaks and valleys in the profiles show sites where light was less or more attenuated. The peak intensities provide information about total attenuation and the peak widths are correlated to the scattering coefficient at that individual portion of the sample. The outcomes of this study provide remarkable information for LLLT dose-dependent studies involving CNS and highlight the importance of LLLT dosimetry in CNS organs for large range of applications in animal and human diseases.
\end{abstract}

Keywords: low-level light therapy dosimetry, low-level light therapy in central nervous system, scattering and absorption coefficients, light interaction with brain, brains diseases, traumatic brain injury, rat brain.

\section{INTRODUCTION}

Nowadays LLLT is being used in branches of medicine that require inflammation reduction, pain relief, healing, tissue regeneration or tissue death prevention [1]. It is broadily accepted that LLLT promotes DNA and RNA synthesis, leading to protein production. The most accepted hypothesis to explain the effectiveness of photobiomodulation in almost all tissues is the increase of production of ATP in the mitochondria after photon absorption by cytochrome-c-oxidase (COX). The absorption spectra of COX has a broad peak at near infrared (NIR) region, approximately $830 \mathrm{~nm}$, and another peak near $665 \mathrm{~nm}$ (red). These absorption peaks are in a region of light spectra known as optical window because light is not strongly attenuated by biological tissues in this region [2].

Remarkable results have been found in Neurology, especially with Transcranial LLLT, a noninvasive treatment for serious brain diseases or injuries [3]. Transcranial LLLT improves motor recovery after strokes in rats [4] and in humans [5]; reduces significantly recovery time in Traumatic Brain Injury (TBI) [6] with little evidence of side effects [7]. Encouraging results of transcranial LLLT were found in some degenerative CNS diseases as familial amyotrophic lateral sclerosis [8], Parkinson's, and Alzheimer's diseases [9,10]. Single neuron light stimulation [11] is connected to pain relief.

Measurements of optical properties of rat brain can expand the knowledge of mechanisms of light based therapies, like LLLT and photodynamic therapy (PDT), as one can better estimate the light fluence in a specific region of the rat brain. The knowledge of optical properties of specific regions of the brain can also support data obtained by light based diagnostic tools like optical coherence tomography (OCT) and optoacoustic tomography (OAT) [12].

The light-tissue interaction gives rise to a large number of effects. Some of them are used to diagnose like optothermal and optoacoustic effects and loss of coherence. On the other hand, photochemical reactions are responsible for Biochemical changes which lead to photobiomodulation,

*contact: marcelovictor@usp.br

Mechanisms for Low-Light Therapy VIII, edited by Michael R. Hamblin, Praveen R. Arany, James D. Carroll, Proc. of SPIE Vol. 8569, 856905 - (c) 2013 SPIE · CCC code: 1605-7422/13/\$18 · doi: $10.1117 / 12.2002836$ 
phosphorescence, fluorescence and so on. Despite this myriad of effects light crossing the interior of biological tissue interacts, basically, in two ways: absorption and scattering [13].

The absorption occurs when a photon interacts with an atom or molecule and the entire energy of the photon is transferred to the atom or molecule. Molecules have specific absorption spectra, which depend on the chemical bounds. The absorption spectrum of a given tissue depends of absorption spectrum of every molecule which compound the tissue. Absorption is quantified by the absorption coefficient $\left(\mu_{\mathrm{a}}\right)$, which is related to the probability of this interaction in a unit of length.

The scattering interactions can change both direction and energy of photons (inelastic scattering), or only the direction (elastic scattering). Visible and NIR light interacting with biological tissue give rise mainly to elastic scattering. The scattering depends on size, shape and refraction index of the scattering center and on the wavelength of the incident light. To quantify elastic scattering two parameters are necessary: the scattering coefficient $\left(\mu_{\mathrm{s}}\right)$, which expresses the probability that scattering occurs, and the anisotropy factor $(\mathrm{g})$, which is defined as the average cosine of the scattering angle. The total attenuation coefficient is $\mu_{\mathrm{t}}=\mu_{\mathrm{a}}+\mu_{\mathrm{s}}[14]$.

Knowledge of the penetration and distribution of light inside biological tissues is an important task to improve LLLT dosimetry. Unfortunately it is a hard problem since absorption and scattering depend on wavelength, tissue biochemistry and anatomy [15].

Historically there are two approaches to the problem of multiple scattering: the analytical approach and the radiation transport theory (RTT). The analytical approach starts from Maxwell's equations and the properties of absorption and scattering of particles to obtain statistical quantities such as average intensities. In another way the RTT deals heuristically with the transport of energy by a turbid medium. A differential equation to describe RTT is equivalent to the Boltzman equation used in the kinetic theory of gases [16].

$$
\frac{d I(\vec{r}, \hat{s})}{d s}=-\rho \sigma_{t} I(\vec{r}, \hat{s})+\frac{\rho \sigma_{t}}{4 \pi} \int_{4 \pi} p\left(\hat{s}, \hat{s}^{\prime}\right) I\left(\vec{r}, \hat{s}^{\prime}\right) d \Omega^{\prime}
$$

This equation can be solved exactly for simple geometries and under certain ranges of concentrations of scatterers and absorbers. The numerical solution of this equation is the basis for software based on Monte Carlo simulation calculating distribution of light in turbid media.

Here we present an experimental study, which show images of samples of specific parts of rat brain illuminated with red $(\lambda=660 \mathrm{~nm})$ and near infrared $(\lambda=808 \mathrm{~nm})$. The differences among optical properties like absorption, and scattering gives rise to differences in light transmission at substructures of the brain. We carried out experiments to determine light radiance through rat brain slices [17].

\section{MATERIALS AND METHODS}

Two diode laser sources were used in this experiment $(\lambda=808 \mathrm{~nm}$ e $\lambda=660 \mathrm{~nm})$, and the main characteristics of these sources are presented in table 1 . The angular apertures of the beams were $30^{\circ}$ producing a broad beam (figure 1). A neutral variable filter was used to regulate light intensity, and a high resolution camera (14.7 Mega pixels, 56 pixels $/ \mathrm{mm}$ ) was used to capture photons transmitted through rat brain slices. The camera lenses were adjusted to focus on the surface of the sample.
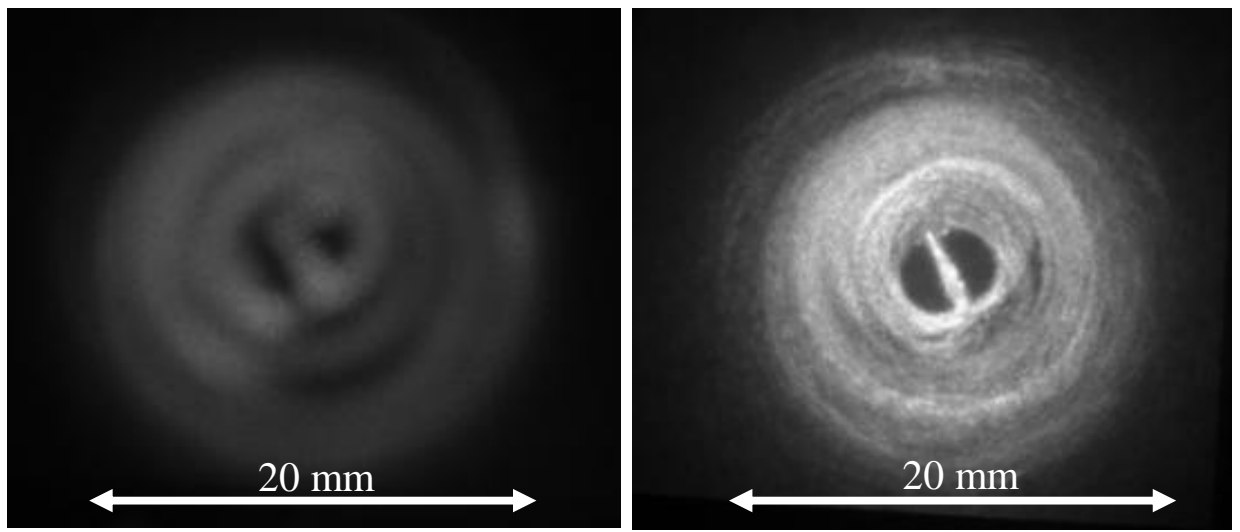

Figure 1: Image of the broad beam without sample, $660 \mathrm{~nm}$ (left), $808 \mathrm{~nm}$ (right). 
Table 1: Characteristics of laser sources.

\begin{tabular}{cccc}
\hline Source & $\lambda(\mathbf{n m})$ & Power $(\mathbf{m W})$ & $\begin{array}{c}\text { Angular } \\
\text { aperture of the } \\
\text { beam }\left(^{\circ}\right)\end{array}$ \\
\hline Red & 660 & 30 & 30 \\
NIR & 808 & 30 & 30 \\
\hline
\end{tabular}

Adult Wistar rat (Rattus Novergicus) were anesthetized euthanized, decapitated and had their brains removed. The brains were sectioned by sagittal cut producing two slices with $2.0 \mathrm{~mm}$ thickness (figure 2). Each slice is considered a parallel plane of turbid material. The slice A is the part of the brain delimited by middle plane and a plane $2.0 \mathrm{~mm}$ away from that. And the slice B is delimitated by planes 2.0 and $4.0 \mathrm{~mm}$ away from the middle
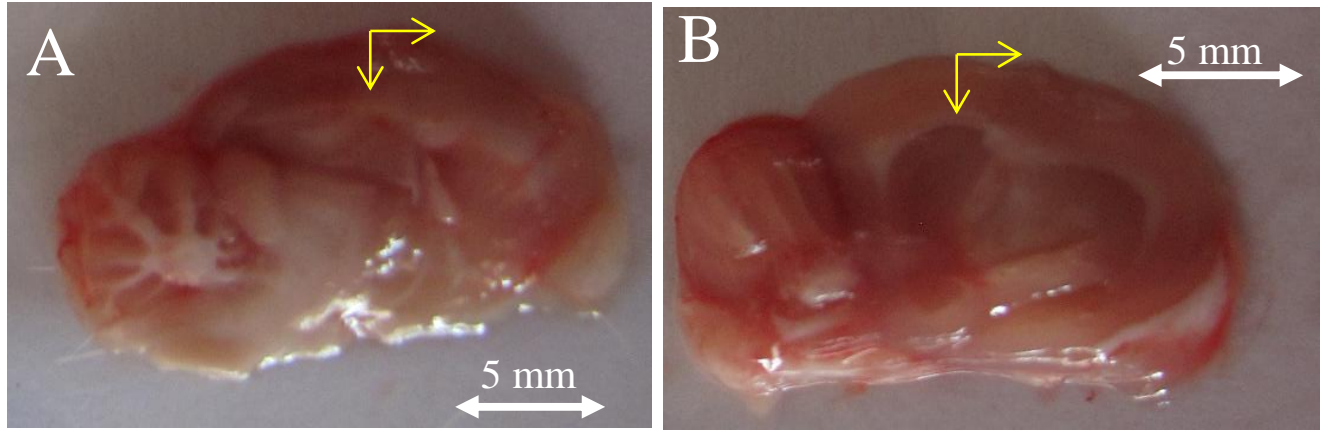

Figure 2: The sample, slice A (left), slice B (right).

Each sample was throughout illuminated by the broad light beam and the light transmitted through the slices was acquired by the camera positioned in the geometry shown in figure 3 . The images produced by the transmitted light and captured by the camera were analyzed with the software ImageJ 1.44. Profiles of the gray levels in the image were traced. The signal was obtained from images in 8-bit format - 256 gray-levels (gl) from black to white [18]. As the sensitivity of the camera is very low for NIR exposure time was $4.0 \mathrm{~s}$ for NIR light and $10 \mathrm{~ms}$ for red light.

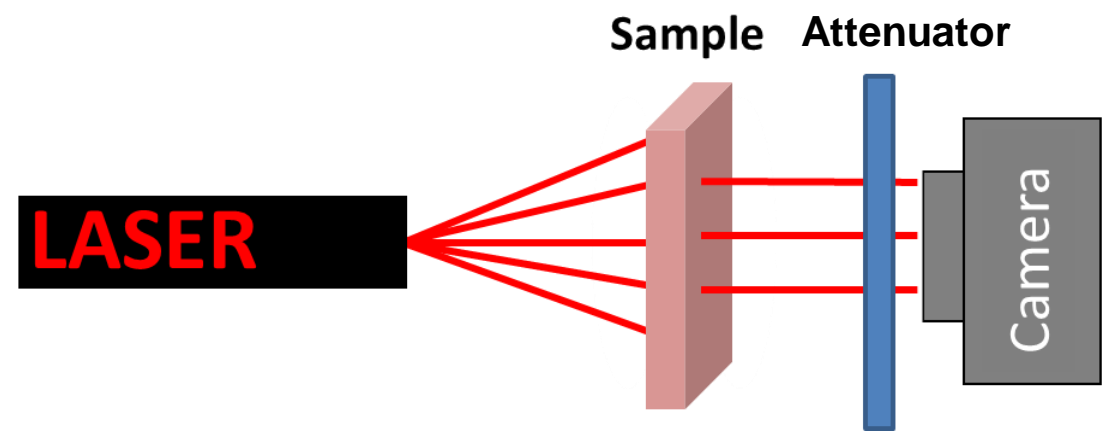

Figure 3: Setup of the experiment, laser illuminates the sample and transmitted light is captured by the camera. 


\section{RESULTS}

The images shown in figures 4 to 7 correspond to the transmitted light of both lasers NIR $(\lambda=808 \mathrm{~nm})$ and red $(\lambda=660 \mathrm{~nm})$ through the slices A and B. The tissue boundaries and the differences of attenuation inside the brain are qualitatively clear in the pictures. Since the light incident on the samples was not uniform and the multiple scattering makes some blur at the image we cannot ensure that the intensity at a given point $(x, y)$ obeys Lambert-Beer equation (2). On the other hand, differences on transmitted light can qualitatively ensure that there are strong differences among sub-structures of rat brain optical properties.

$$
I(\mathrm{z}) I_{0} \mathrm{e}^{-\mu_{\mathrm{t}} z}
$$

Where $I(\mathrm{z})$ is the intensity in a deep $\mathrm{z}, I_{0}$ is the intensity at the surface $(\mathrm{z}=0)$ and $\mu_{\mathrm{t}}$ is the attenuation coefficient.

The light captured by the camera, at $(x, y)$, is proportional to the intensity, $I(x, y)$, shown in graylevel (gl) scale. We traced profiles of intensity changing $x$ position and keeping $y$ constant. We did it for four $y$ positions $(2,4,6,8 \mathrm{~mm}$ away from the top of the sample) in each picture. We do not show the boundaries in the profiles since the thickness of these regions are not uniform.
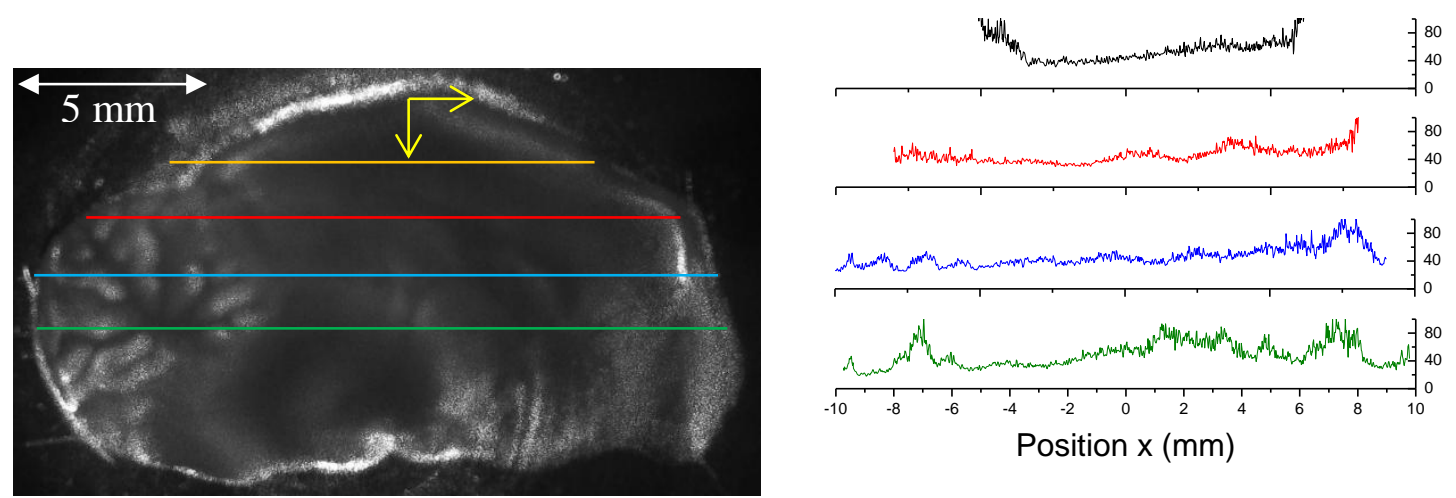

Figure 4: Red $(660 \mathrm{~nm})$ laser light transmitted througt slice A (left). Profiles of intensitis in the $x$ direction in the positions $y=2,4,6,8 \mathrm{~mm}$ from the top of the sample (right).

Figure 4 shows an image generated by red light transmitted through the slice A. We can see clearly that intensity differs for different regions of the brain crossed by the light. In particular in the cerebellum image there are abrupt variations of transmitted intensity point by point. These differences are evidenciated with peaks in the profiles of intensity shown.
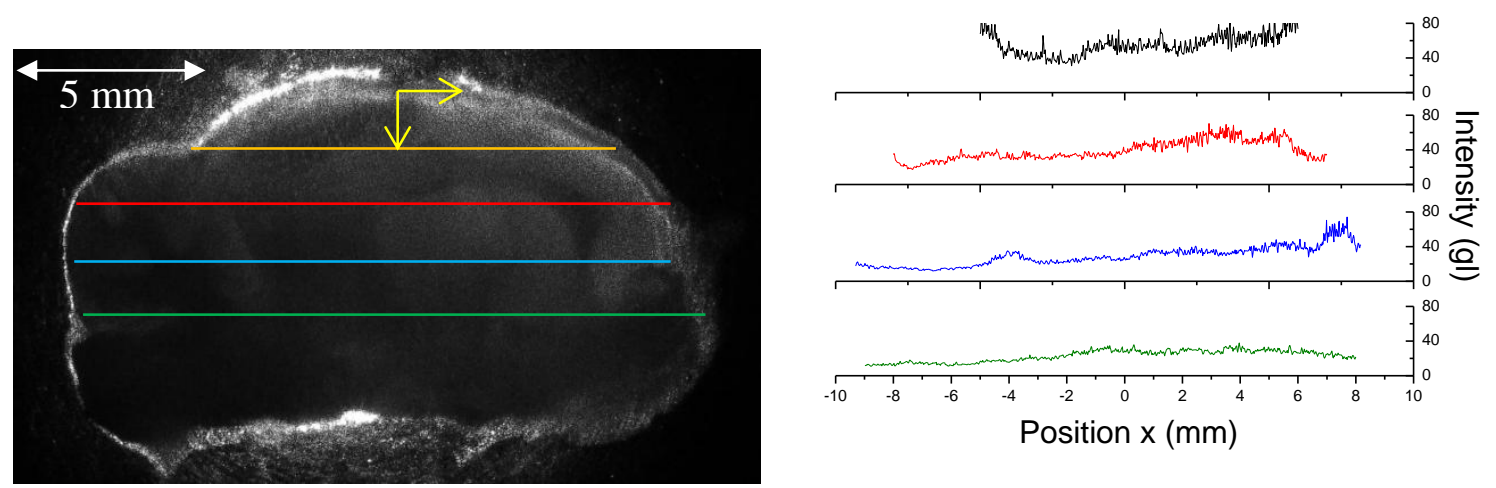

Figure 5: Red $(660 \mathrm{~nm})$ laser light transmitted througt slice B (left). Profiles of intensitis in the $x$ direction in the positions $y=2,4,6,8 \mathrm{~mm}$ from the top of the sample (right). 
The transmitted intensity is smaller in slice B than in slice A. We can see it because the image in figure 5 is darker than the image in the figure 4 . In the profile of slice $B(x=8 \mathrm{~mm}, y=6 \mathrm{~mm})$ we can see a peak meaning low attenuation at this region.
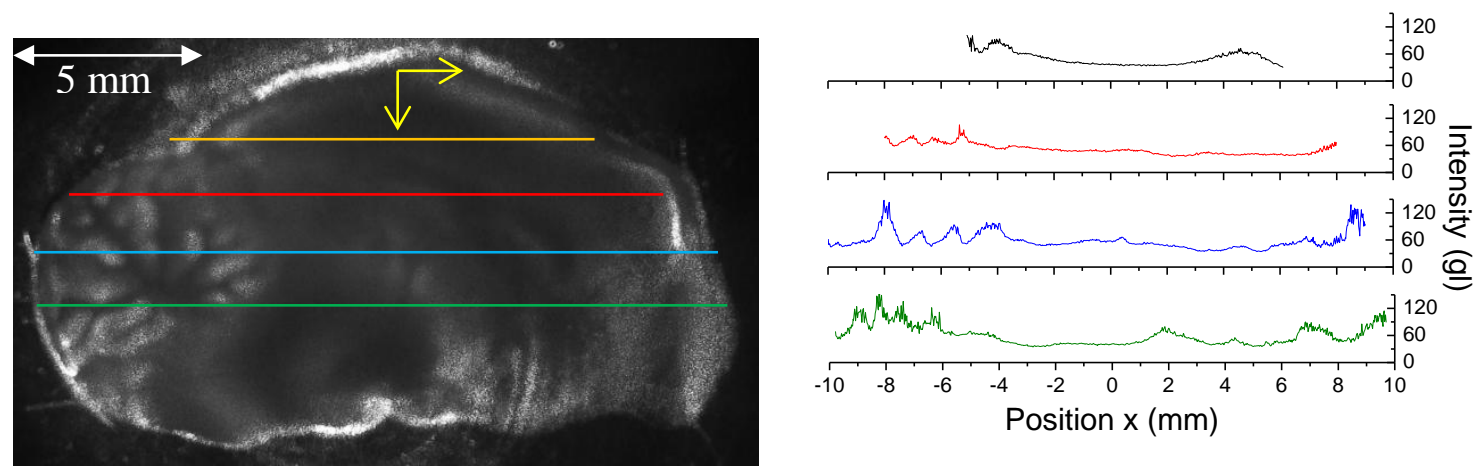

Figure 6: Infrared $(808 \mathrm{~nm}$ ) laser light transmitted througt slice A (left). Profiles of intensitis in the $x$ direction in the positions $y=2,4,6,8 \mathrm{~mm}$ from the top of the sample (right).

Figure 6 shows a image generated by infrared light transmitted through the slice A. Comparing the profiles of light transmitted throught slice A we can see clarly that infrared light is less attenuatted than red lignt. We can see that both present peaks in same points, nevertheless tipical values of peaks for NIR light are two times more intense.
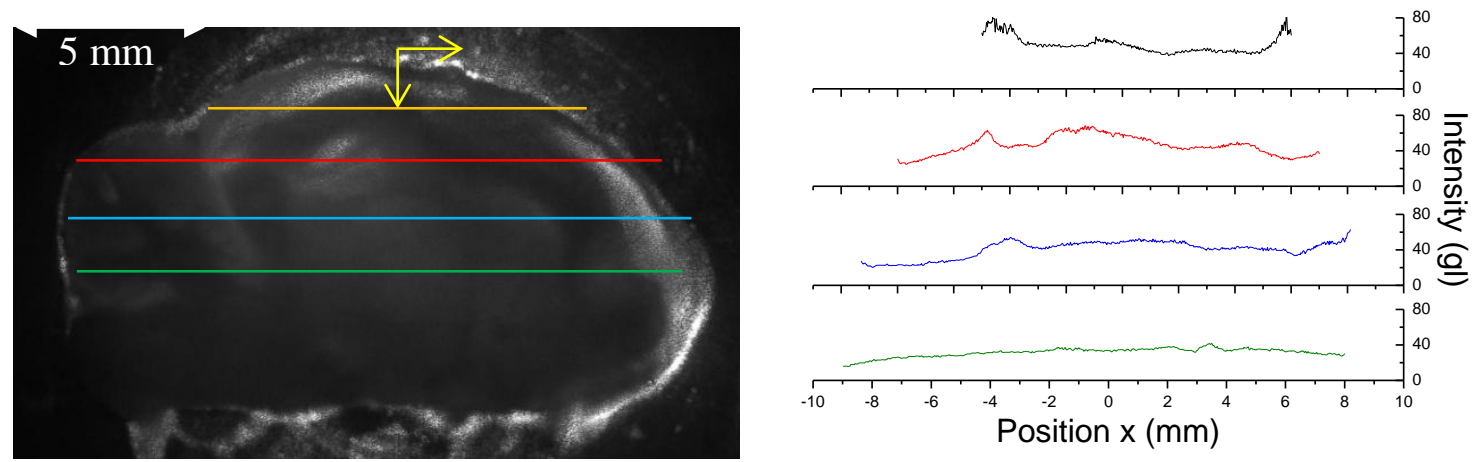

Figure 7: Infrared $(808 \mathrm{~nm}$ ) laser light transmitted througt slice B (left). Profiles of intensitis in the $x$ direction in the positions $y=2,4,6,8 \mathrm{~mm}$ from the top of the sample (right).

In the profile of slice $\mathrm{B}(\mathrm{y}=2 \mathrm{~mm})$ the intensity is too low when compared with other regions. The illumination by the top of the head is common in experiments for trancranial rat brain LLLT. Depending of the targeted area, it would be advisable the illumination by other region in order to avoid the strong attenuation at this area.

\section{CONCLUSIONS}

Studing the images and the profiles we can conclude that sub-structures of brain have different attenuation coefficient and NIR light is less attenuated in the brain than red light. The knowledge of attenuation properties of the whole brain can provide useful information to improve trancranial LLLT dosimetry.

In order to obtain a better contrast of images and differentiate better the brain's sub-structures we have to study thinners slices. To increase resolution we have to use a more uniform source of light. Analyze intensity profiles of images from tissues is a simple and powerful method to study quantitatively and qualitatively optical properties. 


\section{ACKNOWLEDGMENTS}

The authors thank to CNPq for financial support.

\section{REFERENCES}

[1] Baxter G. D. "Therapeutic Lasers: Theory and Practice", London, England: Churchill Livingstone; 89$138,(1984)$.

[2] Chung H., James D Carroll, and Michael R Hamblin, et al. 2012. "The Nuts and Bolts of Low-level Laser (Light) Therapy" 40 (2): 516-533. doi:10.1007/s10439-011-0454-7.

[3] Hashmi, Javad T, Ying-Ying Huang, Bushra Z Osmani, Sulbha K Sharma, Margaret a Naeser, and Michael R Hamblin. 2010. "Role of Low-level Laser Therapy in Neurorehabilitation." PM \& R : the Journal of Injury, Function, and Rehabilitation 2 (12 Suppl 2) (December): S292-305. doi:10.1016/j.pmrj.2010.10.013.

[4] Lampl Y. "Laser treatment for stroke", Expert Rev Neurother; 7:961-965, (2007).

[5] Lampl Y., Zivin J. A., Fisher M., et al. "Infrared laser therapy for ischemic stroke: a new treatment strategy: results of the NeuroThera Effectiveness and Safety Trial-1 (NEST-1)", Stroke; 38:1843-1849, (2007).

[6] Oron A., Oron U., Streeter J., et al. "Low-level laser therapy applied transcranially to mice following traumatic brain injury significantly reduces longterm neurological deficits", J Neurotrauma; 24:651-656, (2007).

[7] Hamblin M., Huang Y. Y., et al., "Low-level light therapy aids traumatic brain injury", SPIE Newroonm. (2011)

[8] Moges H., Vasconcelos O. M., Campbell W. W., et al. "Light therapy and supplementary riboflavin in the SOD1 transgenic mouse model of familial amyotrophic lateral sclerosis (FALS)", Lasers Surg Med; 41:52-59, (2009).

[9] Trimmer P. A., Schwartz K. M., Borland M. K., et al. "Reduced axonal transport in Parkinson's disease cybrid neurites is restored by light therapy", Mol Neurodegener; 4:26, (2009).

[10] Zhang L., Xing D., Zhu D., et al. "Low-power laser irradiation inhibiting Abeta25-35-induced PC12 cell apoptosis via PKC activation", Cell Physiol Biochem; 22:215-222, (2008).

[11] Hirase H., Yuste R., et al. "Multiphoton Stimulation of Neurons", Inc. J Neurobiol 51: 237-247, (2002).

[12] Cox, Ben, Jan G Laufer, Simon R Arridge, and Paul C Beard. "Quantitative Spectroscopic Photoacoustic Imaging : a Review Quantitative Spectroscopic Photoacoustic Imaging :" doi:10.1117/1.JBO.17.6.061202.

[13] Sousa M. V. P., Yoshimura E. M., et al. "Phantoms of fingers with various tones of skin for LLLT dosimetry", Proceedings of SPIE 7906, 79060U (2011)

[14] Cheong W., Prahl S. A., Welch A. J., "A review of the optical properties of the biological tissues", Jornal of Quantum Eletronics, 26 (12): 2166 - 2185, (1990).

[15] Sousa, Marcelo V P, Renato Prates, Ilka T Kato, Caetano P Sabino, C Luis, Martha S Ribeiro, and Elisabeth M Yoshimura. 2012. "Laser Scattering by Transcranial Rat Brain Illumination" 8427 (May): 17. doi:10.1117/12.912616.

[16] Ramos A. Sousa M. V. P. Yoshimura E. M., et al, "Monte Carlo simulations combined with experimental measurements: a new possibility of study of the light distribution in fat emulsions." proceedings SPIE 7567, 756709 (2010).

[17] Silva D.F.T, Ribeiro M.S. "Light attenuation in rat skin following low level laser therapy on burn healing process", Proceedings SPIE 7715, 771510-1 (2010).

[18] SOUSA, M. V. P., Ramos A. L. O, Magalhães A. C., Saito M. T., Yoshimura E. M., Light distribution in phantoms, Brazilian Journal of Medical Physics, 2011. v.5. p.70. 
Basic Neuroscience

\title{
Building, testing and validating a set of home-made von Frey filaments: A precise, accurate and cost effective alternative for nociception assessment
}

\author{
Marcelo Victor Pires de Sousa ${ }^{a, b, *}$, Cleber Ferraresi ${ }^{a, c, d, e}$, Ana Carolina de Magalhães ${ }^{\mathrm{b}}$, \\ Elisabeth Mateus Yoshimura ${ }^{\mathrm{b}}$, Michael R. Hamblin ${ }^{\mathrm{a}, \mathrm{f}, \mathrm{g}}$ \\ a Wellman Center for Photomedicine, Massachusetts General Hospital, Boston, MA 02114, USA \\ b Laboratory of Radiation Dosimetry and Medical Physics, Institute of Physics, São Paulo University, São Paulo, Brazil \\ ${ }^{c}$ Laboratory of Electro-thermo-phototherapy, Department of Physical Therapy, Federal University of São Carlos, São Paulo, Brazil \\ d Post-Graduation Program in Biotechnology, Federal University of São Carlos, São Paulo, Brazil \\ e Optics Group, Physics Institute of Sao Carlos, University of São Paulo, São Carlos, Brazil \\ ${ }^{\mathrm{f}}$ Harvard Medical School, Department of Dermatology, Boston, MA 02115, USA \\ ${ }^{g}$ Harvard-MIT Division of Health Sciences and Technology, Cambridge, MA 02139, USA
}

\section{H I G H L I G H T S}

- Building a set of low-cost von Frey Filaments for pain assessment

- The calibration showed home-made von Frey Filaments are precise and accurate.

- Animal response to home-made and commercial von Frey filaments are similar.

\section{A R T I C L E I N F O}

\section{Article history:}

Received 20 January 2014

Received in revised form 7 April 2014

Accepted 15 April 2014

\section{Keywords:}

von Frey filament

Pain evaluation

Home-made von Frey filament

Validation

\begin{abstract}
A B S T R A C T
Background: A von Frey filament (vFF) is a type of aesthesiometer usually made of nylon perpendicularly held in a base. It can be used in paw withdrawal pain threshold assessment, one of the most popular tests for pain evaluation using animal models. For this test, a set of filaments, each able to exert a different force, is applied to the animal paw, from the weakest to the strongest, until the paw is withdrawn. New method: We made 20 low cost vFF using nylon filaments of different lengths and constant diameter glued perpendicularly to the ends of popsicle sticks. They were calibrated using a laboratory balance scale. Building and calibrating took around $4 \mathrm{~h}$ and confirmed the theoretical prediction that the force exerted is inversely proportional to the length and directly proportional to the width of the filament. Results: The calibration showed that they were precise and accurate. We analyzed the paw withdrawal threshold assessed with the set of home-made vFF and with a high quality commercial set of 5 monofilaments vFF (Stoelting, Wood Dale, USA) in two groups $(n=5)$ of healthy mice.

Comparison with existing methods: The home-made vFF precisely and accurately measured the hind paw withdrawal threshold $(20.3 \pm 0.9 \mathrm{~g})$. The commercial vFF have different diameters while our set has the same diameter avoiding the problem of lower sensitivity to larger diameter filaments.

Conclusion: Building a set of vFF is easy, cost effective, and depending on the kind of tests, can increase precision and accuracy of animal nociception evaluation.
\end{abstract}

(c) 2014 Elsevier B.V. All rights reserved.
* Corresponding author at: Laboratory of Radiation Dosimetry and Medical Physics, Institute of Physics, São Paulo University, Rua do Matão, Travessa R, 187, Cidade Universitária, São Paulo, Zip Code: 05508-090, Brazil. Tel.: +55 1130916993.

E-mail address: marcelovictor@usp.br (M.V.P. de Sousa).

\section{Introduction}

Pain is one of the most researched areas of medicine. It is a consequence of the increasing life expectancy of the world population, the high costs and the side effects of analgesics (Chau et al., 2008). Notwithstanding, in times of world recession and financial crises one of the first sectors to feel the scarcity of funding is experimental 
science investigations. Moreover, there are an increasing number of new laboratories, the majority in developing countries, particularly in the BRICS group (Brazil, Russia, India, China, and South Africa). Nevertheless funding for these laboratories is restricted and the building of homemade equipment is usual. One of the most frequently used devices for pain evaluation is the von Frey filament (vFF). A set of commercial vFF costs approximately 500 USD, however, in this study we will show how someone can easily handcraft a very precise and accurate set of vFF for less than 5 USD.

\subsection{Relevance of pain tests using von Frey filaments}

Animal models are very important to test new medications or procedures, especially for pain management. However, pain cannot be directly monitored - it can only be estimated by examining the response to a specific stimulus like mechanical stimulation with vFF (Pitcher et al., 1999; Le Bars et al., 2001). To perform von Frey nociception tests the filament is applied at the "end point" of response. In animals, these tests are usually performed at the hind paw, and paw withdrawal, sustained retraction, licking and/or flinching are considered as a response to the stimulus (Lambert et al., 2009; Mogil et al., 2001).

The vFF have a broad scope of application such as pain evaluation in conscious animals with neuropathic lesions (Luo et al., 1999; Martinez-Caro and Laird, 2000), anesthetized animals (Krauspe et al., 1992), headache studies performed either with humans (Cooke et al., 2007) or with rats (Oshinsky and Gomonchareonsiri, 2007; Oshinsky et al., 2012) and also to evaluate nociception after central nervous system modulation (Burstein et al., 1998; Bartsch et al., 2004).

Trauma and surgery frequently induce nerve injury, resulting in permanent or temporary disturbances in pain perception. To identify nerve injury, to grade its severity, to monitor its recovery, to facilitate the transfer of information between medical units and to prepare medico-legal reports, it is useful to have tests suitable for daily clinical practice and able to be universally carried out (Poort et al., 2009; Robinson et al., 1992). These tests can be performed with home-made vFF as they are low cost and they can be easily crafted and calibrated in medical units. In addition, a superficial area of anesthesia (or hypo/hyperesthesia) can be mapped by applying the von Frey filament stimulus within the lesion and the surrounding areas in small steps until a sensation is felt (Stubhaug et al., 1997).

\subsection{Pain evaluation with von Frey filaments}

The most used series of commercial von Frey filaments was developed by Semmes et al. (1960) for mapping tactile sensation in patients with brain damage. There are several methodologies of pain assessment with $\mathrm{VFF}$, although, there is no clear evidence that one is superior. Some methods are based on nociceptive scales (Ho Kim and Mo Chung, 1992; Takasaki et al., 2001): a set of 3 or 4 different filaments representing the type of stimuli (e.g., touch, pain, strong pain) is applied to the animal, and the percentage of responses to 5-10 applications of each stimulus is tabulated. This methodology is important for mapping an area affected by neurological damage, surgery or peripheral neuropathy.

Most of the researchers use the vFF to estimate the pain threshold in animals. Various methodologies are available, and in the simplest one, the test begins with the application of the weakest filament of the series to the animal body region. If the animal does not remove the body part from the stimulus a stronger filament is used in a sequence. The pain threshold is considered the force of the filament which causes the withdrawal (Tal and Bennett, 1994). Another approach uses the up-down method, starting the test with the strongest filament, and going down with the forces successively, until the animal does not react accordingly, and the corresponding filament force determines the pain threshold (Bennett, 1993).

A third methodology begins with a middle force filament. Whenever a positive response to a stimulus occurs, the next weaker von Frey filament is applied, and whenever a negative response occurs, the next stronger force is applied. The pain threshold is determined by the first change in response (Chaplan et al., 1994). A fourth methodology starts similarly, but the testing continues for five additional stimuli after the first change in response occurs (Li et al., 2000). The pattern of responses is converted to a $50 \%$ von Frey threshold using the technique described by Dixon (1980).

\subsection{Von Frey filaments}

The physiologist Maximilian von Frey was a pioneer in the study of pain in the late 19th century. To develop these studies he designed a set of filaments each with a different stiffness to evaluate pain sensitivity to touch in humans (Schmidt et al., 1997). These original filaments were made with animal hairs like pig bristles or wispy hairs from a squirrel's tail. With the evolution of the technique, the animal fibers were replaced with manufactured filaments, giving rise to better accuracy and reproducibility. These devices are based on Euler's buckling law, a law of physics which states that an elastic fiber with constant diameter, with one of its ends pressed vertically to a surface such as the skin, and the other end fixed, exerts a constant force. Before the filament starts to bend, the force can be increased, but after bending, the vertical force is constant. The force is directly proportional to the stiffness, directly related to the thickness of the filament and inversely proportional to its squared length (Fruhstorfer et al., 2001; Mogil et al., 2001).

An important parameter of the commercial filaments is the grade or number $(M)$, which is very often confused with the applied force $(F)$. The set of filament numbers create a logarithmic scale (Levin et al., 1978), which is given by:

$M=\log (10 F)$

This parameter is important not only for performing the experiment but also to calibrate and compare equivalent sets of filaments. The vFF can be easily calibrated with a laboratory balance to determine the applied force and consequently the filament number (Levin et al., 1978; Lambert et al., 2009). In this article we will refer to the force in gram-force (gf), which is a unit of force numerically equal to the weight in grams. The SI derived unit for force is the newton (N). Therefore, $1 \mathrm{gf}$ is approximately $9.8 \mathrm{mN}$.

We aimed to demonstrate that homemade von Frey filaments (HmvFF) can be customized to allow a broad range of applications since their bending forces can be precise and accurately controlled. As they are low-cost and easily crafted, HmvFF are adequate for laboratories with low budget or for ones that are not specialized in pain assessment. Clinicians can also benefit from HmvFF, since they can allow quantification of the progression of a nerve injury as well as its treatment, using a cost effective device.

Hence, the objective of this study was to describe how to build, test and validate a set of HmvFF, comparing the results with a commercial set. We show that this equipment produces reliable results and consequently can be used for nociception assessment in animal models. The tests chosen to make the comparison with an animal model were the paw withdrawal threshold with HmvFF and the nociception score both with a set of high quality commercial vFF and with the HmvFF set developed here. 


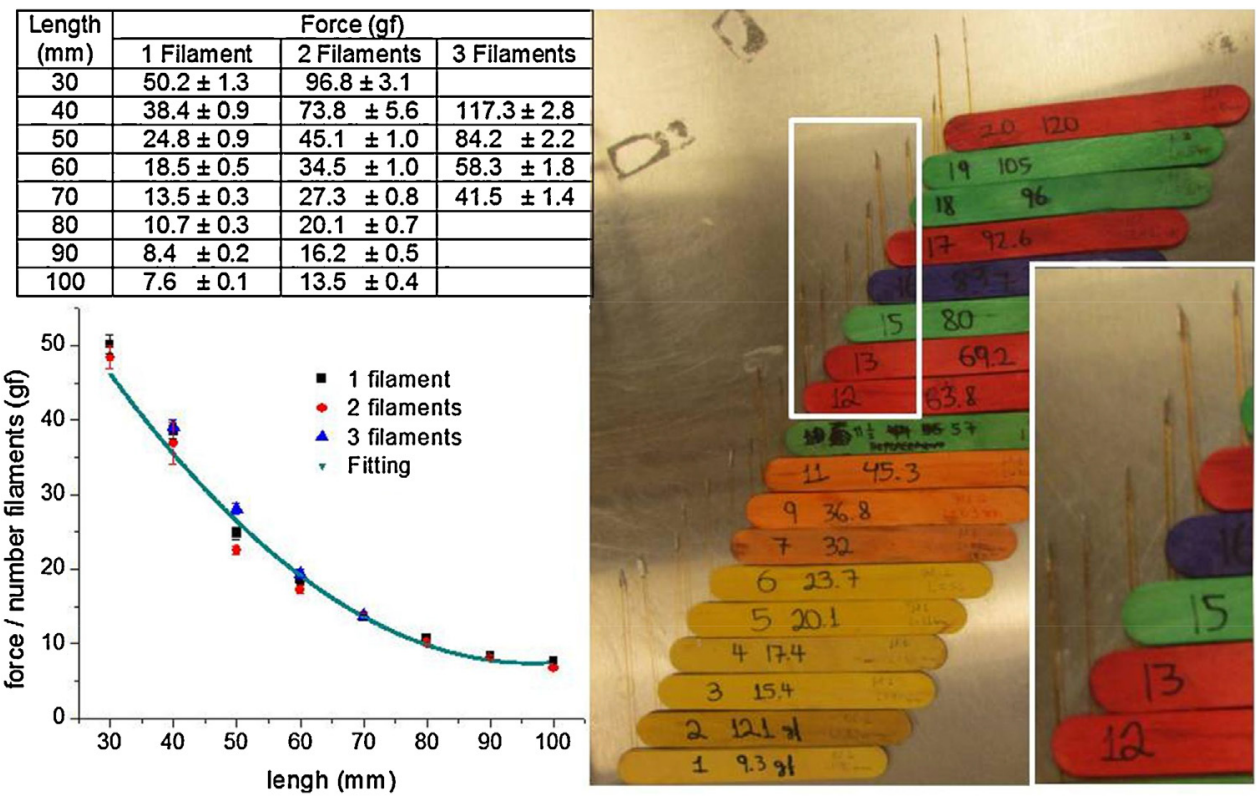

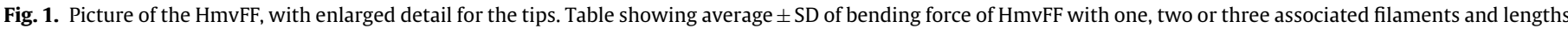
from 30 to $100 \mathrm{~mm}$. Graph of force divided by number of associated filaments $v s$. length when fitted by a second order polynomial function $\left(R^{2}=0.975\right)$

\section{Material and methods}

\subsection{Animals}

All animal procedures were approved by the Subcommittee on Research Animal Care of the Massachusetts General Hospital (protocol \# 2010N000202) and met the guidelines of the National Institutes of Health. Adult male BALB/c mice (weight 20-24 g; Charles River Laboratories, Wilmington, MA) were used in this study. The animals were housed at five mice per cage and were maintained on a 12-h light-12-h dark cycle with access to food and water ad libitum.

\subsection{Construction of HmvFF and commercial $v F F$}

The HmvFF construction was carried out with low-cost materials that are easy to find in common suppliers. Therefore, we used nylon monofilament fishing line $(0.35 \mathrm{~mm}$ diameter, Scientific Anglers ${ }^{\mathrm{TM}}$ Full Sinking Fly Fishing Line) to make the tips of the HmvFF. The monofilament line was cut with scissors in different lengths. The supports for the filaments were made by popsicle sticks (CreateArt) with dimensions of $1.0 \mathrm{~cm} \times 11.2 \mathrm{~cm} \times 0.3 \mathrm{~cm}$. Nylon filaments and popsicles sticks were glued using Loctite ${ }^{\circledR}$ $495^{\mathrm{TM}}$ Super Bonder ${ }^{\circledR}$ Instant Adhesive.

The commercial vFF (Stoelting, Wood Dale, USA) series is a standardized set of filaments, all of constant length but varying in diameter. Each filament is individually calibrated by the manufacturer to deliver its targeted force within a 5\% standard deviation. The support is similar to a plastic pencil. The filaments are retractile and made of flexible plastic. Therefore, they are durable and biocompatible.

\subsection{Designing and calibrating von Frey filaments}

We easily handcrafted 20 low cost vFF with nylon tips glued perpendicularly to the endpoint of popsicle sticks (Fig. 1). In order to obtain a range of forces we made the vFF with different lengths, but the same diameter. Some HmvFF have two (or three) nylon filaments glued together only by the endpoint to duplicate (or triplicate) the force. We were careful to make the end point with only one nylon filament to ensure the same area was always touching the animal. The forces exerted by HmvFF were calibrated with a weighing scale (Andrews, 1993). The average forces \pm standard deviation of 10 measurements are shown in Fig. 1.

According to Euler's equation, the bending force of the filament is inversely proportional to the squared length $(L)$ and is directly proportional to the number of associated filaments. The HmvFF forces divided by the number of associated filaments were fitted by a second order polynomial function as predicted by Euler's equation (Fig. 1). The whole process of handcrafting and calibrating took around $4 \mathrm{~h}$ and the material used was less expensive than five dollars.

\subsection{Assessment of pain sensation using von Frey filaments}

The mice were placed individually in a cage $(10 \mathrm{~cm} \times 20 \mathrm{~cm} \times 15 \mathrm{~cm})$ whose floor was constructed with meshed metal wire (squares of $5 \mathrm{~mm} \times 5 \mathrm{~mm}$ ). Noxious stimulus was obtained when a commercial vFF of bending forces of 10 , $15,26,60,100 \mathrm{gf}$, or a HmvFF of bending forces raging from 7.6 to $27.3 \mathrm{gf}$ (Fig. 1) were pressed perpendicularly upward, through the cage floor, against the plantar hind paw skin and held for approximately $3 \mathrm{~s}$ until it slightly buckled.

Stimuli with the same filament were applied five times to the hind paw at intervals of several seconds. The responses to these stimuli were ranked as follows: 0 , no response; 1 , move paw away from vFF; and 2, immediate flinching or licking of the hind paw. A nociceptive score, based on Takasaki et al. (2001), of each animal was calculated as the sum of the responses to the five stimuli. This gives rise to a scale that ranges from 0 (no response for all noxious stimuli) to 10 (high response for all noxious stimuli). The nociceptive score of the whole group was the average of the individual scores.

The assessment of pain threshold is more direct: the animals were placed and noxiously stimulated in the same way as described above. However, for this test, the mice were successively stimulated starting with the weakest to the strongest filaments. The sequence of stimuli was stopped when the mouse reacted with immediate flinching or licking of the hind paw. The force of the last used 


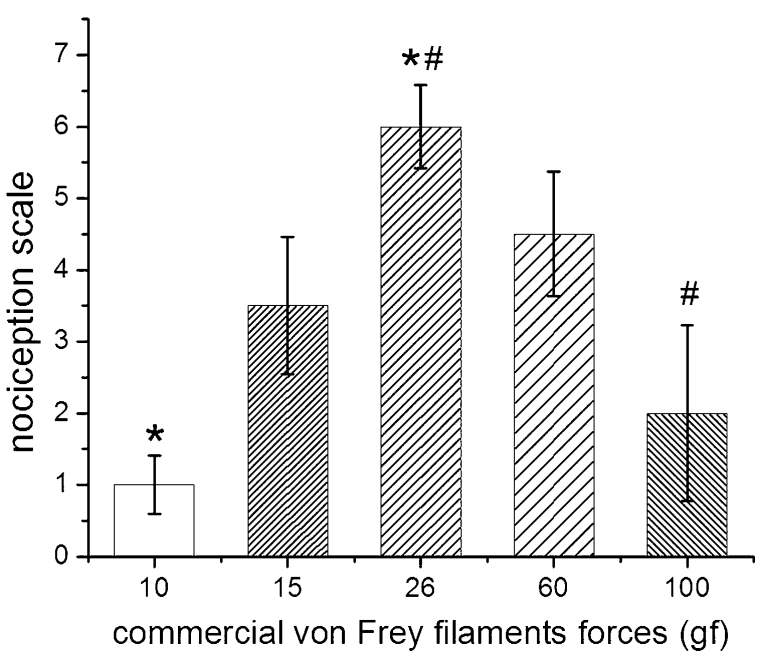

Fig. 2. Healthy mice sensitivity to commercial vFF with different bending forces and diameters. * and \# means statistical difference of $26 \mathrm{gf}$ filament against $10 \mathrm{gf}$ and 100 gf filaments, respectively $(p<0.05)$.

filament was considered the pain threshold. The group pain threshold was the average of individual thresholds.

\subsection{Statistical analyses}

The mean hind paw withdrawal thresholds and nociceptive scores were analyzed using one-way ANOVA and Tukey's test. The mean \pm deviation (SD) withdrawal threshold and nociceptive score values between different groups or within the same group at different time points were considered significantly different when $P<0.05$.

\section{Results}

In this section we compare the mice behavior during the evaluation of pain with commercial and homemade von Frey Filaments.

\subsection{Assessment of pain in healthy mice}

One group of mice $(n=5)$ was tested with commercial vFF and other $(n=5)$ with the set of HmvFF. Preliminary tests, with commercial vFF of bending forces of $10,15,26,60,100 \mathrm{gf}$, were made and we observed that the animals' response increased from 10 to $26 \mathrm{gf}$ and after that it started to decrease until the $100 \mathrm{gf}$. This was a non-expected behavior which happened due to the increase in the contact area of the filament. Therefore we chose $10 \mathrm{gf}$ and $26 \mathrm{gf} \mathrm{vFF}$ to produce the painful stimulus since the former had the lowest sensitivity and the latter the highest (Fig. 2).

There was no statistically significant variation in the nociceptive scores between the five evaluations during the $6 \mathrm{~h}$ of evaluation, for both sets of filaments (Fig. 3). The nociceptive scores for mice tested with 10 and $26 \mathrm{gf}$ commercial vFF and with 7.6 and $10.7 \mathrm{gf}$ HmvFF were $1.5 \pm 0.6,6.3 \pm 0.2,1.75 \pm 0.4$ and $5.4 \pm 0.8$, respectively. The sensitivity of the animals to the $10.7 \mathrm{gf} \mathrm{HmvFF}$ is as high as to the 26 gf commercial vFF. This can be explained when the corresponding pressures (force/area) are compared instead of forces. The pressures applied by 10 and 26 gf commercial vFF or 7.6 and 10.7 gf HmvFF, are $8.2,12.0,8.5$ and $12.0 \mathrm{mN} / \mathrm{mm}^{2}$, respectively. Therefore, filaments which apply approximately the same pressure evoke the same level of response no matter if they are commercial or homemade von Frey Filaments.

For mice tested with the set of HmvFF the minimal pain threshold was $20.2 \pm 2.9 \mathrm{gf}$. Similar to the nociceptive score test, there was

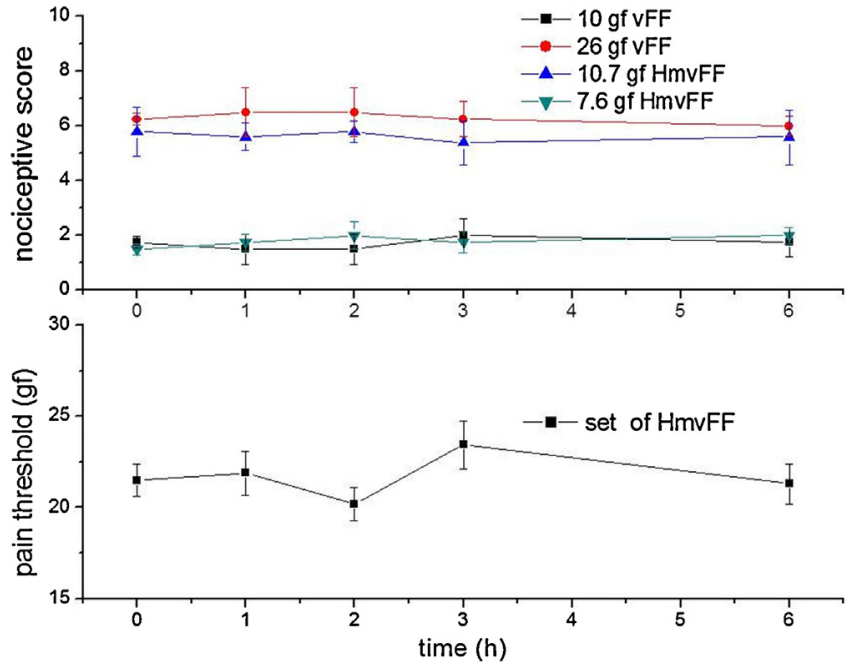

Fig. 3. Average \pm SD of nociceptive score and pain threshold of mice. Nociceptive scores were equivalent for $26 \mathrm{gf}$ vFF and $12 \mathrm{gf} \mathrm{HmvFF}$ since they apply similar pressure (higher than $10 \mathrm{gf} v F F$ ). There was no statistical difference for five tests over $6 \mathrm{~h}$ $(p<0.05)$.

no statistically significant variation of the pain threshold during the $6 \mathrm{~h}$ of evaluation (Fig. 3). Both behaviors are important evidences for the reproducibility and constancy of the animal response to the HmvFF. Pain threshold does not decrease after successive applications, so we can infer that HmvFF stimuli are not harmful, otherwise a hyperalgesic state could lead to a decrease in pain threshold. It did not increase either, showing that the animal did not become used to the test. In addition, we repeated this test five times a day during seven consecutive days and there was no statistical difference in the pain threshold for all these tests.

The response to the commercial vFF was constant too, thus confirming that both commercial and home-made vFF give the same results regarding to the constancy of the animal behavior. It is worth noting that the standard deviations obtained for the pain thresholds (HmvFF) are small values (forces around 2 or $3 \mathrm{gf}$ ), showing the good sensitivity of the set of filaments we built, and the possibility of obtaining a fine evaluation to distinguish pain conditions.

\section{Discussion}

The purpose of this study was to suggest an easy way of building a set of HmvFF, as an alternative to commercial ones. The projected HmvFF consists of wood sticks with nylon filaments firmly glued to them. The difference in bending force was obtained due to the different lengths of the nylon filaments. We showed how to easily handcraft these low-cost HmvFF. The filament calibration can be done using a weighing scale, a common laboratory device. The set of HmvFF is well suited to test mice paw withdrawal response in normal conditions. Furthermore, the reproducibility of the test with HmvFF was very good: the results did not change during the first $6 \mathrm{~h}$ of tests or even after 35 tests over seven consecutive days of evaluation.

Direct comparisons of nociceptive score obtained by stimuli of HmvFF and commercial vFF which apply the same pressure were similar. Therefore, HmvFF can reproduce the results of commercial one. The coefficient of variation (standard deviation divided by the mean), is similar for pain threshold, measured using HmvFF, and the nociceptive scale, measured using commercial vFF. Therefore, both can produce results with the same relative precision. However, HmvFF can be tailored in a broader range of forces to determine a different interval of pain thresholds, and with smaller force increments between successive filaments. Therefore they are useful for 
pain evaluation of mice and other laboratory animals in normal or hypo/hyperesthesia conditions. The data suggest that HmvFF can improve the paw withdrawal reflex measurement since they can be customized to have slightly different bending forces.

\section{Conclusion}

Sets of HmvFF are accurate, precise, and cost-effective and can be easily handcrafted for specific applications. They are versatile either for different kinds of tests, since they can reproduce the tests made with commercial vFF or for the distinct conditions of the subjects, since the animal can be in a normal or hypo/hyperesthesia state.

\section{Acknowledgements}

The authors are grateful to the Brazilian agencies CAPES (1295712-7) and CNPq (140216/2011-1) for financial support. Research in the Hamblin Laboratory is supported by US NIH R01AI050875.

\section{References}

Andrews K. The effect of changes in temperature and humidity on the accuracy of von Frey hairs. J Neurosci Methods 1993;50:91-3.

Bartsch T, Knight YE, Goadsby PJ. Activation of 5-HT1B/1D receptor in the periaqueductal gray inhibits nociception. Ann Neurol 2004;56:371-81.

Bennett GJ. An animal model of neuropathic pain: a review. Muscle Nerve 1993; 16:1040-8.

Burstein R, Yamamura H, Malick A, Strassman AM. Chemical stimulation of the intracranial dura induces enhanced responses to facial stimulation in brain stem trigeminal neurons. J Neurophysiol 1998;79:964-82.

Chaplan S, Bach F, Pogrel J, Chung J, Yaksh T. Quantitative assessment of tactile allodynia in the rat paw. J Neurosci Methods 1994;53:55-63.

Chau DL, Walker V, Pai L, Cho LM. Opiates and elderly: use and side effects. Clin Interv Aging 2008;3:273.

Cooke L, Eliasziw M, Becker WJ. Cutaneous allodynia in transformed migraine patients. Headache 2007; 47:531-9.

Dixon WJ. Efficient analysis of experimental observations. Annu Rev Pharmacool Toxicol 1980;20:441-62.

Fruhstorfer H, Gross W, Selbmann O. von Frey hairs: new materials for a new design. Eur J Pain 2001;5:341-2.

Ho Kim S, Mo Chung J. An experimental model for peripheral neuropathy produced by segmental spinal nerve ligation in the rat. Pain 1992;50:355-63.
Krauspe R, Schmidt M, Schaible HG. Sensory innervation of the anterior cruciate ligament. An electrophysiological study of the response properties of single identified mechanoreceptors in the cat. J Bone Joint Surg Am 1992;74: 390.

Lambert GA, Mallos G, Zagami AS. Von Frey's hairs - a review of their technology and use - a novel automated von Frey device for improved testing for hyperalgesia. J Neurosci Methods 2009;177:420-6.

Le Bars D, Gozariu M, Cadden SW. Animal models of nociception. Pharmacol Rev 2001;53:597-652

Levin S, Pearsall G, Ruderman RJ. Von Frey's method of measuring pressure sensibility in the hand: an engineering analysis of the Weinstein-Semmes pressure aesthesiometer. J Hand Surg 1978;3:211-6.

Li. Y, Dorsi MJ, Meyer RA, Belzberg AJ. Mechanical hyperalgesia after an L5 spinal nerve lesion in the rat is not dependent on input from injured nerve fibers. Pain 2000;85:493-502.

Luo ZD, Chaplan S, Scott B, Cizkova D, Calcutt N, Yaksh T. Neuronal nitric oxide synthase mRNA upregulation in rat sensory neurons after spinal nerve ligation: lack of a role in allodynia development. J Neurosci 1999;19:9201-8.

Martinez-Caro L, Laird JM. Allodynia and hyperalgesia evoked by sciatic mononeuropathy in NK1 receptor knockout mice. Neuroreport 2000;11:1213-7.

Mogil JS, Wilson SG, Wan Y. Assessing nociception in murine subjects. Methods Pain Res 2001:11-39.

Oshinsky ML, Gomonchareonsiri S. Episodic dural stimulation in awake rats: a mode for recurrent headache. Headache 2007;47:1026-36.

Oshinsky ML, Sanghvi MM, Maxwell CR, Gonzalez D, Spangenberg RJ, Cooper M, et al. Spontaneous trigeminal allodynia in rats: a model of primary headache. Headache 2012;52:1336-49.

Pitcher GM, Ritchie J, Henry JL. Paw withdrawal threshold in the von Frey hair test is influenced by the surface on which the rat stands. J Neurosci Methods 1999;87:185-93.

Poort LJ, Van Neck JW, Van Der Wal KGH. Sensory testing of inferior alveolar nerve injuries: a review of methods used in prospective studies. J Oral Maxillofac Surg 2009;67:292-300

Robinson PP, Smith KG, Johnson FP, Coppins DA. Equipment and methods for simple sensory testing. Br J Oral Maxillofac Surg 1992;30:387-9.

Schmidt R, Schmelz M, Ringkamp M, Handwerker HO, Torebjörk HE. Innervation territories of mechanically activated $C$ nociceptor units in human skin. J Neurophysiol 1997;78:2641-8.

Semmes J, Weinstein S, Ghent L, Teuber H-L. Somatosensory changes after penetrating brain wounds in man; 1960 .

Stubhaug A, Breivik H, Eide P, Kreunen M, Foss A. Mapping of punctuate hyperalgesia around a surgical incision demonstrates that ketamine is a powerful suppressor of central sensitization to pain following surgery. Acta Anaesthesiol Scand 1997;41:1124-32.

Takasaki I, Andoh T, Nojima H, Shiraki K, Kuraishi Y. Gabapentin antinociception in mice with acute herpetic pain induced by herpes simplex virus infection. Pharmacol Exp Ther 2001;296:270-5.

Tal M, Bennett GJ. Extra-territorial pain in rats with a peripheral mononeuropathy: mechano-hyperalgesia and mechano-allodynia in the territory of an uninjured nerve. Pain 1994;57:375-82. 


\author{
Photopathology Core \\ Wellman Center for Photomedicine \\ Massachusetts General Hospital \\ HISTOPATHOLOGY Protocol \#31 \\ Immunofluorescence Staining \\ For Paraffin Sections
}

\title{
Reagents
}

1. Target Retrieval Solution, 10X, (DAKO, Cat\#S1699)

2. Super PAP Pen: Fisher, Cat\# NC9888126

3. Goat serum, Sigma, cat\# G9023-10ML

4. Bovine Serum Albumin (BSA), Sigma, cat\# A2153-10G

5. Triton X-100, Sigma, cat\# X100-100ml

6. 10x TBS, VWR, cat\# 82021-504

7. 20X TBS, Tween-20, VWR, cat\# 100219-916

8. In-house made Protein blocking and Ab dilution solution: 10\% Goat serum, $3 \%$ BSA

9. 1X TBS (prepared from 10X)

10. $0.1 \%$ Triton $X-100$ in $1 X$ TBS (prepared from $100 \%$ )

\section{Day 1}

\section{Slides preparation}

1. Bake slides in $60^{\circ} \mathrm{C}$ oven for $1 \mathrm{hr}$ (for deparaffinizing) then cool down the slides at room temperature for $10 \mathrm{~min}$. This step can be done days before.

2. Label the slides for IHC experiment (during cool down).

3. Deparaffinization, Rehydrate

CitriSolv

$100 \% \mathrm{ETOH}$
$3 \times 8$ min (dip few times within the $8 \mathrm{~min}$ )

$2 \times 2 \min$ 


$$
\begin{array}{ll}
95 \% \mathrm{ETOH} & 1 \times 2 \mathrm{~min} \\
70 \% \mathrm{ETOH} & 1 \times 2 \mathrm{~min}
\end{array}
$$

NOTE: Never let the slides to dry out once they are rehydrated.

4. Pre-heat water bath to $98^{\circ} \mathrm{C}$ during the Deparaffinization, Rehydrate steps

5. Prepare Ag retrieval solution during CitriSolv step:

DAKO Target Retrieval Solution (S1699, 10X----> 18ml into 162ml $\mathrm{dH} 2 \mathrm{O}, \mathrm{pH} 6.0-6.2)$

6. Wash

Dip slides 5 times in 3 changes of $\mathrm{dH} 2 \mathrm{O}$, then start wash in clean $\mathrm{dH} 2 \mathrm{O}$ Distilled water $\quad 3 \times 2$ min

\section{Antigen Retrieval}

\section{Water Bath method:}

- Place slide rack into room temperature 1X Target retrieval Solution and place this slides container into the pre-heated $98^{\circ} \mathrm{C}$ water bath. Loosely cover the container to prevent the steam $\mathrm{H} 2 \mathrm{O}$ fall into the container.

- Incubate the slides in $95-99^{\circ} \mathrm{C}$ water bath for $30 \mathrm{~min}$.

- Cool down the sample after 30min Ag retrieval:

i Take out the slides container from the hot water bath (KEEP the slides inside the container).

ii. Cool down on bench for $\mathbf{1 0} \mathrm{min}$ (DO NOT take slides out of the $\mathrm{Ag}$ retrieval solution)

iii. Cool down in cold running water (using a water bath) for $\mathbf{5}$ min (DO NOT take slides out of the Ag retrieval solution, DO NOT run water into the slide container) 


\section{Wash}

Dip slides 5 times in 3 changes of $\mathrm{dH} 2 \mathrm{O}$, then start wash in clean $\mathrm{dH} 2 \mathrm{O}$ Distilled water $\mathbf{3} \times \mathbf{2} \mathrm{min}$

9. Permeabilization: if needed for intracellular biomarkers. Incubate slides with $0.1 \%$ Triton $\mathrm{X}-100$ TBS for $\mathbf{1 5} \mathrm{min}$ (at room temperature)

0.1\% TBS-Triton X-100: add $1 \mathrm{ml}$ of Triton-100 into $1 \mathrm{~L}$ of $1 \times$ TBS,

10. Wash

Dip slides 5 times in 3 changes of $\mathrm{dH} 2 \mathrm{O}$, then start wash in clean $\mathrm{dH} 2 \mathrm{O}$ Distilled water $\quad 2 \times 2 \mathrm{~min}$ TBS $\quad 1 \times 2 \min$

\section{Protein Blocking:}

i. Tap off the wash buffer and wipe off access TBS around tissue.

ii. Circle around tissue with PAP pen on the slides. Using color marker pen to circle around the tissue on the bottom of the slide

iii. Cover tissue sections with Protein blocking solution and incubate for 30-60 min. (Do not blocking for too long. Too long blocking might increase the background)

12. Prepare primary Ab dilution on ice during protein blocking step using protein blocking solution.

13. Primary Ab incubation: Tap off protein blocking solution- $\rightarrow$ wipe off access solution $\rightarrow$ cover tissue sections with primary Ab. Incubate overnight at $4^{\circ} \mathrm{C}$ in a moisture chamber. Place enough $A b$ to cover the entire tissue.

Note: never let the tissue to dry out during staining. 
Day2:

Take out the slides from $4^{\circ} \mathrm{C}$ and allow slides to equilibrate to room temperature for 15-30min.

14. Wash:

i. Tap off primary $A b \rightarrow$ dip slides 5 times in 3 changes of $\mathrm{dH} 2 \mathrm{O}$ then start wash in clean buffer.

ii. Wash with TBS

$4 \times 5 \min$

iii. Tap off the wash buffer and wipe off access TBS around tissue. Incubate with blocking reagent for $\mathbf{1 0} \mathbf{~ m i n}$

15. Dilute secondary $A b$ on ice using protein blocking solution during blocking step. All the steps from now on should be performed in dark or dim light condition.

16. Tap off protein blocking solution- $\rightarrow$ wipe off access solution $-\rightarrow$ Cover with fluorescent conjugated secondary $A b$ and incubate in dark for 30min - 40min in moisture chamber at room temperature (usually 1:200 dilution).

17. Wash:

i. Tap off primary $\mathrm{Ab} \rightarrow$ dip slides 5 times in 3 changes of $\mathrm{dH} 2 \mathrm{O}$ then start wash in clean buffer.

ii. Wash with TBS $4 \times 5 \mathbf{m i n}$

14. Dip slides 5 times in $\mathrm{dH} 2 \mathrm{O}$

15. Mount coverslips using DAPI mounting media (Invitrogen ProLong Gold Antifade Reagent with DAPI, 5 x 2ml, Cat\# P36935).

16. Acquire fluorescent images using confocal or other fluorescent microscope. 


\section{Hematoxylin and Eosin Staining (H\&E, Paraffin Sections)}

1. CitriSolv $2 \times 8 \mathrm{~min}$ (deparaffin)

2. $100 \% \mathrm{ETOH} 2 \times 2$ min (rehydrate)

3. $95 \% \mathrm{ETOH} \quad 2 \mathrm{~min}$

4. $70 \% \mathrm{ETOH} \quad 2 \mathrm{~min}$

5. $50 \% \mathrm{ETOH} \quad 2 \mathrm{~min}$

6. Tap water 4 dips in 2 changes

7. Running tap water $3 \mathrm{~min}$

8. Hematoxylin $2 \quad 15 \mathrm{~min}$ (stain nuclei) or $20 \mathrm{~min}$ for hard to stain tissue

Filter each day to remove oxidized particles

9. Tap water: $\quad 4$ dips in 2 changes

10. Running tap water $3 \mathrm{~min}$

11. $0.5 \%$ Acid Alcohol 1 dip (remove excess blue stain)

12. Tap water: $\quad 4$ dips in 2 changes

13. Running tap water 3 min

14. Lithium carbonate 6 dips (bluing agent) 1:1 diluted with dH2O before use

15. Tap water: $\quad 4$ dips in 2 changes

16. Running tap water $3 \mathrm{~min}$

17. $70 \% \mathrm{ETOH} \quad 2 \min$

18. Eosin-Y $\quad 4$ min or 6 min for hard to stain tissue (filter each day)

19. $70 \% \mathrm{ETOH} 6$ dips (to clear) (discard each day)

20. $95 \% \mathrm{ETOH} \quad 2 \times 2 \min \left(\right.$ discard the $1^{\text {st }}$ 95\% ETOH each day)

21. $100 \% \mathrm{ETOH} \quad 3 \times 2 \mathrm{~min}$

22. CitriSolv $3 \times 3$ min (clearing) 


\section{Hematoxylin 2}

Vender: Richard-Allan Scientific

www.rallansci.com Tel.: 800-522-7270

Recorder \# 7231

1 Pint/473 ml

$\mathrm{R} 4 / 05 \quad 927723110$

Lot 103196

( No catalog \# found)

\section{Eosin-Y}

Vender: Richard-Allan Scientific

www.rallansci.com Tel.: 800-522-7270

Recorder \# 7771

1 Pint/473 ml

R4/05 92903116

Lot 98936

( No catalog \# found)

0.5\% Acid Alcohol: (as in Histologic Staining Methods, Lee G. Luna, p38)

$\mathrm{HCl}$ (Hydrochloric acid) (Concentrated, 37\%) $5 \mathrm{ml}$

$70 \%$ Alcohol

$1,000 \mathrm{ml}$

\section{Lithium carbonate (Saturated solution):}

Lithium carbonate

$5 \mathrm{gm}$

Distilled water $500 \mathrm{ml}$

1) Stirring overnight $---\rightarrow$ filtering with filter paper

2) $1: 1$ diluted with $\mathrm{dH} 2 \mathrm{O}$ before use 


\title{
ANEXO B
}

\author{
Photopathology Core
}

Wellman Center for Photomedicine, Massachusetts General Hospital

HISTOPATHOLOGY

\section{$\underline{\text { ATP - Luciferin/Luciferase protocol }}$}

\section{Reagents:}

- ATP standard (biovision)

- Cell titer Glo Luminescent [promega] - (luciferin + luciferase) - mix $10 \mathrm{ml}$ of the liquid from the white flask into the powder from ambar flask.

- 96 wells White plate

- Plate reader

\section{Experiment:}

1- Schedule your time on the plate reader agenda

2- Dilute $10 \mu \mathrm{L}$ ATP standard in $90 \mu \mathrm{L}$ of distilled water (DW) - this is the sample that you will use to do your Standard Curve. Pipette everything in duplicate!

\begin{tabular}{|c|c|c|c|}
\hline 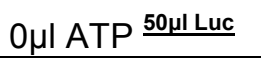 & $0 \mu \mathrm{l}$ ATP $\underline{50 \mu \mathrm{l} \text { Luc }}$ & $10 \mu \mathrm{l}$ sample $A \stackrel{40 \mu \mathrm{l} \text { Luc }}{ }$ & $10 \mu$ l sample $A \stackrel{40 \mu l \text { Luc }}{ }$ \\
\hline $2 \mu \mathrm{l}$ ATP $\underline{48 \mu \mathrm{l} \text { Luc }}$ & $2 \mu \mathrm{l}$ ATP $\underline{48 \mu \mathrm{l} \text { Luc }}$ & $10 \mu$ l sample $B^{40 \mu I \text { Luc }}$ & $10 \mu$ l sample B $\stackrel{40 \mu \mathrm{l} \text { Luc }}{ }$ \\
\hline $4 \mu \mathrm{l}$ ATP $\underline{46 \mu \mathrm{l} \mathrm{Luc}}$ & $4 \mu \mathrm{l}$ ATP $46 \mu \mathrm{l}$ Luc & $10 \mu$ l sample $C^{40 \mu l \text { Luc }}$ & $10 \mu \mathrm{l}$ sample $C \stackrel{40 \mu \mathrm{l} \text { Luc }}{ }$ \\
\hline $6 \mu \mathrm{l}$ ATP $\underline{44 \mu \mathrm{l} \text { Luc }}$ & $6 \mu \mathrm{l}$ ATP $\underline{44 \mu \mathrm{l} \mathrm{Luc}}$ & $10 \mu \mathrm{l}$ sample $\mathrm{D} \stackrel{40 \mu \mathrm{l} \text { Luc }}{ }$ & $10 \mu$ l sample D $\stackrel{40 \mu \mathrm{l} \text { Luc }}{ }$ \\
\hline $8 \mu \mathrm{l}$ ATP $\underline{42 \mu l \text { Luc }}$ & $8 \mu \mathrm{l}$ ATP $\underline{42 \mu \mathrm{l} \text { Luc }}$ & $10 \mu \mathrm{l}$ sample $\mathrm{E} \underline{40 \mu \mathrm{l} \text { Luc }}$ & $10 \mu \mathrm{l}$ sample $\mathrm{E} \underline{40 \mu \mathrm{l} \text { Luc }}$ \\
\hline $10 \mu \mathrm{l}$ ATP $\underline{40 \mu \mathrm{I} \text { Luc }}$ & $10 \mu \mathrm{l}$ ATP $\underline{40 \mu \mathrm{I} \text { Luc }}$ & & \\
\hline
\end{tabular}

IMPORTANT!!! - last thing to put is the cell titer (Luciferin/Luciferase).

OBS: If you going to measure the ATP in vitro, remember to separate the medium from the cells. Then apply the Luciferin directly into de cells and into the medium wells.

3- Incubate the plate for 10 minutes in room temperature and covered with Aluminum foil.

4- Read the plate on $570 \mathrm{~nm}$.

- Remember that ATP takes longer to be read.

- Your results must be into the gap of the minimum and maximum of the stand ard curve. 